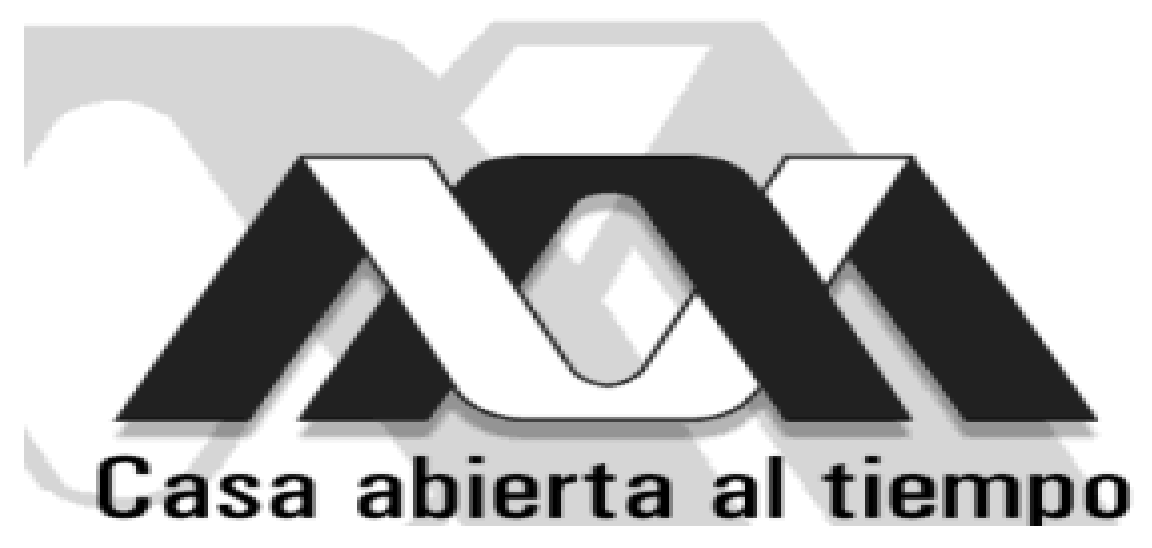

UNIVERSIDAD AUTONÓMA METROPOLITANA

UNIDAD IZTAPALAPA

DIVISION DE CIENCIAS SOCIALES Y HUMANIDADES

\title{
PROCESO DE INNOVACIÓN ORGANIZACIONAL. EL CASO DE INFOTEC
}

\author{
TESIS \\ QUE PARA OBTENER EL GRADO DE \\ MAESTRA EN ESTUDIOS ORGANIZACIONALES \\ PRESENTA:
}

MARIA DEL ROSARIO MONROY SANTANA

DIRECTOR DE TESIS: DR. ANTONIO BARBA ÁLVAREZ 


\section{Agradecimientos}

Mi sincero agradecimiento al profesor Dr. Antonio Barba por el ejemplo de lucha constante que me dio durante dos años. Asimismo, a la Dra. Teresa Montoya, porque ambos me impulsaron con sus sabios consejos para culminar la tesis.

A los empleados de Infotec, y en especial al Dr. Valentino Morales, les agradezco que me hayan brindado su confianza para realizar mi estudio de caso en dicha organización.

A mi familia y amigos, les reconozco que sus palabras, su apoyo y comprensión durante esa etapa crítica fueron un gran estímulo para lograr mi propósito.

Gracias infinitas... 


\section{Tabla de contenido}

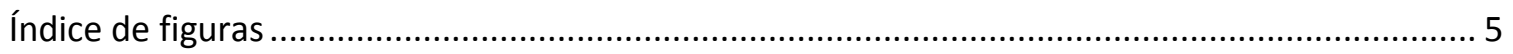

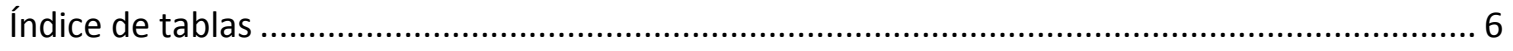

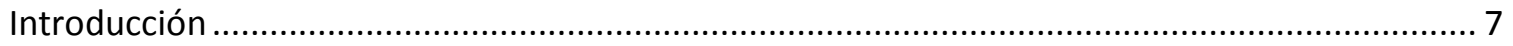

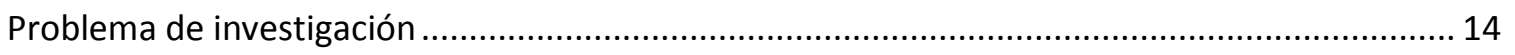

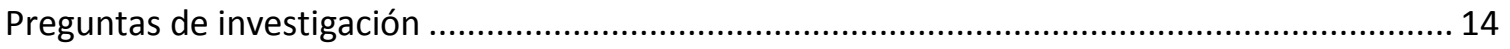

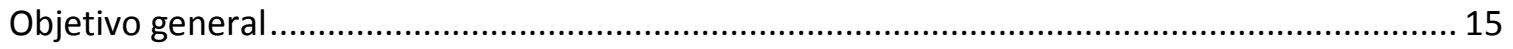

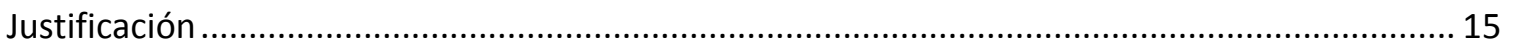

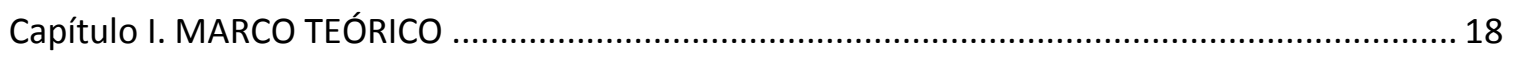

1.1 Enfoques para el estudio del Cambio en la organización ...................................................... 18

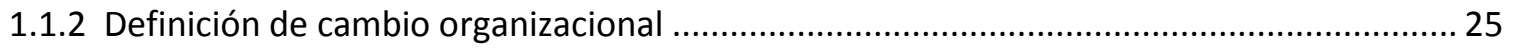

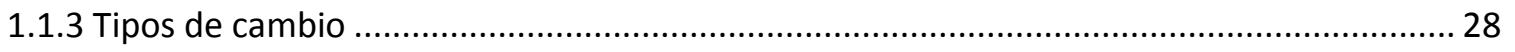

1.2 Elementos representativos para el estudio de la Estructura Organizacional ......................... 34

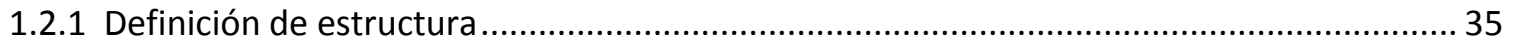

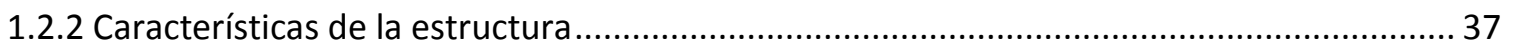

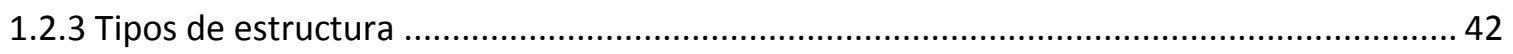

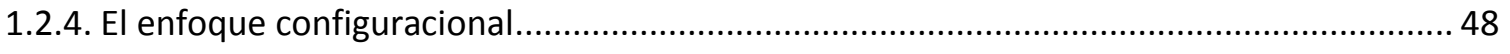

1.3 Cultura organizacional: un mediador para el cambio ......................................................... 51

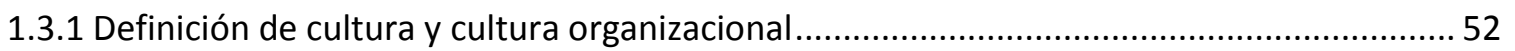

1.3.2. La cultura desde la perspectiva de los estudios organizacionales ..................................... 58

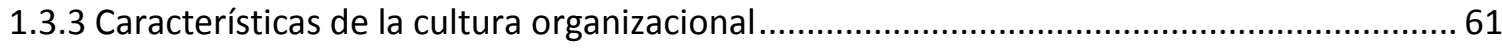

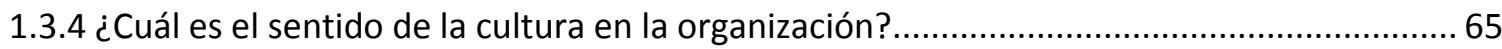

1.4 Tecnologías de la Información y Comunicaciones: Un agente de cambio para la organización

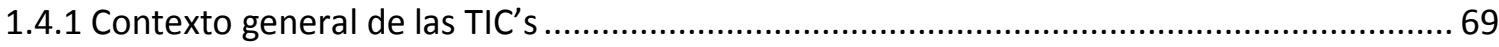

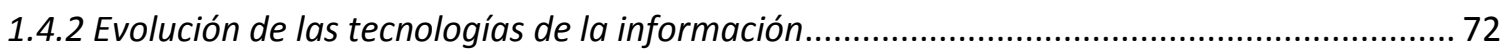

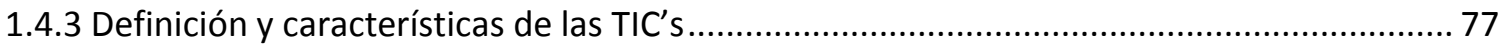

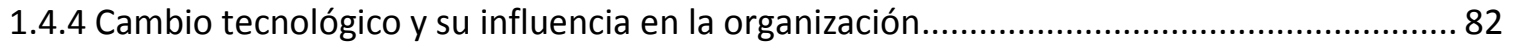

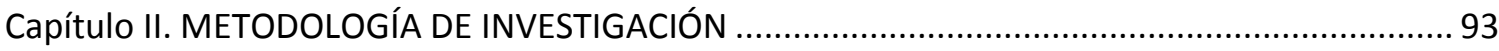

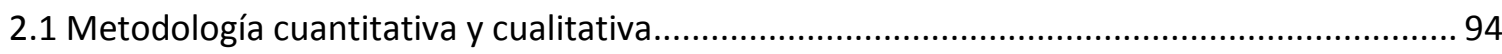

2.2 El estudio de caso: una herramienta para evidenciar la realidad de la organización..............97

2.3 Herramientas metodológicas para el estudio de caso ....................................................... 100 
2.4 Un estudio de caso explicativo desde el enfoque organizacional ....................................... 103

2.5 La observación no participante y la ruta de estudio en Infotec............................................. 106

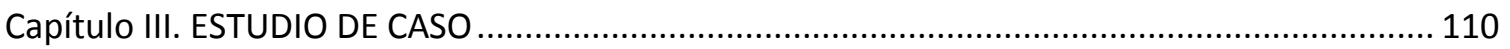

3.1 La Política de Ciencia y Tecnología en México ................................................................... 111

3.2 CONACYT y los Centros Públicos de Investigación ............................................................ 116

3.3 El Infotec y los servicios de información científica y tecnológica ....................................... 120

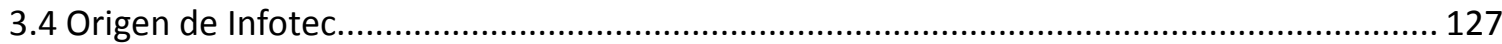

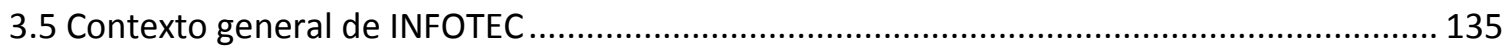

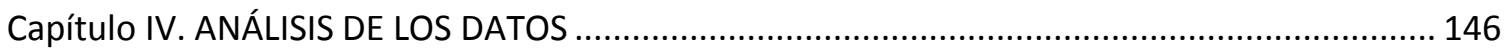

4.1 Etapa 1 Análisis de los eventos críticos de Infotec: Hacia la construcción de una organización

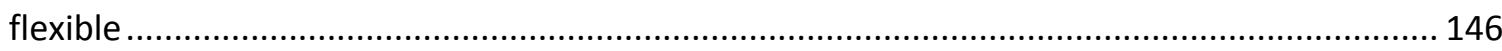

4.2 Etapa 2. El comportamiento de las variables organizacionales en la historia de Infotec

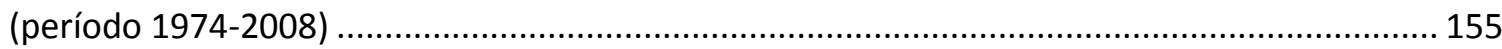

4.3 Etapa 3. La relación entre cambio, estructura y cultura organizacional de Infotec en relación

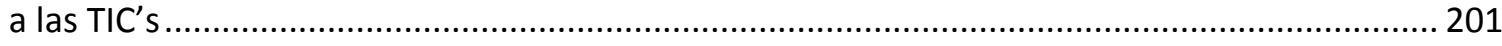

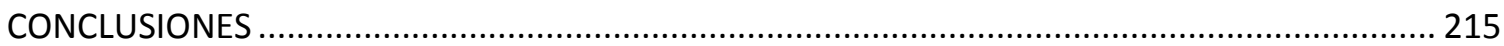

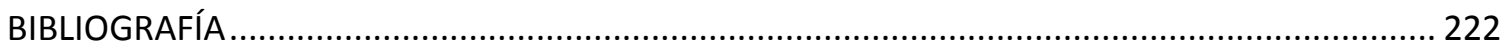

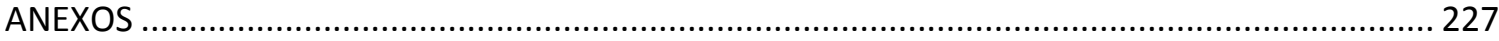




\section{Índice de figuras}

Figura 1 Eventos críticos de Infotec (1974-2009)

Página

Figura 2 La relación de las variables organizacionales en referencia a las TIC's

Figura 3 Enfoques de cambio organizacional 22

Figura 4 Tipos de cambio organizacional 30

Figura 5 La dimensión de la estructura organizacional 34

Figura 6 La interacción de las características estructurales en la 37 organización

Figura 7 Formas estructurales en la organización 43

Figura 8 La noción de cultura $\quad 52$

Figura 9 Cultura organizacional 56

Figura 10 Factores para entender la cultura organizacional 60

Figura 11 Producción de software mental 62

Figura 12 Modelo factorial para el estudio de las organizaciones 65

Figura 13 Evolución de las tecnologías de la información 74

Figura 14 Elementos de las TIC's.

Figura 15 Oficina Automatizada $\quad 85$

Figura 16 Ruta de la creación de Estudio de Caso 106

Figura 17 Organigrama de INFOTEC del período 2009-2011 139

Figura 18 Estructura jerárquica de Infotec en 1999

Figura 19 Relación de las variables organizacionales y las TIC's en el 201 evento crítico de 1974

Figura 20 Relación de las variables organizacionales y las TIC's en el 204 evento crítico de 1994

Figura 21 Relación de las variables organizacionales y las TIC's en el 207 evento crítico de 1996

Figura 22 Relación de las variables organizacionales y las TIC's en el 210 evento crítico de 2007 


\section{Índice de tablas}

Tabla 1

Tabla 2

Tabla 3

Tabla 4

Tabla 5

Tabla 6

Tabla 7

Tabla 8

Tabla 9

Tabla 10

Tabla 11
Factores del contexto organizacional

Página

Dimensiones de la estructura

38

Tipos de Configuración de Mintzberg

Características organizacionales de la cultura

Ejemplos de TIC's

Implicaciones de las TIC's sobre las organizaciones

Características de los paradigmas en la investigación social

Etapas para el desarrollo de Estudio de Caso de Infotec

Causas que favorecieron a la creación de Organismos Públicos de Ciencia y Tecnología en México

Etapas de transición de la política de CyT en México

Eventos críticos para el estudio de INFOTEC y su relación con las variables de estudio
113

39

45

59

79

84

93

106

112

153 


\section{Introducción}

La época que se vive actualmente tiene una alta tendencia al ambiente complejo y turbulento que va de la mano con la incertidumbre. A su vez, la sociedad se encuentra envuelta de problemas económicos, políticos y sociales que reparan en uno de los lugares donde los individuos pueden desempeñar el rol de reconocimiento ante la colectividad: la organización. La organización al estar conformada por individuos necesariamente se conecta con el ambiente externo de manera bilateral.

En ese sentido, la organización tiene que adaptarse a las contingencias que se encuentran fuera y dentro de ella. No puede estar aislada de los diversos eventos que se suscitan todos los días, así como la sociedad no puede aislarse de las organizaciones. Por eso, es importante resaltar la imperante tarea de los Estudios Organizacionales la cual implica comprender a estas entidades, de manera que se hallen los diferentes vínculos que se pueden crear dentro de ellas, más allá de un mero hecho de rentabilidad económica.

Pero, ¿Cuál es el sentido de estudiar a las organizaciones? En este caso, surge la necesidad de vislumbrar qué efecto han causado las tecnologías de Información y Comunicaciones a estas entidades. Y es que el tema de la tecnología no es nuevo en su estudio, pero, en el caso específico de estas tecnologías, hay un hecho que no se puede negar: que son tecnologías que cambian constantemente y que la forma de entenderlas y operarlas tiene que seguir el mismo ritmo. 
Esta es la razón de que sean objeto de estudio desde la perspectiva de Estudios Organizacionales. En especial, entender como las organizaciones mexicanas reaccionan ante este cambio. Por lo tanto, se pretende realizar un análisis de un estudio de caso en una organización que otorga servicios en el área de TIC's a empresas privadas y gobierno. El Fondo de Información y Documentación para la Industria (Infotec), es una organización que ha sobrevivido a diferentes circunstancias económicas y políticas, con base en la adopción de las TIC's.

Estudiar a las tecnologías de información y comunicaciones desde la perspectiva organizacional, tiene la pretensión de mostrar a estas tecnologías como un agente de cambio dentro de las mismas. El estudio del cambio organizacional en Infotec se consideró a partir de los eventos críticos que se han suscitado desde el origen de la organización hasta el 2007, ya que se tiene un marco de referencia amplio y la organización sigue vigente hasta la fecha.

Por evento crítico se debe entender a aquella influencia que tiene la capacidad de generar un cambio en la organización, sin embargo, este evento crítico es el resultado de eventos aislados o en conjunto que se producen dentro y/o fuera de la organización. En el caso de Infotec se considera un evento a los hechos más importantes que han acontecido en la organización. $Y$ un evento critico es aquel que ha provocado algún cambio en la organización, desde la perspectiva de las TIC's.

En la siguiente figura se muestran los principales eventos que el Infotec considera importantes, y los eventos críticos que la autora de este trabajo considera como los más representativos para realizar esta tesis. 
Figura 1. Eventos críticos de Infotec (1974-2009)

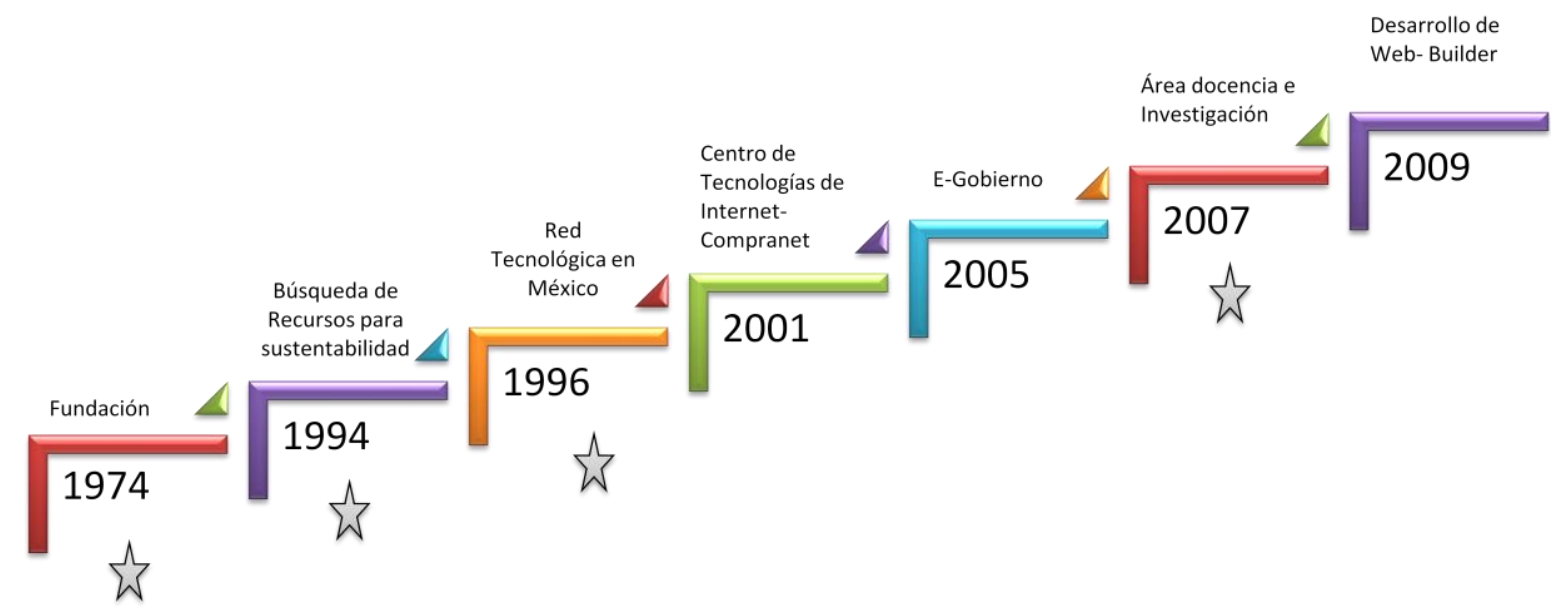

Fuente: Elaboración propia

Sin perder el enfoque organizacional, estos eventos críticos no fueron elegidos al azar, con base en la historia documentada y en las entrevistas realizadas, la autora llegó a la conclusión de que estos eventos críticos permitían captar el cambio organizacional con la introducción de las TIC's a Infotec, y además explicar cómo impactaba este fenómeno dentro de la institución.

Asimismo, se deriva el supuesto de que dos áreas específicas de la organización se veían afectadas por el cambio, de esta manera se suma la estructura y la cultura organizacional. Así que, para entender como es este proceso y exponerlo en el estudio de caso, se diseñó una figura que pudiera explicar la relación entre estas variables en la organización.

La figura siguiente se pretende utilizar como un punto de apoyo para explicar que la organización está conformada por elementos que ayudan a su constitución y reproducción, pero al mismo tiempo las contingencias externas se presentan para modificar esos elementos. A favor se considera que la organización de estudio 
hace uso de las tecnologías de Información y Comunicaciones para el cumplimiento de su objetivo organizacional.

Figura 2. La relación de las variables organizacionales en referencia a las TIC's

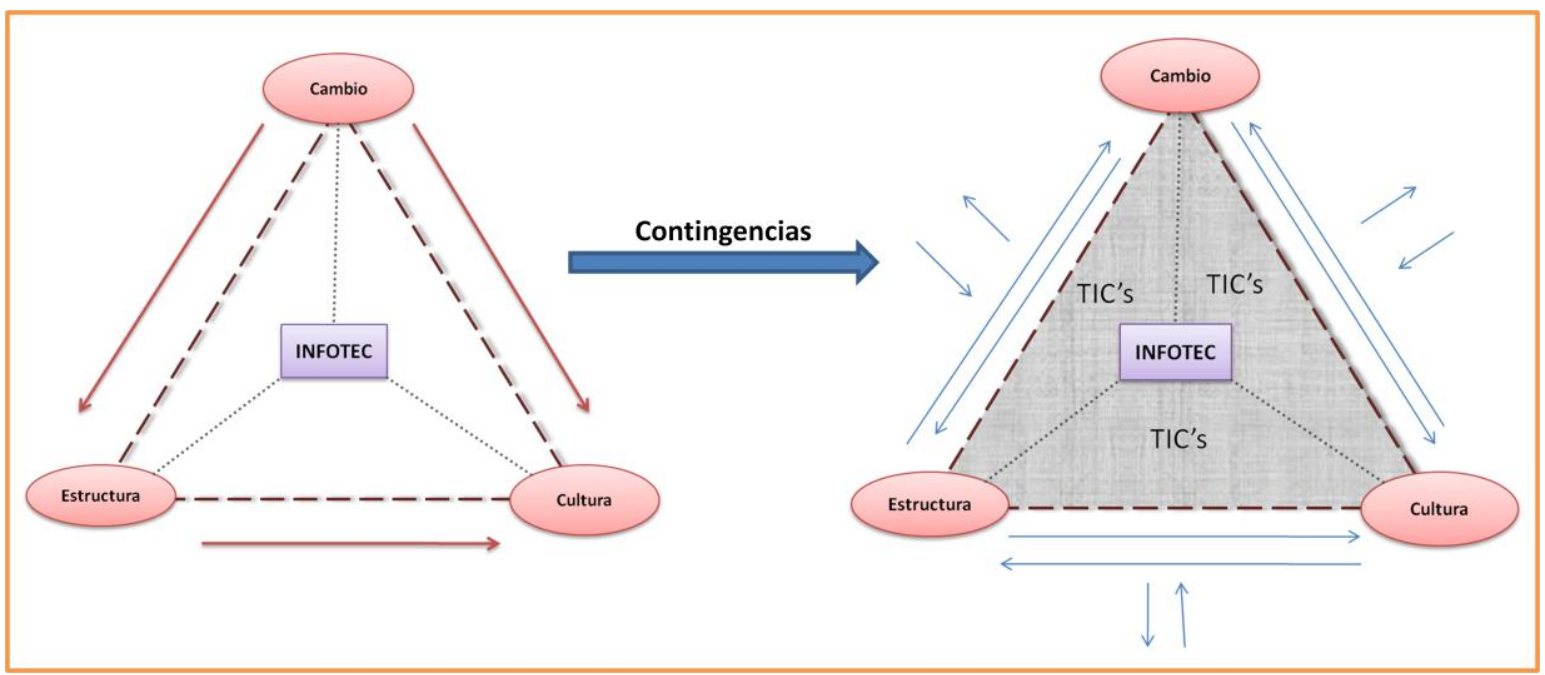

Elaboración propia

En el lado izquierdo se muestra a la organización (Infotec) como un prisma (en este caso se muestra en forma plana) el cual se representa por líneas punteadas. Estas líneas punteadas permiten entender que la organización no es un ente cerrado, sino que es receptiva de contingencias que pueden modificar su estructura y cultura organizacional a través de la gestación de cambios. A su vez, estos elementos tienen una relación entre ellos mismos, pero que no se conoce en qué forma se presentan, ya que cada organización responde de diferente manera ante los vínculos que se puedan crear.

Cuando las contingencias traspasan la estructura de la organización, y en el caso específico del Infotec, se considera como contingencia el hecho de introducir a las TIC's más que como una tecnología, para hacerlo parte de su cultura organizacional. Lo anterior, permite percibir que las variables de la organización se 
han de comportar de distinta manera, y sus relaciones o vínculos toman un orden diferente al esperado. Por eso, es que como se verá en capítulos posteriores, este prisma puede tomar diferentes formas de acuerdo a la relación que tengan estos elementos que se consideran eje para el estudio de análisis de la organización.

Sin embargo, gracias a la pertinencia de dicho esquema y del desarrollo de la investigación, se encontró de manera fortuita que la relación entre las variables presentadas, no se realizaba de manera estática como pudiera notarse en el esquema, sino que había otro concepto que saltaba a la luz, y este factor se le considera como proceso de innovación organizacional', el cual, permite comprender que el Infotec se ha reinventado desde su fundación con apoyo de distintos elementos de la propia organización.

Aunque, en el desarrollo del trabajo se menciona el concepto de innovación ${ }^{2}$, también es importante señalar que este término es utilizado en distintos campos de investigación y desarrollo, no pertenece meramente al ámbito tecnológico, como se muestra más adelante, la innovación para Infotec además de su aplicación en las TIC's, asimismo es utilizado como un valor de la organización.

El hecho de que la organización de estudio permanezca vigente se debe a que en cada uno de los eventos críticos por los que ha pasado, ha visto una oportunidad para generar un proceso de creatividad que ha sido impulsada por un cambio, que a su vez, en este cambio está implícita la relación con las TIC's. Por lo tanto, es

\footnotetext{
1 De acuerdo con la propuesta de la autora de esta tesis, se entiende por proceso de innovación organizacional: la capacidad que tiene la organización de reinventar o modernizar elementos estructurales, culturales, tecnológicos y financieros, con el fin de generar un progreso o renovación que le permita conseguir los objetivos y mejorar su desempeño.

${ }^{2}$ Innovación en términos generales para la RAE es mudar o alterar algo, introduciendo novedades.
} 
necesario advertir al lector que la relación entre las variables eje de este trabajo, no son representadas de manera lineal.

Las líneas punteadas que aparecen en el prisma, permiten comprender que la organización no se representa como un ente estático, sino que puede adquirir otra forma, y reconoce la pertinencia del proceso de innovación organizacional, que al ser producto de un cambio, va a permitir que éste último cumpla el objetivo independientemente del impacto que pueda generar en la organización, por medio de la reinvención de la organización. Sin embargo, es necesario aclarar que este hallazgo no es el tema central de la tesis.

Esta introducción, tiene como finalidad que el lector se interese en conocer cómo se comportan las variables mencionadas en una organización que se enfoca a vender e innovar servicios de TIC's y que ha tenido una historia llena de eventos distintos que contribuyen a la realización del estudio. No obstante, no son supuestos aislados los que se proponen en este trabajo, en primera instancia se formularon preguntas de investigación con el objetivo de entender como reproduce la relación que indica la figura.

Por lo que en los siguientes apartados se muestra la teoría relacionada con las variables de estudio, empezando por el cambio que se considera como el eje principal del trabajo en relación a las TIC's, posterior le siguen la estructura y la cultura como variables que son modificadas por el cambio organizacional. En el siguiente capítulo se hace mención de la metodología de la investigación, donde se expone que la metodología de estudio de caso explicativo es el pertinente para realizar el análisis de los datos. 
Finalmente, se presenta el estudio de caso, contextualizando al Infotec en la historia de la Ciencia en México con la intención de hacer comprensible su fundación, luego se presentan las tres etapas en las cuales se realiza la explicación del análisis y con ello conocer las respuestas de las preguntas de investigación. En último lugar, se encuentran las reflexiones finales y hallazgos que puedan derivar del análisis del estudio de caso 


\section{Problema de investigación}

El impacto más directo de las tecnologías de la información es en la economía y la sociedad, su uso en y por organizaciones, particularmente por grandes empresas privadas y burocracias públicas, puede ser la más importante e inmediata fuente de cambio en las sociedades y regiones, así como en las mismas organizaciones. En México, la atención del gobierno federal por las Tecnologías de la Información, cobraron sentido a finales de la década de los 70's, lo que ayudó al surgimiento de numerosas Instituciones que apoyaran el uso y desarrollo de las mismas. La cuestión es ¿Cómo se presenta el cambio en la Organización con la inserción de las TIC's en México?

De acuerdo a lo anterior, el cambio puede modificar aspectos de la organización como la estructura a través de mecanismos de control, creación de nuevas configuraciones, haciendo mayor la complejidad y la centralización o en dado caso disminuyendo las anteriores para hacer más flexible a la organización. Por su parte, la cultura organizacional también es afectada, ya que en un macronivel modifica el comportamiento de las sociedades y en un micronivel modifica el comportamiento de los individuos dentro de la organización, provocando cambios en los valores, creencias e identidad.

\section{Preguntas de investigación}

¿Cómo influyen las TIC’s en el cambio organizacional?

¿Cuál es la relación entre estructura, cambio organizacional y TIC’s?

¿Cuál es el rol de la cultura organizacional en el trinomio cambio-estructura-TIC's? 


\section{Objetivo general}

- Analizar la relación que se establece a partir de las TIC's y su reciprocidad con el cambio, estructura y cultura organizacional.

\section{Objetivos específicos}

- Identificar los tipos de cambio organizacional que se reproducen en la organización respecto a las TIC's

- Exponer cómo la estructura organizacional es modificada con la introducción de las TIC's en la Organización

- Evidenciar la transformación de la cultura organizacional con la introducción de las TIC's en la Organización

\section{Justificación}

El estudio de las diversas modificaciones que han surgido en las organizaciones ha cobrado mayor relevancia a partir de la década de los 60's, y esto ha sido ocasionado por los cambios sociales, culturales, políticos y económicos generados a partir del fenómeno de la globalización a consecuencia de que en las esferas organizacionales se han propiciado cambios con la intención de desistir de los modelos administrativos tradicionales y se han desarrollado nuevas formas que crean habilidades para solucionar problemas de procesos, administrativos 0 estructurales. 


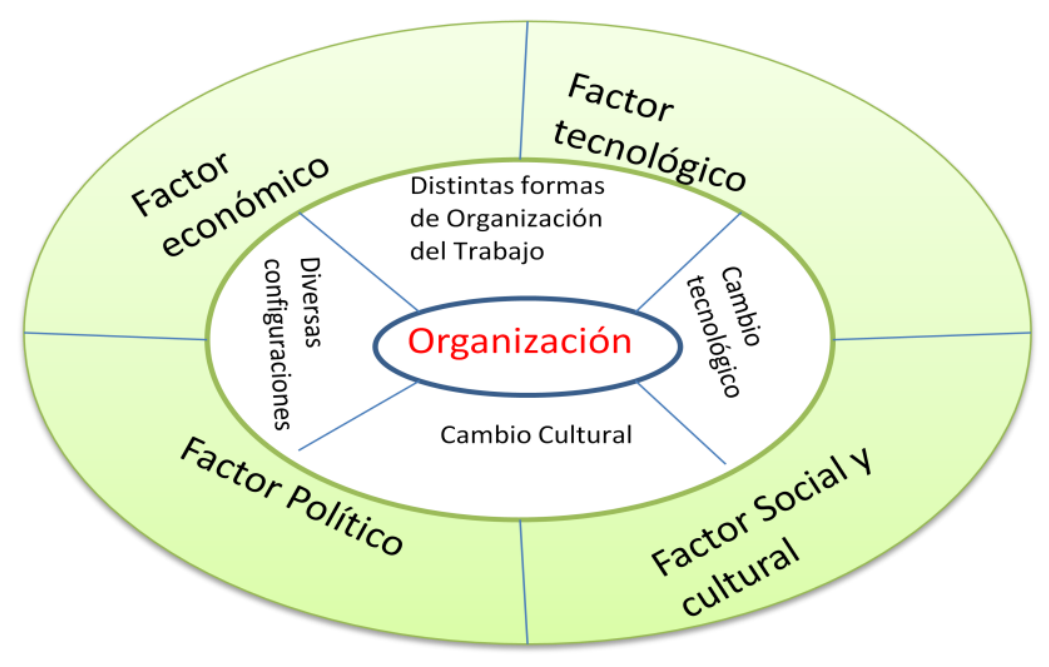

Son diversos y muy amplios factores que afectan o condicionan la presencia del cambio en las organizaciones, por lo que su explicación y estudio requiere la exploración de procesos complejos, fortuitos y a menudo contradictorios. Ya sea desde una visión netamente adaptativa o a través de un determinismo tecnológico, o bien buscando congruencia entre una diversidad de factores organizacionales, tales como tamaño, estructura, objetivos y tipo de control, entre otros.

Aunque, visto desde otro enfoque, la cultura organizacional, también es modificada cuando existe un cambio organizacional, dónde se hace cargo del pensamiento o del determinismo que debe tener los individuos de la organización, porque la revolución tecnológica de la información, al igual que en el caso de las anteriores revoluciones tecnologías, se ha caracterizado por su capacidad de penetración en todos los ámbitos de la actividad humana.

Puede parecer obvio qué cuando una nación, una sociedad o una organización cambian la forma de llevar a cabo sus rutinas, es porque transitaron por una "nueva" forma de hacer las cosas. Lo anterior, es de suma importancia en la organización, ya que en tiempos actuales necesitan adaptarse a estos cambios 
que sufre el ambiente de manera constante y en el peor de los casos no es de forma gradual. El cambio que será objeto de estudio será el que se ha visto envuelto por la introducción de las TIC's en la organización. Para ello, es necesario revisar la perspectiva teórica para ayudar a comprender cómo se lleva a cabo este proceso. 


\section{Capítulo I. MARCO TEÓRICO}

\subsection{Enfoques para el estudio del Cambio en la organización}

En este primer capítulo se pretende enraizar al lector sobre los conceptos que se abordaran a lo largo de la tesis, aunque cada uno de estos conceptos tendrá su propio espacio de desarrollo. El recorrido teórico de este trabajo inicia con el estudio del cambio organizacional, porque es el área eje de estudio en la organización que así ha considerado la autora de este escrito. Además como se muestra en las siguientes líneas, este tema es la base para entender por qué es importante para los estudios organizacionales así como su relación con otros temas que pudieran parecer ajenos a dicha corriente.

Actualmente, el discurso de cambio organizacional se encuentra más presente entre la comunidad de los estudiosos de la organización. Lo anterior, no es por causa de hacer un estudio académico más o por hablar de la praxis de este tema en particular, sino por el hecho de que el cambio se haga presente en las organizaciones conlleva a una serie de alteraciones dentro de las mismas que hace fructífero saber cómo se produce, en qué parte de la organización impacta y porqué impacta. Sin embargo, también es importante hacer referencia a la definición de la palabra cambio organizacional, con el objeto de no confundir con sus similares como puede ser reestructura, reingeniería, innovación, etc. 
¿Y por qué hacer énfasis en su definición?, principalmente, porque distintas organizaciones hacen mal uso del término, por ejemplo, - el otro día una persona fue al banco de las letras azules. Cuando llegó vio que la parte de los cajeros estaba cerrada, y que la gente hacia filas enormes en la parte de afuera del banco para pasar. No entendía porque el piso era una mezcla de cemento y tierra, y que la luz apenas era suficiente para que las cajeras y ejecutivos pudieran hacer su trabajo. Además los plafones en el techo hacían sus esfuerzos para no caer en la cabeza de los allí presentes. Aunado a eso, los trabajadores del banco no ayudaban para hacer más corta la espera del servicio.

Ante tantos reclamos y molestias de la gente, el gerente del banco sólo atinaba a mostrar su mejor cara y decir: "estamos cambiando a la organización para ustedes", "estamos cambiando nuestra sucursal para que tengan un mejor servicio y una buena presentación". La gente sólo lo miró y le hacía gestos, no les interesaba sí el banco cambiaría, lo único que querían era salir de ese lugar que no parecía lo que debía ser.

Este ejemplo, quizá un poco burdo, tiene la intención de poner sobre entendimiento lo que pudiera ser en un intento de explicar un fenómeno que sucede en la organización a partir del cambio. Por ello, es muy importante comprender que el cambio organizacional se manifiesta dentro (intraorganizacional) de la organización y puede tener algún impacto hacia fuera 
de ella. $Y$ de manera opuesta, el ambiente externo puede tener alguna relevancia para la organización y hacer que esta cambie.

Metafóricamente, es como si la naturaleza del cambio organizacional fuera la tercera Ley de Newton del movimiento: acción y reacción, en la cual debe existir la interacción mutua de dos fuerzas y donde ninguna de las dos existe sin la otra. Llevando esta metáfora a la organización, se puede decir que cuando se genera un cambio en la organización impactará sobre otra área de la organización y por el contrario un área organizacional puede generar un cambio que impacte a toda la entidad.

Hoy en día, por las diversas circunstancias en las que se encuentran las organizaciones se logran presentar cambios de forma gradual o inmediata, puede que éste cause relevancia para algunos miembros de la organización y para otros no, significar una nueva forma de hacer las cosas o ser tan grande que modifique alguna parte de la organización (como la cultura, la estructura, la ideología, etc.).

De alguna manera el cambio organizacional se hace presente en las diversas organizaciones de tipo gubernamental, pyme, corporativa, ONG, entre otras, por lo que, en los últimos años ha tomado mayor relevancia su estudio en el ámbito académico y empresarial. En la esfera académica permite estudiarse desde distintas disciplinas y por lo tanto permite realizar teorías acerca de su proceso y el impacto que puede generar. $Y$ en el ámbito empresarial, porque puede ayudar a encontrar diversas formas de gestión que a su vez son aprovechadas para obtener mayor productividad. 
Por consiguiente, y para efectos de este enfoque explicativo que se pretende realizar en este trabajo, el cambio tiene que ser abordado, desde la perspectiva organizacional, ya que según Cohen (1999) es necesario conocer cómo es que a través de nuestra historia surgen acontecimientos que no se presentan de manera gradual y que estos generan cambios que causan nuevos disturbios en la sociedad. Asimismo en las organizaciones.

En la época actual, es casi imposible no reconocer que las organizaciones atraviesan por procesos de cambio y que se han manifestado en todas las épocas, que ha sido en parte, gracias a la profundidad de los efectos producidos por la globalización, la regionalización y la internacionalización (Barba: 2002), así como por el neoliberalismo que generan contextos de alta incertidumbre en los que el cambio ya está siendo asimilado en todos tipos de organización.

Con la pequeña introducción presentada, se trata de ejemplificar que el cambio en la organización está presente, ahora se requiere conocer cómo es que el cambio organizacional se crea o surge, que factores intervienen, quién lo estudia, etc. Por ello, es necesario revisar a los expositores del cambio organizacional que han propuesto diferentes enfoques para su estudio; cabe señalar que más de un enfoque se puede retomar para estudiar alguna organización en particular, por ejemplo, una organización mecánica, orgánica, flexible, virtual, etc.

Skip (2001) señala que hay dos tipos de enfoque para estudiar el cambio organizacional: el determinista y el interdependiente. El enfoque determinista 
propone que las organizaciones reaccionan a los problemas causados por el medio ambiente con la finalidad de adaptarse al entorno y de esta manera alcanzar la productividad. En el enfoque interdependiente las organizaciones interactúan regularmente con su medio ambiente y adoptan políticas más proactivas para tratar de modificar el medio ambiente creando condiciones favorables para su supervivencia.

Por otro lado, el enfoque que presentan Dimaggio y Powell en el ámbito institucional permite entender porque las organizaciones sufren procesos de cambio, ellos denominan isomorfismo al "proceso de restricción que obliga a una unidad en una población a parecerse a otras unidades que se enfrentan a la misma serie de condiciones ambientales" (Dimaggio y Powell: 1983: 149), en este sentido es semejante a la teoría determinista, solo que los autores proponen tres maneras en que se puede dar dicho cambio: isomorfismo mimético (la organización copia algunas características de otras organizaciones), isomorfismo normativo (el gobierno limita las funciones de la organización mediante mecanismos de regulación) y por último isomorfismo coercitivo (otras organizaciones presionan para que haya cambios en una organización).

La teoría de la naturaleza del cambio organizacional de Burke (2011) propone dos principales teorías: el cambio revolucionario y el cambio evolucionario. El cambio revolucionario, bajo la premisa de Tushman y Romanelli (citado en Burke: 2011:75) señala que las organizaciones no evolucionan pero que sí son propensas a cambiar en reorientaciones estratégicas que exigen significativamente diferentes 
patrones de operación, por lo tanto, cuando la organización sufre una perturbación, ya nada vuelve a ser igual en ella.

En el cambio revolucionario puede detectarse por medio de la propuesta de Gersick's1991 (citado en Burke: 2011: 75).

- Estructura profunda. En esta fase, la organización tiene una configuración básica, pero las unidades del sistema y los recursos cambian con el ambiente.

- Períodos de equilibrio. El período de equilibrio consiste en mantener el sistema a través de la elección de las actividades llamadas "jugadas", pero sin estar por encima de las reglas, estándares y los procesos.

- Periodo de revolución. Cuando la estructura tiene largos períodos de estar intacta, tiende a generar una fuerte inercia, esto provoca que el sistema genere alternativas fuera de sus límites, y luego empuja algunas desviaciones que ocurren de nuevo en línea.

Por otro lado, el cambio evolucionario, es el que está presente en la mayoría de las organizaciones, ya que de acuerdo con Orlikowski (citado en Burke: 2011: 79) dice que cada variación de una forma dada no es un evento brusco o discreto, tampoco es, por sí mismo discontinuo. Si no, a través de una serie de adaptaciones y modificaciones (que se basan en las variaciones anteriores y futuras) pueden ser suficientes y son promulgadas en el tiempo donde se logran cambios fundamentales. Cada cambio en la práctica crea las condiciones para un mayor desglose de resultados inesperados y las innovaciones, que a su vez se 
encuentran con más variaciones. Estas variaciones están en curso, no hay principio ni punto final en este proceso de cambio.

La figura 3 presenta la asociación entre los distintos enfoques, donde la organización es representada por el primer círculo y el ambiente es el segundo círculo. La línea punteada indica el cambio evolutivo, en el que se crean cambios dentro de la organización para la supervivencia de la misma; estos cambios se pueden dar de forma gradual y tener impacto en toda la organización o en una parte de ella.

La línea discontinua muestra el cambio revolucionario, el cual atraviesa la organización y el ambiente a consecuencia de los cambios que se gestan en ambos sentidos, y que según sus características el ambiente puede provocar cambios en la organización, como la organización en el ambiente, con la intención de obtener su supervivencia. Finalmente, las líneas con doble flecha representan la metáfora de acción y reacción, en el cual, los cambios generados tienen repercusiones dentro de la organización para generar cambios de distinta complejidad en todos los niveles.

Figura 3: Enfoques de cambio organizacional 


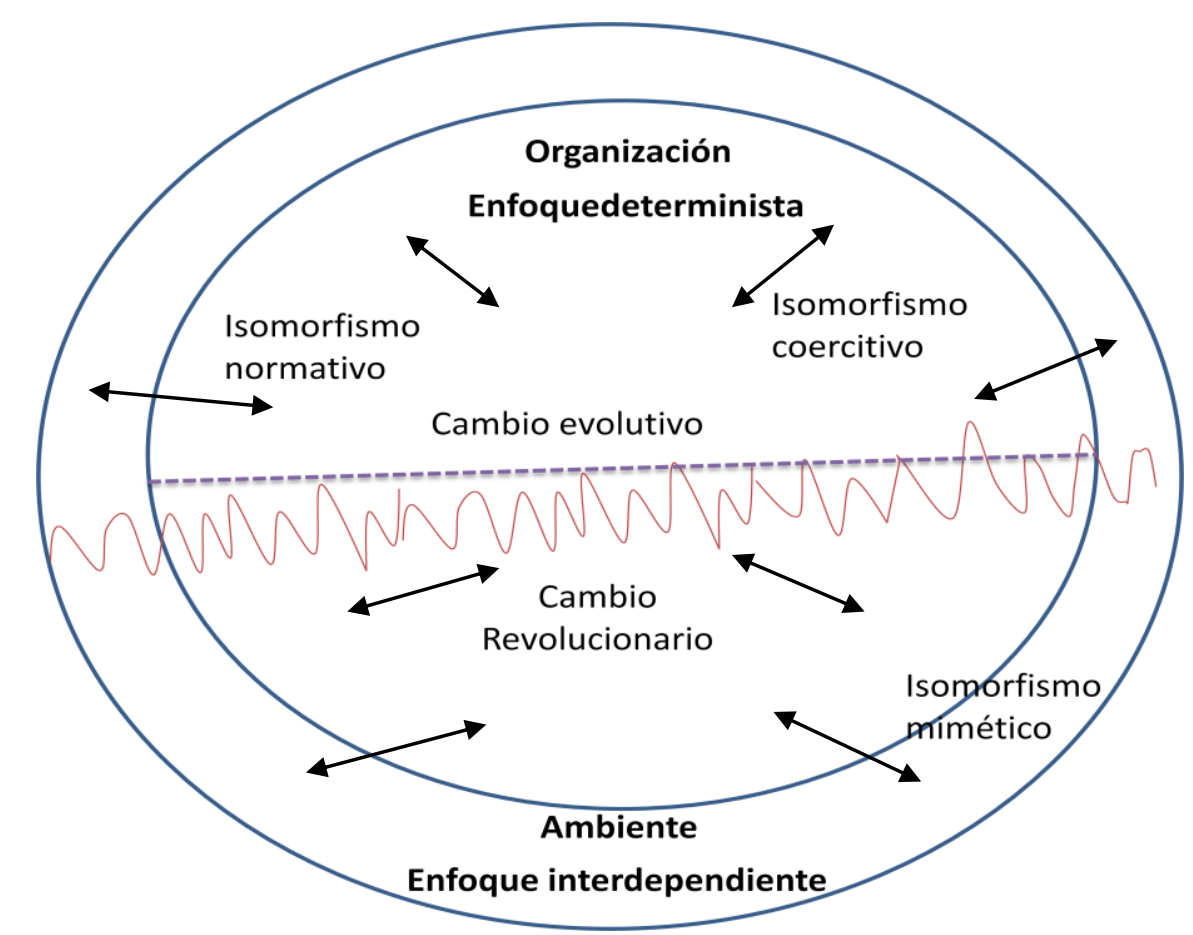

Fuente: Elaboración propia con base en Burke (2001), Dimaggio y Powell (1983) y Skip (2001)

\subsubsection{Definición de cambio organizacional}

A lo largo de este trabajo se ha mencionado la palabra cambio, pero, ¿qué es el cambio organizacional? Y ¿por qué se da? En una aproximación simplista puede decirse que el cambio se da para hacer o ser diferente una organización. Se revisa que la definición de cambio tiene diferentes ramas de estudio, ya que cada disciplina toma características de la definición y las adapta a su área de estudio. En este sentido, en el área organizacional también hay diferentes perspectivas para su estudio, y lo interesante de esta perspectiva es que la definición de cambio no solo se queda en la cuestión de modificar a la organización, sino siempre considera los fenómenos que se presentan alrededor de este suceso. 
En el ámbito organizacional este vocablo permite hacer estudios realizados desde diferentes temas organizacionales, como el poder, la cultura, la estrategia, la estructura, y a su vez permite relacionar los impactos entre las mismas áreas organizacionales, un ejemplo de ello es el estudio de caso que se propone en esta tesis. A continuación se presentan algunas propuestas para dar cuerpo a la definición de cambio.

La palabra cambio en una organización puede significar la insatisfacción con la vieja creencia y con la nueva, así como intercambiar, remplazar, reformar, transferir, transformar, reubicar, mejorar ${ }^{3}$ alguna 0 algunas partes de la organización. Esta insatisfacción puede surgir de una deficiencia precedida en un sistema existente. La deficiencia en este sentido es la incapacidad de un sistema para responder a las presiones ambientales, económicas, políticas, culturales y los impactos tecnológicos.

Es necesario mencionar, que la definición de cambio puede variar de acuerdo a la ciencia que la estudia, así como a las perspectivas del autor, por la manera en que se quiera representar, y de igual forma depende del tipo de organización a la que se remite esta definición. En un sentido más del comportamiento, el cambio subyace una forma cualitativamente diferente de percibir, pensar y comportarse para mejorar en el pasado y el presente (Harigopal: 2001).

Como señala Lewin (citado en Arellano: 2001:78) "por consiguiente, no resulta sorprendente encontrar diversos tipos de cambio organizacional, que se suceden

\footnotetext{
${ }^{3}$ Según la concepción de Arellano (2000) y Harigopal(2001)
} 
en distintos niveles y con diferentes grados de complejidad. En efecto, puede hablarse de cambio como un fenómeno que abarca a toda la organización pero también involucrando sólo una parte de ella y; como lo han presentado algunas teorías del comportamiento, también se pueden identificar procesos de cambio en el nivel de análisis más bajo, aunque no más sencillo, en el nivel de los individuos".

Las definiciones presentadas, tienen un rasgo en común, y es porque muestran diferentes elementos de los que se compone la organización, como la cultura, la estructura, los individuos. Por lo tanto, en esta ocasión se tomará en cuenta los elementos que desarrollan los autores presentados y se propone que: el cambio organizacional es un fenómeno presente en la organización, que modifica los elementos organizacionales a través del tiempo, y, puede ser provocado por el transcurrir cotidiano de la organización como del ambiente, además involucra distintos niveles de participación, lo que genera un nuevo perfil en la organización ${ }^{4}$.

Como se mencionó anteriormente, este tema es muy basto en cuanto discusión teórica se refiere, porque incluye dos tópicos que requieren de dinamismo y de cuestionamientos, por un lado hablar de cambio y el sin número de sinónimos que lo relacionan y por otro lado la organización ${ }^{5}$, que en esta ocasión le da una connotación diferente al vocablo de cambio. Como señalan Coronilla y del Castillo (citados en Arellano, 2001), cambiar y organizar son ciertamente nociones

\footnotetext{
${ }^{4}$ Propuesta de la autora basada en Burke (2011) y Lewin (citado en Arellano: 2001)

${ }^{5}$ De acuerdo con Coronilla y del Castillo (citados en Arellano: 2001:82) para algunos autores, organización significa por ejemplo, un agregado humano con estructura definida, es decir, con una jerarquía de autoridad y capacidad de toma de decisiones delimitada y en el que se persigue un fin o varios fines determinado a partir de varios medios funcionalmente diferenciados y coordinados (Scott, Schein y Thompson).
} 
diferentes. El primero remite a lo inmutable, a lo nuevo, a lo novedoso. El segundo remite al mundo del orden, de la coherencia, de la estabilidad. Sin embargo, en este apartado no se pretende realizar una discusión teórica, sino anticipar al lector sobre algunas características del cambio organizacional para que en posteriores capítulos que se retoma este tema, localice algunos de los aspectos aquí señalados.

\subsubsection{Tipos de cambio}

En el segmento anterior se ha propuesto que el cambio organizacional puede asumir dos orientaciones en la actualidad. Éste denota, en ocasiones, un carácter reactivo y/o adaptativo en virtud de que se manifiesta por medio de acciones encaminadas a responder (reacciones) a los desafíos del medio ambiente ${ }^{6}$. 0 puede tener, a veces, un carácter pro-activo y/o prospectivo en tanto se compone de estrategias que se orientan a mejorar cualitativa y cuantitativamente el desempeño de las organizaciones ${ }^{7}$. En ambos casos, el cambio organizacional tiene un carácter prescriptivo puesto que se implanta para superar los problemas que agobian continuamente a las organizaciones.

Por ejemplo, Barba (2001) y Magallón (2004) ${ }^{8}$ hacen una distinción del cambio, de acuerdo a la estructura de la organización. Señalan al cambio como un proceso racional normativo, donde las estrategias se convierten en medios formales que

\footnotetext{
${ }^{6}$ Según se desprende de las definiciones de Hage, citado por Hall (1991), y de la OECD, citada por Kosacoff y López (2000)

${ }^{7}$ De acuerdo a la visión de Certo (1992) y de Sillince (1999)

${ }^{8} \mathrm{La}$ autora le denomina cambio como proceso formal (en la que se involucran las primeras escuelas de teoría de la organización) y cambio como acción colectiva de significados (en la que se involucran las escuelas de de contingencia, cultural y nuevas formas de organización)
} 
permiten alcanzar el cambio y, consecuentemente conservar y perpetuar el modelo de organización generado por el mismo. Las estrategias se diseñan para mantener el control organizacional, como lo representan la Administración Científica, la Escuela de las Relaciones humanas, la Teoría de la Burocracia y la Teoría Contingente.

Por otra parte, el cambio como un proceso regulativo, es una perspectiva que comienza a desarrollar sus propuestas bajo un contexto no sólo altamente heterogéneo, turbulento y complejo, sino que avanza de manera acelerada. En adelante, las organizaciones se deben a la imperiosa necesidad de adaptarse y aprender para responder de manera rápida y efectiva, entre y frente a ambientes altamente inciertos; permitiendo visualizar la noción de cambio organizacional como un suceso no sólo desplegado en términos racionales, lineales y lógicos a través de una planeación formal, como destaca la tradición clásica organizativa.

Para no tener la idea de que el cambio solo presenta en forma normativa o un proceso regulativo, Coronilla y del Castillo (citado en Arellano: 2000:106:130) proponen que el cambio se da en la organización particularmente de tres maneras:

1. Cambio planeado: hace referencia a aquellas actividades y procedimientos que se llevan a cabo de manera consciente e intencional con el objeto de realizar un cambio en la organización, sea a un nivel individual, grupal o de la organización en su conjunto. El cambio se mira como un proceso secuencial y racional, tendiente a que la organización mejore su eficiencia o desempeño. Este 
enfoque parte del supuesto de que el cambio organizacional se inicia y termina con el cambio de las personas que participan en ella. Según los autores, se considera que la tarea de análisis de cambio organizacional es encontrar relaciones o conexiones entre el trabajo deseado por la organización y los valores, preferencias o necesidades de los individuos.

2. Cambio como un proceso de adaptación: hace referencia a las transformaciones incrementales o radicales, anticipadas o emergentes, que llevan a cabo las organizaciones con el objeto de ajustar a su funcionamiento a nuevos requerimientos de su medio ambiente, o bien, a desequilibrios generados por las rivalidades entre los individuos o grupos de la organización. Por su naturaleza, este tipo de cambio prevé, por tanto, que las organizaciones tengan la capacidad de cambiar tanto sus modos de operación como sus estructuras por medios de procesos de planeación y control. Este tipo de cambio se explica porque la organización no sólo se adapta en función de las fuerzas externas sino que también se produce el cambio por la necesidad que tiene la organización de adaptar algunos de sus componentes a un equilibrio de sus fuerzas internas con la finalidad de asegurar su sobrevivencia. Por lo tanto, no es sorpresivo que se generen vínculos de poder y de la influencia de los individuos, dando lugar a la creación de estrategias personales o grupales y a las diversas contingencias.

3. Cambio como un proceso accidental: para este enfoque, el cambio es una actividad confusa, en suma, se trata de una ambigüedad organizativa, donde es difícil establecer qué está pasando, por qué está pasando y quién está dirigiendo las cosas. Donde se destaca la incapacidad de los individuos para 
descubrir los procesos organizacionales en general y de la toma de decisiones en particular como un hecho sencillo, medible y racional. Las teorías de la ambigüedad organizativa demuestran que los procesos de cambio, los problemas, las soluciones y los participantes se encuentran entre ellos de forma accidental más que planeada o buscada. Lo importante de este cambio es que sigue trayectorias o rutas de acción complejas antes de llegar al resultado final, donde en ocasiones ese resultado final se da porque los problemas, las soluciones y los participantes se encuentran entre ellos de forma accidental más que planeada o buscada.

Por último, Brunson (2004) menciona que las organizaciones están institucionalizadas en la medida en que su comportamiento está determinado por reglas culturalmente condicionadas, las cuales se manifiestan en ciertas rutinas de acción y le dan significado a esas acciones, reflejan valores, intereses, opiniones, expectativas y recursos relativamente estables. La propuesta de este autor es el cambio a través de la reforma, en la cual se propone modificar las deficiencias de la organización para hacerla más eficaz, a través de institucionalizar nuevas prácticas que estén de acuerdo al ambiente, para crear estas reformas, es necesario que la organización sufra algún tipo de cambio de los que ya se han mencionado.

En la figura 4 se puede observar la interacción de los tipos de cambio en la organización y en el ambiente. Estos tipos de cambio pueden crear intersecciones que a su vez generen nuevos cambios, aunque no significa que todos se generen en la vida de la organización, ni tampoco que se conciban en el mismo tiempo y 
espacio. Las flechas que están hacia dentro indican los cambios que se generan propiamente dentro de la organización y que sólo le afectan a ella. Las flechas que están hacia afuera muestran los cambios que se generan en el ambiente y que afectan a la organización de manera total o parcial.

Figura 4. Tipos de cambio organizacional

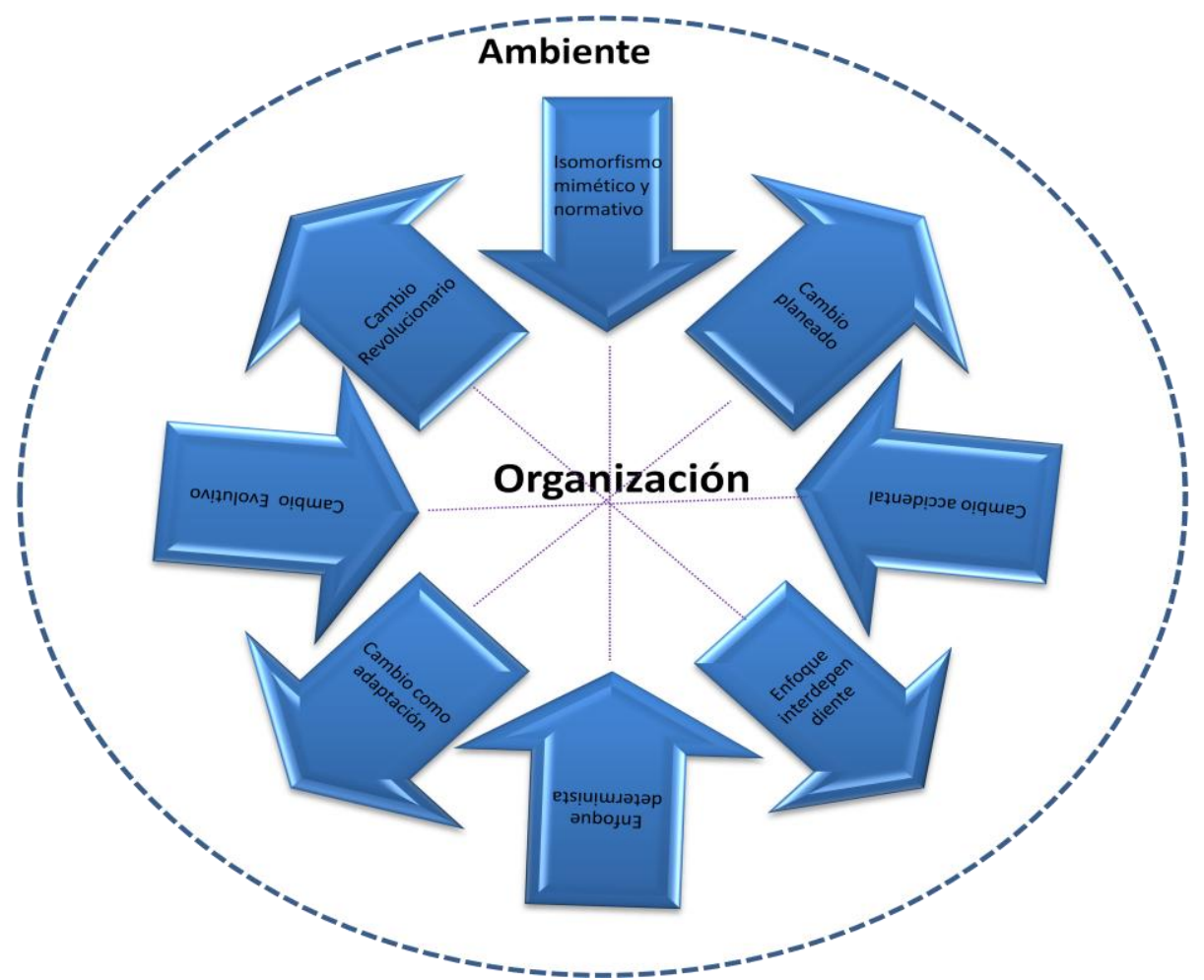

Fuente: Elaboración propia con base en Barba (2001), Magallón (2004), Coronilla y del Castillo (en Arellano: 2001), Brunson (2004)

Este tema permite realizar una introducción más concisa de cómo es la interacción de diversos factores en la organización, haciendo una presentación de qué es lo que sucede dentro y fuera de la misma, asimismo de los actores que intervienen en ella. Lo anterior, le da oportunidad a los estudios organizacionales de investigar y crear teorías sobre las relaciones que se van gestando con la aparición de nuevos fenómenos. 
Sin embargo, como se verá en los siguientes capítulos, las piezas que conforman a la organización en su totalidad, tienen un carácter ambiguo por lo que no reaccionan de igual manera ante los hechos, ni a las circunstancias que se puedan presentar dentro y fuera de ellas. Este es el caso de la estructura, donde se puede ver que uno de los impactos del cambio en la organización es en la forma en cómo se constituye su configuración organizativa y manera inversa, la estructura también puede causar que se genere un cambio. Por consiguiente, es necesario repasar algunas características de la estructura para entender cómo puede manifestarse. 


\subsection{Elementos representativos para el estudio de la Estructura Organizacional}

En el transcurso del capítulo de cambio, se ha hecho notoria la importancia que ha tenido la década de los 60 's, ya que diversos temas organizacionales tuvieron su mayor auge, pero también declinaban a causa de que los investigadores tomaban partido por temas que para ellos eran de mayor relevancia, o por los nuevos paradigmas que tuvieron notabilidad a finales de los 70's y principios de los 80 's (por ejemplo las revueltas sociales-políticas en todo el mundo, el surgimiento de la posmodernidad y la revolución de las TIC's)

En este caso, la estructura pudiera no ser relevante porque no se aprecia en sentido estricto, ya que, puede interpretarse únicamente de carácter formal (como jerarquía o el total de áreas de una organización), o incluso únicamente como la estructura física. Por lo tanto, en este capítulo se pretende, entender a partir de los acontecimientos que surgieron en los 70 's, los resultados estructurales para la organización, como el nacimiento de la estructura (flexible) y los diversos tipos de configuraciones, y cuáles son sus características.

El análisis de la estructura organizacional es muy interesante porque permite detectar con mayor facilidad cuál es la parte de la organización que sufre cambios y los acontecimientos que se generan a partir de la relación entre ambos componentes. Es como si se pusiera una lupa por afuera de la organización y esta permite ver claramente cómo es la relación de la estructura con otras variables de la organización (cultura, cambio, tecnología, ambiente, individuos, etc.). Cabe 
mencionar, que las estructuras organizacionales pueden ser semejantes entre la diversidad de organizaciones (isomorfismo) y que pueden reflejar lo que está pasando en ese momento en el ambiente exterior. De igual manera, como el cambio organizacional y la cultura, la estructura está compuesta de factores internos y externos a la organización que necesitan de su revisión.

\subsubsection{Definición de estructura}

La estructura organizacional tiene varios significados de acuerdo a la perspectiva que es estudiada, algunas definiciones que permiten aclarar la enredada idea de lo que es en sentido estricto la estructura a través de los estudios organizacionales, son las siguientes: Sewell (citado en Hall:1992:53), menciona que "las estructuras configuran las prácticas de la gente, pero también es cierto que las prácticas de la gente constituyen (y reproducen) la estructura", similar a esto, Ranson, Hinings y Greenwood (citado en Hall:1992:53) perciben a la estructura como "un medio complejo de control que se produce y recrea continuamente en la interacción y sin embargo da forma a esa configuración: las estructuras se constituyen y son constituyentes".

De acuerdo con las definiciones anteriores, se puede notar que tienen algo en común, y es que ambas remarcan la interacción de los individuos en la organización, de manera tal que se perfila una forma multidimensional de reproducción de estructuras en la organización. Se puede visualizar su representación a través de la figura 2.1 , en la cual, se puede considerar a la organización como un tablero de ajedrez, y a los individuos como las piezas que conforman el juego, y por último se puede considerar a las contingencias como los 
jugadores que serán encargados de mover las piezas en el tablero de acuerdo a la estrategia que se requiera para obtener una buena jugada.

En este sentido, se muestra en la figura 5 que de acuerdo a las posiciones de los individuos en la organización, se empiezan a formar interacciones que pueden pasar uno o más individuos al mismo tiempo, o de uno a otro sin tener que pasar por los demás individuos (de acuerdo a la definición de Sewell). Lo anterior va generando la o las estructuras dentro de la organización, así como las relaciones interpersonales de los individuos. Aunque, existen otros factores que también determinan la estructura, y que aparecen como una nueva jugada. Algunos de estos factores pueden ser el cambio organizacional, la tecnología, el medio ambiente, la complejidad organizacional como la cultura, el poder, toma de decisiones, etc.

Figura 5 La dimensión de la estructura organizacional

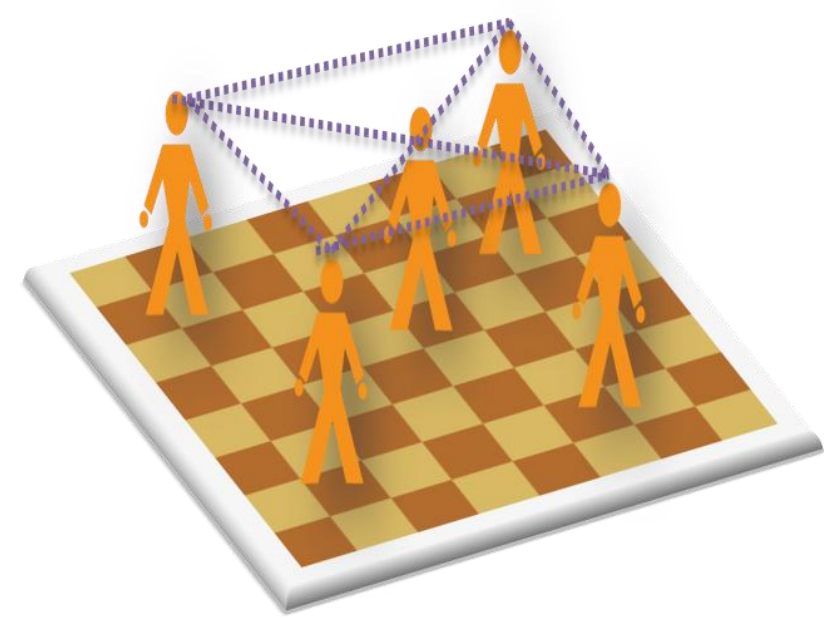

Fuente: Elaboración propia con base en Hall (1992) 
Para seguir entendiendo que es la estructura, a continuación se describe cuál son las tres principales funciones en la organización de dicho tópico: 1) tienen la intención de elaborar productos organizacionales y alcanzar objetivos (como señala Mintzberg, 1999), por lo que una organización a lo largo de su vida puede pasar por diversas estructuras para cumplir con el objetivo que se requiere en determinado tiempo y espacio). 2) las estructuras se diseñan para minimizar o por lo menos regular, la influencia de las variaciones individuales sobre la organización (según la explicación de la figura 5, los individuos son participes de la creación de la estructura, pero, esto significa que lo harán bajo la influencia de sus propios intereses, sino que tienen que ajustarse a los requerimientos organizacionales), y 3) las estructuras son el ambiente donde se ejercita el poder, donde se toman decisiones y donde se desarrollan las actividades de las organizaciones (Hall:1992:53). Por lo tanto, factores como el tamaño (Blau, 1970), la tecnología (Woodward, 1985) y la división del trabajo incrementa la complejidad de las relaciones internas en una organización.

\subsubsection{Características de la estructura}

Como se ha visto en las definiciones anteriores y al conocer cuáles son las funciones de la estructura en la organización, se reflexiona que existen más características que se suman a la creación de la misma. Por lo que es necesario conocer lo que propicia que la estructura en cada organización sea diferente, así como también, las áreas divisionales de una misma organización puedan tener estructuras diferentes. 
A través de los estudios empíricos que han hecho los estudiosos en la materia del campo organizacional, ha dado como resultado la propuesta de diferentes características y factores que pueden ayudar a crearse una red de conceptos que enlazados dos o más de ellos permitan darle sentido a la estructura en la organización. Además, los investigadores han demostrado que cuando se realice un estudio de estructura organizacional, solo se debe retomar los conceptos y características que estén presentes en dicha entidad.

El discurso de Hall, hace notar que la estructura no es únicamente creada a partir de la influencia de los individuos, de la tecnología o de las necesidades de la organización, sino que también el ambiente externo (que ya se ha mencionado en el apartado anterior) juega un papel de intercesión en la organización. Por lo tanto, las siguientes propuestas de Pugh (1973) y Hall (1992), ayudarán a seguir ejemplificando como se conforma la estructura organizacional.

\section{Factores contextuales}

Los investigadores Pugh (1973) y Hall (1992) necesitaban tener más evidencia empírica para realizar cuestionamientos sobre la estructura, para que no bastara con crear supuestos sobre su existencia. Así, cada uno reunió evidencia, por una parte Hall recopiló investigaciones de diversas variables de la estructura y Pugh desarrolló su propia investigación tomando características clave. Ambos investigadores coinciden en que los factores contextuales determinan la estructura, aunque también con esta propuesta se genera un debate para que no sea considerado como una réplica de estudios anteriores y por lo tanto se puedan 
realizar más conjeturas al respecto. Por consiguiente, se presentan las características estructurales que ambos autores encuentran. En la figura 6 se muestra cómo se va conformando una estructura multidimensional a través del enfoque que comparten los autores.

Figura 6 La interacción de las características estructurales en la organización

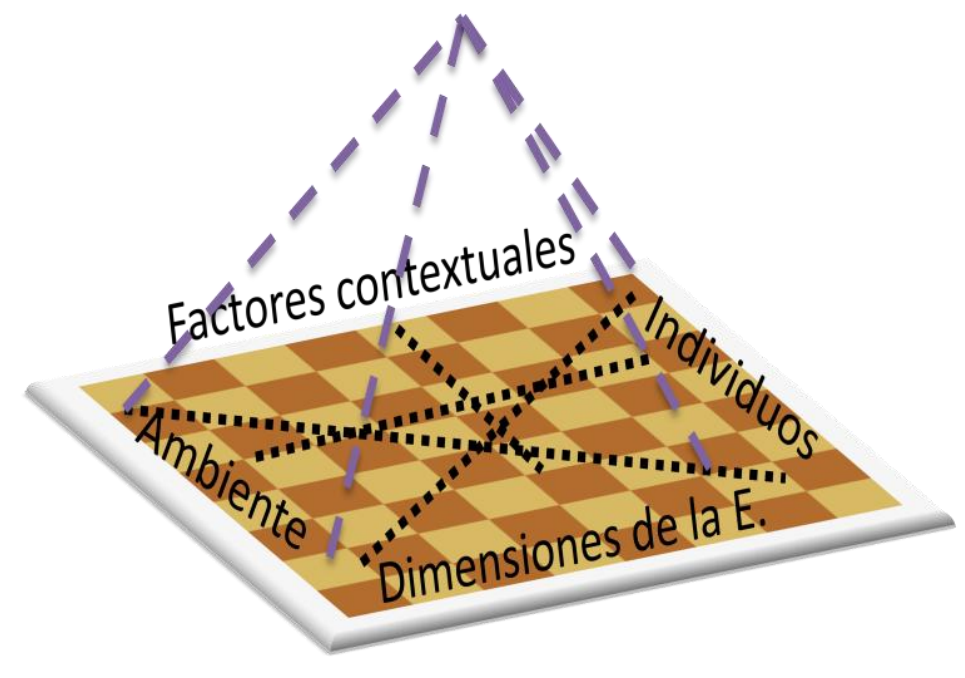

Fuente: Elaboración propia con base en Hall (1992) y Pugh (1973)

En la figura 6 puede apreciarse que aparece de nueva cuenta el tablero de ajedrez como la base organizacional, en el cual ahora se encuentran interrelacionados los factores contextuales, el ambiente, los individuos y las dimensiones de la estructura. Estos factores al relacionarse unos con otros darán lugar a la formación de la estructura organizacional, estas relaciones están representadas por las líneas punteadas que sobresalen del tablero. Cabe aclarar, que existen diversas formas estructurales (las cuales serán abordadas más adelante). En principio, solo se mencionan para anticipar al lector y ayudar a conformar una idea más clara de cómo se percibe la estructura en la organización. 
Tabla 1 Factores del contexto organizacional

\begin{tabular}{|c|l|}
\hline Factor & \multicolumn{1}{|c|}{ Descripción } \\
\hline Tamaño & $\begin{array}{l}\text { Principalmente se conforma de 1) la } \\
\text { capacidad física de la organización, 2) el } \\
\text { número de personal que se encuentra } \\
\text { laborando, 3) los insumos o productos que } \\
\text { utiliza la organización y, 4) los recursos } \\
\text { discrecionales con los que cuenta la } \\
\text { organización en forma de riquezas o } \\
\text { activos }{ }^{9} \text {. }\end{array}$ \\
\hline Tecnología & $\begin{array}{l}\text { La tecnología }{ }^{10} \text { involucra la actuación sobre } \\
\text { y/o cambio de un objeto de un estado a } \\
\text { otro...el objeto puede ser un ser viviente, } \\
\text { un símbolo o un objeto inanimado }{ }^{11} . \\
\text { También puede ser el grado de integración } \\
\text { logrado en un proceso de trabajo de la } \\
\text { organización }{ }^{12}\end{array}$ \\
\hline Cultura interna & $\begin{array}{l}\text { Es un conjunto bastante estable de } \\
\text { supuestos dados por sentados, significados } \\
\text { compartidos y valores que forman una } \\
\text { especie de escenario para la acción }{ }^{13}\end{array}$ \\
\hline El factor ambiental & $\begin{array}{l}\text { Es la infraestructura socioeconómica en } \\
\text { que se ubican las organizaciones. La } \\
\text { situación demográfica, inclusive factores } \\
\text { como las mezclas raciales y étnicas }\end{array}$ \\
\hline
\end{tabular}

\footnotetext{
${ }^{9}$ De acuerdo a los estudios de Kimberly 1976 (citado en Hall:1992:94)

${ }^{10}$ Como ya se mencionó en el apartado de cambio, el interés por estudiar la tecnología como componente principal del análisis organizacional se da a partir de la década de 1960 por el trabajo de Woodward (1958, 1965), Thompson (1967) y Perrow (1967) entre muchos otros. "Los trabajos de Woodward muestran que la naturaleza de la tecnología afectó de forma vital las estructuras administrativas de las compañías que se estudiaron. El número de niveles en la jerarquía administrativa, el tramo de control de los supervisores de primera línea y la relación de administradores y supervisores con el otro personal fueron todos afectados por la tecnología utilizada. No sólo se afectó la estructura, sino que el éxito o efectividad de las organizaciones estaba relacionada al ajuste entre la tecnología y la estructura" (Hall, 1996: 98).

${ }^{11}$ De acuerdo con Goodman, Griffith y Fenner, 1990: 48 (en Hall, 1996: 97)

${ }^{12}$ La investigación realizada por Pugh (1973:32) señala que por el contrario a lo que rescata Woodward del factor tecnológico, él encontró que no tiene mayor relevancia más que en el número de trabajadores u no en la producción.

${ }^{13}$ Según la definición de Smircich (1985), aunque la interpretación de Hall dice que "Las culturas internas son un contexto organizacional conservador en que se forman las estructuras. Junto con el tamaño y la tecnología, es parte de la configuración de los factores organizacionales internos que se han formado en interacción para obtener la estructura y que componen el contexto en que se desarrollan los arreglos estructurales futuros" (Hall, 1996: 103).
} 


\begin{tabular}{|c|l|}
\hline & $\begin{array}{l}\text { presentes y los valores institucionalizados } \\
\text { que rodean a la organización }\end{array}$ \\
\hline Origen e historia & $\begin{array}{l}\text { Cómo se fundó la organización y que } \\
\text { cambios ha tenido en sus propietarios, } \\
\text { ubicación, etc. }\end{array}$ \\
\hline Propiedad y control & $\begin{array}{l}\text { Tipo de propiedad, pública o privada y si el } \\
\text { control está en unos pocos o muchos. }\end{array}$ \\
\hline Constitución & $\begin{array}{l}\text { Naturaleza y cantidad de bienes y } \\
\text { servicios. }\end{array}$ \\
\hline Interdependencia & $\begin{array}{l}\text { Grado en que la organización depende de } \\
\text { clientes, proveedores, sindicatos, etc. }\end{array}$ \\
\hline
\end{tabular}

Fuente: Elaboración propia con base en Hall (1992) y Pugh (1973)

\section{Dimensiones de la estructura}

En otra perspectiva, Pugh (1973) propone que la parte formal para medir la estructura organizacional, en la que considera seis dimensiones básicas de la estructura. Este es el resultado de obtuvo de un estudio empírico en el cual los datos fueron recolectados de cincuenta y dos organizaciones en el área de Birmingham a mediados de 1964, con la finalidad de encontrar relaciones y/o correlaciones entre sí, de esta investigación concluyó con su propuesta de las seis dimensiones básicas de la estructura, las cuales posteriormente retoma Hall en sus escritos. En la tabla 2 se describen cuales son:

Tabla 2. Dimensiones de la estructura

\begin{tabular}{|c|l|}
\hline Dimensión estructural & \multicolumn{1}{|c|}{ Descripción } \\
\hline Estandarización & $\begin{array}{l}\text { Aspecto básico en términos de la } \\
\text { estructura organizacional y en términos de } \\
\text { Weber quien distinguió las organizaciones } \\
\text { burocráticas, tradicionales y carismáticas }\end{array}$ \\
\hline
\end{tabular}

\footnotetext{
${ }^{14}$ Otra forma de visualizar los ambientes es si son o no hostiles o amigables. Un ambiente amigable da apoyo, proporciona fondos y valores de apoyo. Un ambiente hostil es una situación en que están amenazados los propios fundamentos de la organización (Khandawalla, 1972 en Hall, 1996: 103).
} 


\begin{tabular}{|c|l|}
\hline Formalización & $\begin{array}{l}\text { Denota el grado en que las normas, } \\
\text { procedimientos, instrucciones y } \\
\text { comunicaciones son establecidos }\end{array}$ \\
\hline Centralización & $\begin{array}{l}\text { Tiene que ver con el lugar de la autoridad } \\
\text { para tomar decisiones que afectan a la } \\
\text { organización, también se identifica con el } \\
\text { nivel de jerarquía que existe en la } \\
\text { organización y de quien es la persona que } \\
\text { toma las decisiones }\end{array}$ \\
\hline Configuración & $\begin{array}{l}\text { Es la forma del rol de la estructura, los } \\
\text { datos que se obtuvieron debieron manejar } \\
\text { un amplio contenido de cada rol de la } \\
\text { organización }\end{array}$ \\
\hline Tradicionalismo & $\begin{array}{l}\text { La manera como se realizan los procesos } \\
\text { cotidianamente. }\end{array}$ \\
\hline Especialización & $\begin{array}{l}\text { El grado en que las actividades de la } \\
\text { organización están divididas en roles } \\
\text { especializados. }\end{array}$ \\
\hline
\end{tabular}

Fuente: Elaborado con base en Pugh (1973)

\subsubsection{Tipos de estructura}

Al inicio del tema, se ha reiterado sobre el tipo de estructura, las características organizacionales y a las dimensiones de la estructura que se presentaron en los cuadros 1 y 2., y teniendo como base a la figura 6 , se tiene una base sólida que ayuda a entender lo que algunos investigadores han propuesto acerca de las formas estructurales con el propósito de definir a una organización de acuerdo a las características que ésta presente. Hay diversas propuestas acerca de tipos de estructura, pero para fines de esta tesis sólo tomaran en cuenta los planteamientos de Hall (1992), Mintzberg (1999) y Derray (2006).

Ahora que han sido presentadas las características estructurales, se debe recordar que la estructura organizacional no es la misma para todas las organizaciones (isomorfismo), en primera porque ninguna organización es igual a otra, y en segunda porque las variables organizacionales se presentan indistintamente de acuerdo a los objetivos de cada organización. A continuación 
se enfatizan las principales fuentes de éste tema. En primera instancia, se tiene una definición práctica de estructura organizacional, esta es la forma mecánica y orgánica descrita por Hall ${ }^{15}$ (1992:54:55).

El autor señala que la forma mecánica es aquella que está muy cercana al tipo ideal de burocracia propuesto por Weber en 1947, el cual señala que tiene jerarquía de autoridad, autoridad limitada, división de labores, participantes técnicamente competentes, procedimientos para el trabajo, reglas para los ocupantes de los puestos y compensaciones diferenciadas. Por su parte, la forma orgánica tiene forma de control de red, en lugar de una especialización sobre una tarea, un ajuste continuo y redefinición de tareas, en lugar de una supervisión de tareas, un contexto de comunicaciones que involucran información y asesoría.

Aunque, de la propuesta de Hall, pueden derivarse algunas otras como presenta Derray (2006), él estudia que existen fuerzas organizacionales y factores de contingencia que conllevan a la existencia de muchos tipos diferentes de organizaciones, pero existen algunos tipos muy marcados como: las estructuras empresariales, las estructuras funcionales, las estructuras divisionales 0 matriciales.

Por estructura empresarial, entiende que la dirección tiene un rol muy importante, porque todo se realiza en torno a ella y esta mantiene las relaciones de interacción entre el personal, además el campo de acción de cada agente es voluntariamente impreciso, esto es el vector que permite la flexibilidad y la adaptación al cambio.

\footnotetext{
${ }^{15}$ Hall retoma la idea de Burns y Stalker, 1961 (citado en Hall: 1992:54) respecto al modelo de formas organizacionales múltiples, en la cual destacan que en lugar de tener autoridad jerárquica, las organizaciones orgánicas tienen una estructura de control en forma de red.
} 
Nada está formalizado y esto mismo propicia una polivalencia general y la proximidad de los actores hace que no sea necesaria una coordinación fuerte (Derray: 2006:39:40), esta propuesta del autor es similar a la estructura mecánica de Hall (1992).

La estructura funcional también entra dentro de la estructura de tipo mecánica, la diferencia con la empresarial, es que ésta estructura se encuentra en organizaciones con mayor número de departamentos, con más funciones que las básicas (que tiene la empresarial). Lo anterior permite que las funciones determinen el número de divisiones que rigen a dicha estructura. Cada posición ocupa un lugar muy preciso y las decisiones y comunicaciones siguen una línea jerárquica directa.

Las siguientes estructuras propuestas por Derray (2006), entran en la categoría de forma orgánica que proponen Burns y Stalker (1961). La primera de ellas, es la estructura divisional. Este tipo de estructura es más descentralizada y cada división es una unidad completa, casi autónoma y la dirección general realiza el ensamble. El ápice estratégico delega a las divisiones el poder de decisión y responsabilidades para los problemas de carácter operacional, pero se reserva las decisiones estratégicas, aunque esta estructura es a menudo inestable y tiene siempre la tendencia a transformarse en una estructura centralizada o una colección de empresas autónomas.

Finalmente, la estructura matricial es la que posee un enfoque "orgánico puro" de la empresa, porque los responsables aportan soluciones a los problemas que 
encuentran por medio de ajustes mutuos. La eficacia de la organización matricial depende ampliamente de la comprensión y la aceptación, de parte de los miembros, de las reglas de juego. Esto hace que una organización matricial valore más el rendimiento colectivo que el individual, ya que las decisiones son siempre el resultado de una coperación entre responsables. A partir de una gran matriz de portafolios tecnológicos, las empresas realizan sus estrategias de diversificación. Asignan medios idénticos a actividades diferenciadas que a menudo no pueden jerarquizar. Esta dificultad, la imposibilidad de la clasificación, hace poco operante una estructura departamentalizada.

Gráficamente, las formas estructurales propuestas por Derray se pueden apreciar en la figura 7, permitiendo apreciar la diferencia entre las diversas formas estructurales en la organización de las que también habla Hall.

Figura 7 Formas estructurales en la organización 

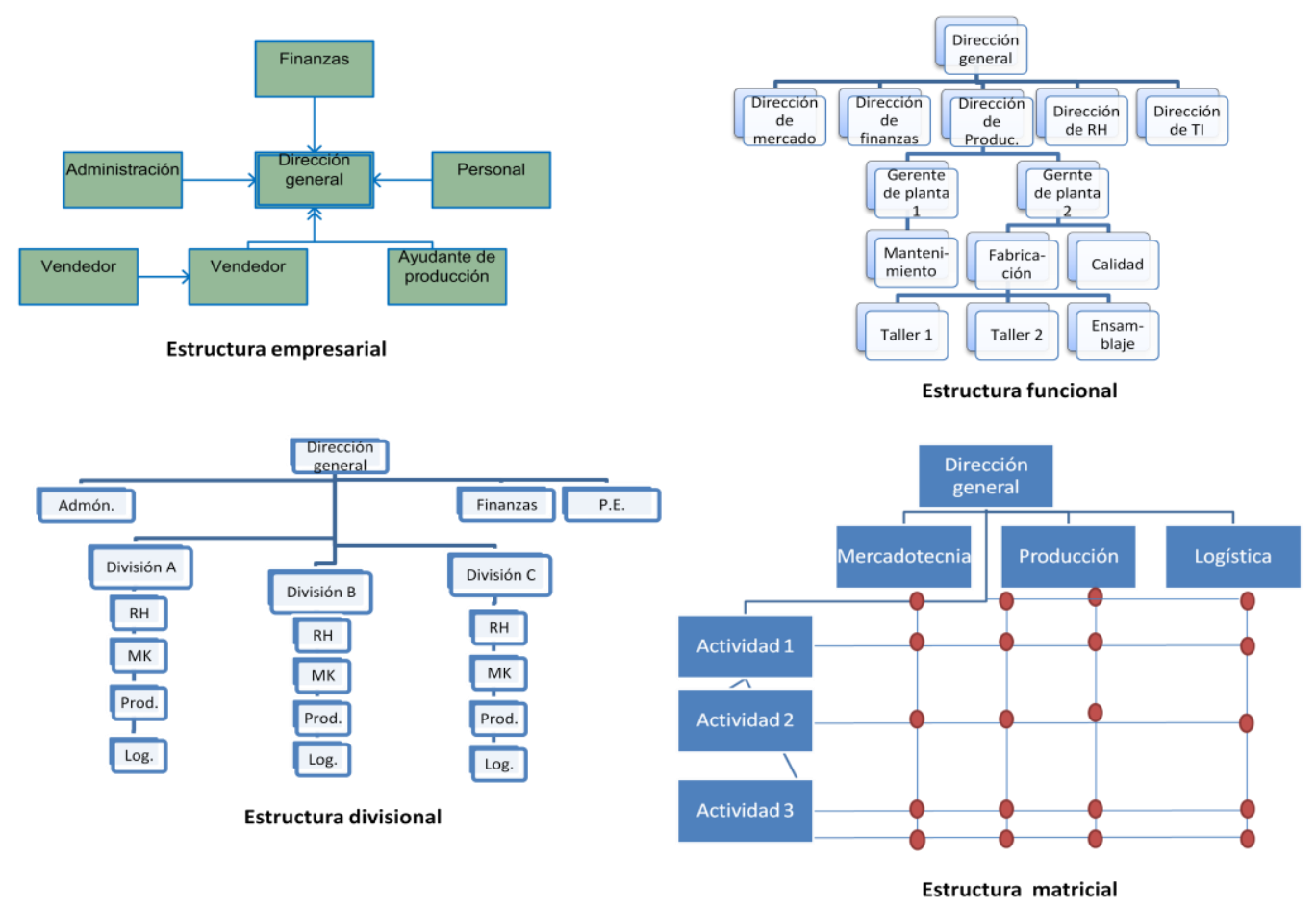

Fuente: Tomado de Derray (2006:41:45)

Para finalizar esta secuencia de propuestas de los tipos de estructura, se expone a un autor que es clásico en la materia: Mintzberg (1999). Este autor propone que dependiendo de la forma estructural de una organización ésta va a generar una determinada configuración. Asimismo plantea que es interesante explorar a las organizaciones aunque sean similares, ya que siempre se encontrarán diferencias en su configuración, e incluso se puede agregar que también se alcanza una conjunción entre dos o quizá más configuraciones en una misma organización.

Mintzberg realizó una vasta investigación en la cual plasma todas las características organizacionales que se pueden encontrar en dichas entidades así como la forma en que afecta la interacción de las propias características en la organización. Empero, en esta ocasión solo retomaran las características para 
describir cuales son las configuraciones que propone el autor, ya que se complementan con las propuestas mencionadas anteriormente.

Tabla 3 Tipos de Configuración de Mintzberg

\begin{tabular}{|c|c|}
\hline Configuración & Estructura \\
\hline Empresarial & $\begin{array}{l}\text { Tiene poco staff o ninguno, una ligera división de } \\
\text { la mano de obra y una pequeña jerarquía } \\
\text { directiva. Pocas actividades formalizadas y un uso } \\
\text { mínimo de los procedimientos de planificación. }\end{array}$ \\
\hline Maquinal & $\begin{array}{l}\text { Tareas muy especializadas, de rutina; } \\
\text { comunicación formalizada en toda la organización, } \\
\text { unidades operativas de gran tamaño, poder para } \\
\text { tomar decisiones relativamente centralizado. }\end{array}$ \\
\hline Diversificada & $\begin{array}{l}\text { Divisiones basadas en el mercado débilmente } \\
\text { acopladas bajo la central administrativa. Las } \\
\text { divisiones tienen descentralización limitada para } \\
\text { dirigir de manera autónoma. Las divisiones son } \\
\text { sometidas a un sistema de control del } \\
\text { comportamiento que normaliza sus outputs. }\end{array}$ \\
\hline Profesional & $\begin{array}{l}\text { Organización burocrática (burocracia profesional) } \\
\text { pero descentralizada, ya que el trabajo tiene que } \\
\text { ser controlado por profesionales. Alta dependencia } \\
\text { de las habilidades y conocimientos del profesional } \\
\text { operativo para funcionar. }\end{array}$ \\
\hline Innovadora & $\begin{array}{l}\text { Estructura descentralizada, con expertos } \\
\text { funcionales en equipos multidisciplinarios. } \\
\text { Rodeada de un entorno complejo y dinámico que } \\
\text { incluye alta tecnología. Se puede presentar en } \\
\text { forma de una adhocracia operativa o } \\
\text { administrativa. }\end{array}$ \\
\hline Misionera & $\begin{array}{l}\text { Sistema vasto de valores y creencias que } \\
\text { distinguen particularmente a esa organización. } \\
\text { Desarrollada a lo largo de tradiciones y sagas y } \\
\text { luego reforzada por medio de identificaciones. }\end{array}$ \\
\hline Política & $\begin{array}{l}\text { Ausencia de cualquiera de las formas de orden } \\
\text { que se encuentran en las organizaciones } \\
\text { convencionales. No hay un tipo definido de } \\
\text { descentralización, todo depende la fluidez del } \\
\text { poder informal, dispuesto a vencer en temas } \\
\text { individuales. }\end{array}$ \\
\hline
\end{tabular}

Fuente: elaboración propia con base en Mintzberg (1999:137:284) 
De las tipologías mencionadas, se puede considerar que la organización orgánica de Hall, la tipología divisional y matricial de Derray, y la configuración profesional e innovadora de Mintzberg, coinciden con las características de la organización flexible, en la cual existe una estructura horizontal, la toma de decisiones es descentralizada, divisiones altamente profesionales, con sentido de respuesta a las contingencias internas y externas de la organización.

\subsubsection{El enfoque configuracional}

Con los elementos de la estructura que se han venido presentando, puede quedar la duda sí solo las teorías mencionadas sirven para estudiar la estructura. Aunque al principio de este apartado se mencionó que el enfoque contingencial de la estructura perdió fuerza a finales de los 60's-70', esto dio paso a un nuevo enfoque para poder explicar las diversas estructuras que puede tener una organización en tiempos actuales, así como su relación con otros fenómenos organizacionales. Es así que el enfoque configuracional desplazó la teoría de la contingencia como la perspectiva dominante en la literatura sobre el cambio en la década de 1980.

La principal idea del enfoque configuracional ${ }^{16}$ es la que Demers (2007) recapitula y presenta en su artículo de una aproximación al enfoque configuracional, donde el eje central es el cambio. Partiendo de la premisa de que las organizaciones

\footnotetext{
${ }^{16}$ Greenwood, Hinings, y sus colegas contribuyen a la perspectiva configuracional mediante la elaboración de un modelo más rico de la dinámica del cambio radical. Su estructura incluye la posibilidad de intentos fallidos de cambio, mientras que la mayor parte de la literatura se centra exclusivamente en los intentos exitosos. Además, al integrar la perspectiva de la construcción social con la perspectiva de la estructura formal en el cambio organizacional, ponen de relieve el papel de los procesos de creación de sentido y de la política en el cambio organizacional. En este sentido, son una clara sintonía con los nuevos desarrollos en teoría de la organización (Reed, 1992) que traen a primer plano lo cognitivo y lo cultural, así como los enfoques políticos del cambio. Por último, a pesar de su enfoque sobre el cambio radical que ponen firmemente en el segundo período, su concepción de las organizaciones y de la dinámica de la evolución organizacional previa la tercera era con su énfasis en el cambio emergente. (Demers:2007:55)
} 
pueden ser concebidas como configuraciones o arquetipos -constelaciones de elementos estrechamente integrados- sus defensores definen el cambio radical como un cambio de configuración.

Esta conjetura transporta a retomar la idea de cambio que se presentó en el capítulo anterior. Así que, en resumen el modelo de equilibrio puntuado es un modelo genérico de la evolución organizacional que muestra cierta afinidad con la teoría del ciclo de vida. Se especifican dos fases distintas donde el cambio se describe como un fenómeno totalmente diferente en términos de su naturaleza y del proceso. En este modelo, la organización sigue siendo un instrumento en las manos de los directivos quienes, a través de las decisiones sobre factores tales como los valores, la estrategia, la estructura y control, tienen poderosas influencias (o ventajas) para ajustar o transformar la organización en función de sus objetivos. En términos prácticos, es una visión del cambio de arriba-abajo. (Demers: 2007:52).

Por tanto, se puede apreciar que el cambio organizacional tiene una amplia relación con la estructura organizacional; como se mencionó en el capítulo anterior, el cambio, puede tener como consecuencia la creación de una nueva configuración en la organización, así como sus características formales y de contexto también son modificadas. Pero, para que un individuo de la organización acepte los supuestos estructurales como los objetivos y las estrategias, se debe tomar especial atención a la cultura organizacional, porque como se verá en el siguiente apartado, a través de la implementación de los elementos culturales se puede favorecer a la estructura y al cambio. 


\subsection{Cultura organizacional: un mediador para el cambio}

En el apartado anterior se percibió que las organizaciones se constituyen con diferentes características y que no todas responden de igual manera a los cambios que se gestan dentro de ellas, ya que, así como la intervención del ambiente tiene un impacto distinto en la formación de sus características tanto estructural, material y tecnológico, la cultura también influye de la misma manera, pero con la diferencia de que la cultura es más difícil de descifrar y de rebuscar porque la generación de comportamientos, de valores, de convivencias, de buscar la identidad con la organización, será diferente en la percepción de los individuos que la conforman, así como entre las organizaciones.

Por lo que más allá del sector al que pertenece o al número de empleados que integran una organización, la cultura es un aspecto que hace única e irrepetible a cada una de estas entidades. Esto lleva a preguntar: ¿Cómo pueden convivir las distintas variables internas de la organización y cumplir con los objetivos establecidos? y ¿Cómo poder adaptarse al cambio en una organización con una cultura quizá, de resistencia al cambio?

El discurso organizacional centrado en un ambiente que exige cada vez más altos estándares de calidad y productividad, promueve la innovación de estructuras de trabajo más flexibles que implican una integración más participativa del individuo; y entonces, es la cultura la facilitadora de la interiorización de ese discurso para 
lograr que los miembros adopten comportamientos más leales y eficaces ante las inminentes reformas generadas por el contexto, entre las que se pueden mencionar la creación, desarrollo, aplicación y transferencia de nueva tecnología, así como el cambio que se genere en la organización.

\subsubsection{Definición de cultura y cultura organizacional}

El término de cultura es en sí una palabra que genera amplio debate, por la cuestión de su origen antropológico, y sobre todo por el interés que distintas disciplinas le proporcionan, generando así, que cada una de ellas, le dé su propia connotación. En ese sentido, y de acuerdo a la naturaleza del tema que se presenta en este ensayo, el enfoque que será de mayor atención es el de cultura organizacional. Pero, es necesario ir de lo general a lo particular, por lo que se revisará el término de cultura y posterior, el de cultura organizacional.

Para relacionar cultura y organización hay que remitirse en principio a la integración del concepto de cultura en el contexto organizacional a través del recurso de la metáfora. Como en el caso de cambio, definir a la cultura, puede causar cierta ambigüedad, ya que sus orígenes están en la antropología, y ha sido retomada por los estudios organizacionales, lo que ha permitido que se pluralicen los conceptos y los elementos que la conforman, ya que cada autor retoma lo que considera viable para su estudio. 
Como se verá más adelante, la cultura puede estar representada por una nación, un grupo de personas, o un individuo. ¿Por qué en todas estas formas y/o representaciones? Porque de acuerdo con Alvesson (1992) la cultura es la fábrica de significado en términos de los cuales el ser humano interpreta su experiencia y guía su acción; la estructura social es la forma que toma la acción, la red realmente existente de relaciones sociales. Por consiguiente, de esta definición, se puede entender que la cultura es ambigua en sí, por el simple hecho de ser una representación de la realidad de los individuos.

Para Schein (1997) la cultura puede tener muchos significados: puede significar sofisticación, puede, por otro lado para un antropólogo referirse a costumbres y rituales desarrollados por la sociedad. Para los estudiosos de las organizaciones puede indicar clima y prácticas desarrolladas por las organizaciones alrededor de su manejo de la gente o los valores y credo de la organización. Y sobre todo, el concepto de cultura ayuda a entender mejor por qué los grupos de gente o las organizaciones pueden ser tan diferentes y también por qué son tan difíciles de cambiar.

La propuesta de Varela es muy sencilla en términos de su léxico, sin embargo, muestra que la cultura puede tener más de una concepción y presentarse de muchas forma distintas, tanto en un individuo como en un grupo de individuos. $Y$ así entonces, Varela dice: "cultura es la matriz de símbolos y signos que permiten otorgar significados comunes a las acciones de los miembros de una comunidad, 
lo que se expresa en costumbres, creencias y valores relativamente compartidos por la mayoría" (Varela, citado por Rendón: 2003:122).

Por otro lado, la definición de Néstor García (citado por Portal: 1991:31) le da énfasis a conceptos que son de carácter ideológico, ya que en sus términos define a la cultura como: “... la producción de fenómenos que contribuyen, mediante la representación o reelaboración simbólica de las estructuras materiales, a comprender, reproducir o transformar el sistema social, es decir, todas las prácticas e instituciones dedicadas a la administración, renovación y reestructuración del sentido".

Para entender la pluralidad de conceptos, se tiene la figura 8 en la que se puede observar la representación de la cultura según los autores citados anteriormente. En primera instancia las flechas gruesas indican que la cultura está regida por las estructuras materiales y el sistema social que se encuentran en la sociedad y a su vez impactará tanto al individuo como a la colectividad.

Esto ocasiona que se forme una especie de matriz como consecuencia de la interacción de los elementos psicosociales (símbolos, signos, creencias, costumbres, valores y comportamientos) que están alrededor del individuo y de la colectividad, lo que propiciará que el individuo al relacionarse con la sociedad genere nuevos aspectos culturales para sí mismo, y luego se integrará a la sociedad con una cultura distinta. 


\section{Figura 8 La noción de cultura}

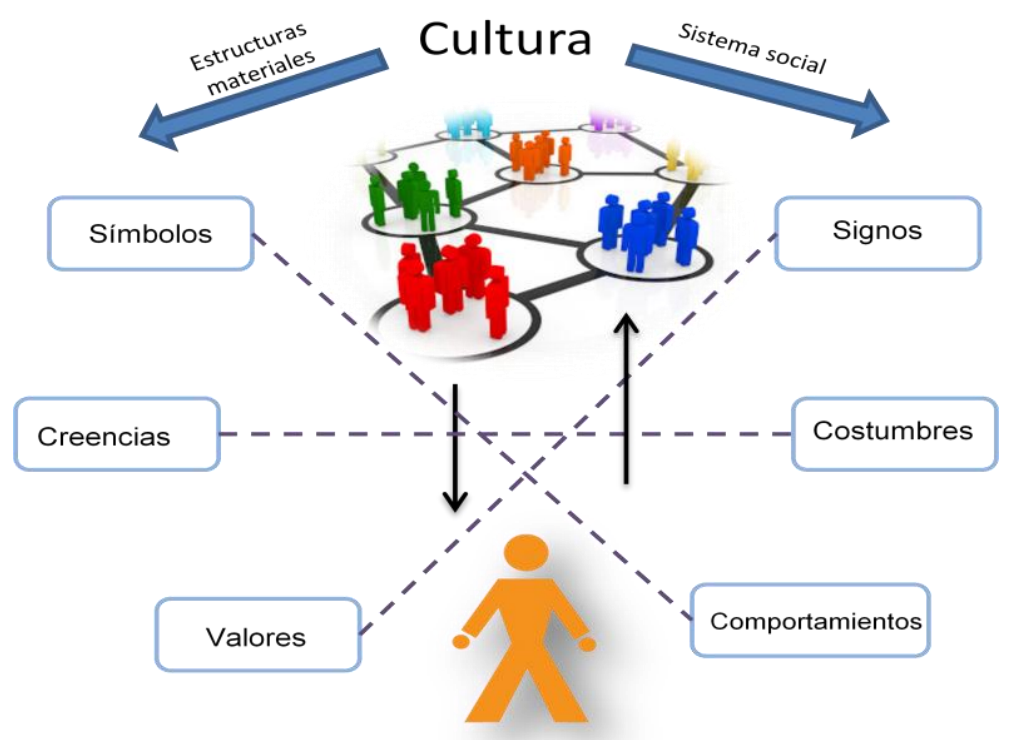

Elaboración propia con base en Varela (citado en Rendón: 2006) y García (citado en Portal: 1991)

\section{Definición de cultura organizacional}

Al principio del capítulo se menciona que la cultura es demasiado ambigua en esencia y en interpretación, y, que cada autor, dependiendo de su perspectiva le dará un uso de acuerdo a su contexto. Sin embargo, hay características que son indispensables para entender la cultura, independientemente de que disciplina utilice el concepto. También, como ya se había señalado para el uso de este trabajo, la cultura organizacional tomará un papel importante en el estudio de caso.

Por eso es que, en este sentido, y aun cuando ni siquiera en su disciplina se tiene una definición clara del concepto cultural, se muestran algunas definiciones de la cultura organizacional, para posteriormente retomar sus características y algunos 
enfoques que los estudiosos de las organizaciones han propuesto. De igual forma, surge un amplio debate para definir que es la cultura organizacional, ya que cada autor clasifica el concepto de acuerdo a su línea de investigación.

Es imprescindible mencionar que la cultura organizacional toma en consideración a todos los individuos que conforman la organización y que asienta especial atención en los aspectos de los símbolos, costumbres, mitos, etc., con la finalidad de hacer interpretaciones acerca del comportamiento de la gente que conforma la organización. Linda Smirchich (1983) propone que el concepto de cultura consigue adquirir dos sentidos en la organización, como una variable organizacional y como metáfora. Como variable significa que es algo que la organización posee (como la estructura y la estrategia), y puede ser una variable externa (cultura nacional) o interna (cultura organizacional).

La autora dice que la cultura como una metáfora de base en la organización promueve una visión de las organizaciones como formas expresivas, manifestaciones de la conciencia humana", porque las organizaciones se entienden y analizan en términos de sus aspectos expresivos, ideales y simbólicos y no simplemente en términos económicos o materiales. Y es así, en sentido metafórico que permite que haya una mayor interpretación de cómo puede ser la cultura en una organización específica.

Rendón (2006) agrega a las definiciones anteriores que la cultura organizacional comprende e interpreta los elemento simbólicos compartidos por los miembros de 
la organización, por lo que la cultura se manifiesta a través de lo informal, es decir, se encuentra de manera implícita en los símbolos, comportamientos, mitos, creencias, ceremonias, etc. La definición de Rendón, subraya el aspecto informal de la organización, ósea lo que no está regido por normas o políticas formalmente definidas, lo que genera que haya más de una demostración cultural dentro de la misma organización.

En este sentido de caracterización de la cultura organizacional, Alleire y Firsirotu, (1992: 35), presentan una propuesta bastante detallada, en la que relacionan aspectos de la cultura en general y lo identifican en la organización como : "un sistema de símbolos compartidos y dotados de sentido que surgen de la historia y de la gestión de la compañía, de su contexto sociocultural, y de factores contingentes (tecnología, tipo de industria, etc.) pero formada por el proceso de atribución colectiva de sentido a flujos continuos de acciones y reacciones. Estos símbolos importantes se expresan con mitos, ideologías y principios que se traducen en numerosos fenómenos culturales: ritos, ceremonias, hábitos; glosarios, léxicos, abreviaciones, metáforas y lemas; epopeyas, cuentos y leyendas; arquitectura, emblemas, etc."

Como se muestra en la figura 9, se presenta una intersección de la matriz de la cultura (figura 8), esta intersección simbolizada por un triángulo es la organización. La cultura organizacional es el resultado de la influencia de la cultura externa, la cual se genera por la encrucijada del ambiente, de la sociedad 
y de las contingencias, así como de la interacción de los individuos que conforman la organización con la sociedad. El resultado de dicha matriz entrará a la organización como una variable o como una metáfora, para dar lugar a los símbolos, historias, creencias, costumbres, etc.

Figura 9 Cultura organizacional

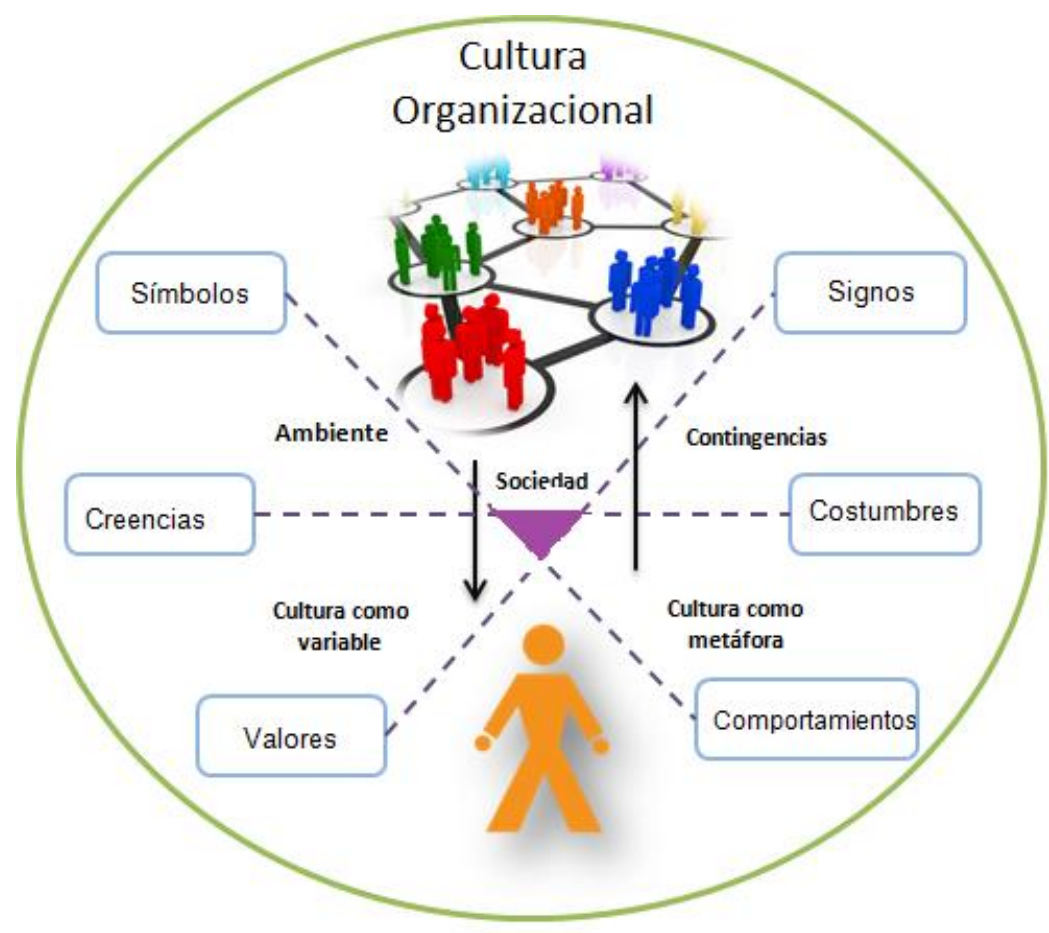

Fuente: Elaboración propia con base en Alleire y Firsirotu, (1992), Smirchich (1983) y Varela (citado en Rendón: 2006)

\subsubsection{La cultura desde la perspectiva de los estudios organizacionales}

\section{La cultura como variable de la organización}

De raíces marcadamente funcionalistas, esta perspectiva considera que la cultura es importada a la organización a través de los miembros; así mismo, analiza la relación entre cultura y estructura organizacional a un nivel macro; mientras que a 
nivel micro, evalúa las similitudes y diferencias en las actitudes de los gerentes con diferentes culturas.

Esta concepción radica en que las organizaciones, son generadoras de una cultura a través de la producción de los aspectos expresivos y afectivos de la organización en un sistema colectivo de significados simbólicos: los mitos, las ideologías y los valores. Comprende también los artefactos culturales (ritos, ceremonias, y costumbres; metáforas, acrónimos, léxicos y eslóganes; cuentos, leyendas y folclor organizacional; emblemas, arquitectura).

Dichos artefactos culturales a decir de Smircich (1983:345), se convierten en "mecanismos simbólicos poderosos de comunicación, usados para construir consistencia, racionalizar o legitimar actividades, motivar al personal y facilitar la socialización". Estos artefactos, tomarán relevancia más adelante porque son importantes para el análisis del estudio de caso. Bajo esta perspectiva, que dibuja a la cultura bajo una visión instrumentalista, esta vendría a ser sólo el conjunto de agregados simbólicos expresados en la misión, visión y códigos de ética empresariales, que generan un tipo de cultura en particular dentro de la organización: la cultura corporativa (aunque este no es el enfoque que retoma el presente trabajo).

\section{La cultura como perspectiva metafórica de la organización}

Esta visión permite dar un espacio a la integración de conceptos, y al libre albedrio para encontrar más de una postura en el análisis de cultura organizacional, ya que 
como señala Smircich (1983:347) "las organizaciones son vistas como formas expresivas, manifestaciones de la conciencia humana, son analizadas en términos de sus expresiones, ideales y aspectos simbólicos". Como se presentó en el apartado de cambio; las organizaciones no tienden a ser estáticas, por lo que la cultura organizacional puede cambiar a causa de los eventos que se produzcan en la organización a través del tiempo.

Esta posición interpretativa considera el fenómeno cultural como una matriz de significados gracias a la cual es posible la acción organizada, de modo que a decir de Smircich, la mayor consecuencia práctica de esta vertiente radicaría en el énfasis puesto en la mente y el pensamiento, en la visualización de los miembros de la organización como seres pensantes y actuantes. Por lo que, la inclusión y comprensión de las acciones humanas y por tanto subjetivas de los miembros en las organizaciones, vendrían a ser fundamentales en el presente, como consecuencia del acelerado ritmo en que viven las sociedades.

En este sentido es importante como menciona Cruz (2010) considerar a la cultura organizacional como un campo de conocimiento orientado a la comprensión e interpretación de los fenómenos que se dan lugar dentro de la organización pero que no se limitan simplemente a las aspiraciones de la gerencia ni a un grupo en particular. Dicha comprensión permite conocer aspectos más cercanos a la realidad organizacional donde se acepta la 
particularidad de cada fenómeno y donde el contexto y la historia que enmarcan a la organización son elementos inseparables del análisis.

\subsubsection{Características de la cultura organizacional}

Allaire y Firsirotu (1992) hacen una distinción del sistema cultural, en donde señalan la importancia que adquieren el individuo, el grupo de individuos y la sociedad para formar la cultura organizacional. Por lo que especifican que actores y de qué manera pueden manipular la cultura para obtener ciertos beneficios, así como mantener unida a la organización a través de características que se comparte dentro de la organización. En la Tabla 3.1 se muestran las características más importantes que intervienen en el desarrollo de la cultura organizacional.

Tabla 4. Características organizacionales de la cultura

\begin{tabular}{|c|c|}
\hline Símbolos & $\begin{array}{l}\text { Palabras, gestos, imágenes u objetos que tienen un significado particular de } \\
\text { los miembros de la organización }\end{array}$ \\
\hline Héroes & $\begin{array}{l}\text { Personas, vivas o muertas, reales o imaginarias que poseen características } \\
\text { altamente apreciadas en una cultura y que sirve como modelos de } \\
\text { comportamiento }\end{array}$ \\
\hline Ritu & $\begin{array}{l}\text { Son actividades colectivas, técnicamente superfluas en alcanzar fines } \\
\text { deseados. }\end{array}$ \\
\hline Artefa & $\begin{array}{l}\text { Los fenómenos observables y productos visibles: arquitectura del ambiente } \\
\text { físico, lenguaje, tecnología. También el comportamiento visible del grupo y los } \\
\text { procesos que se convierten en rutinas. }\end{array}$ \\
\hline Valores & $\begin{array}{l}\text { Los valores requieren de validación social, solamente pueden ser confirmados } \\
\text { por la experiencia social compartida de un grupo }\end{array}$ \\
\hline & $\begin{array}{l}\text { Se refiere a la colección de valores, creencias, descripciones e id } \\
\text { relacionados en un ambiente. }\end{array}$ \\
\hline
\end{tabular}

Fuente: Elaborado con base en Alvesson (1992), Hofstede (1980) y Schein (1997)

De igual manera, Schein (1997) propone que para entender las características de la cultura organizacional (como las mencionadas en la tabla 4), se deben tener en la organización: artefactos, valores adoptados y supuestos básicos. Estos tres 
factores los propone en orden jerárquico, como se muestra en la figura 10, ya que los artefactos pueden modificar los valores, así como los supuestos básicos. Pero a la inversa también se ven afectados los otros dos factores. Además, estos tres factores también influyen en la programación del software mental de cada individuo que pertenece a la organización. Al generalizarse, la mayoría de los integrantes de la organización tendrán una concepción similar de su entorno cultural.

\section{Figura 10. Factores para entender la cultura organizacional}

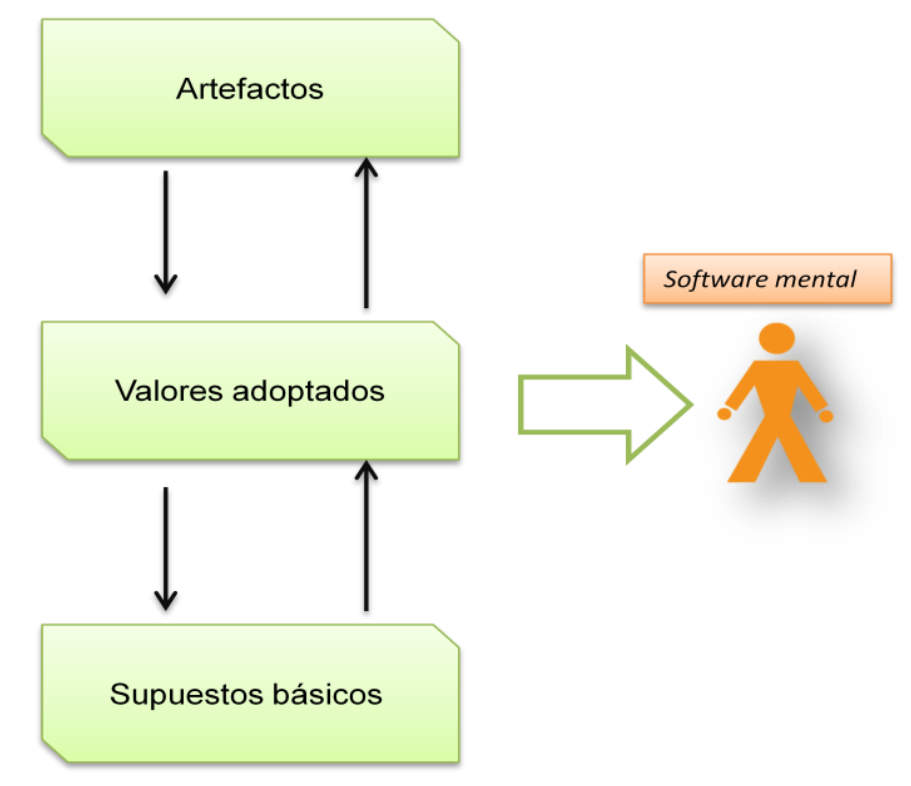

Fuente: Elaboración propia con base en Schein (1997)

De manera breve se describen que son los factores que propone Schein:

- Artefactos: Se refiere a los fenómenos observables y productos visibles: como la arquitectura del ambiente físico, lenguaje, tecnología. Incluye también el comportamiento visible del grupo y los procesos 
organizacionales que los convierten en rutinas. Son fáciles de observar pero difíciles de descifrar

- Valores adoptados: son valores individuales los que están representados por los principios sociales, filosóficos, metas, y estándares de valor intrínseco que recaen en la organización.

- Supuestos básicos: la cultura como supuestos básicos, define a lo que se le presta atención, lo que tendrá significado y cómo reaccionar emocionalmente a lo que sucede así como las acciones a tomar en diferentes situaciones. Es por eso que los individuos se sienten más a gusto con otros que compartan el mismo conjunto de supuestos.

\section{Niveles de la cultura}

Para entender cómo se va conformando la cultura hasta penetrar en las diversas organizaciones, se requiere revisar las propuestas de Alvesson (1992) y Hofstede (1997) coinciden en que la cultura debe dividirse en subculturas para su estudio, ya que consideran que existen diferencias étnicas y religiosas que trascienden barreras políticas nacionales y pueden diferenciar culturas nacionales hasta las culturas organizacionales que aplican a las diferencias entre países. De la misma manera las orientaciones religiosas imponen decisiones que orientan el comportamiento de los miembros de la organización.

Así, Alvesson (1992) refiere que la cultura puede ser estudiada en varios niveles, como la cultura nacional, cultura de sectores (a lo que Hofstede señala como cultura regional y local), cultura organizacional y corporativa, y cultura individual. 
De acuerdo a lo anterior, es importante distinguir los niveles de cultura, ya que en una organización se puede encontrar una mezcla de los diferentes niveles, lo que da como resultado la generación de una nueva cultura.

Por su parte, Hofstede (1980) denomina a la cultura como una programación o software mental, como consecuencia de que las personas pertenecen a distintos niveles culturales: nacional, regional, étnico, religioso o lingüístico, así como de género, clase social y organización, lo que significa que los individuos al pasar por cada una de estas colectividades va generando un programa mental en el que involucra patrones de pensamiento, sentimiento y acción, por lo que la cultura no es heredada sino aprendida por cada una de las personas que conforman a la organización.

En la figura 11 se muestra gráficamente como se crea el software mental a través de la interacción de las distintas capas de la cultura y las colectividades por las cuales pasa el individuo en su vida, lo que genera que el individuo tenga diferentes perspectivas culturales. Esto puede ocasionar que al llegar a la capa de la cultura organizacional, pueda encontrar diferencias de generación de los símbolos, héroes, rituales y valores. Lo anterior puede parecer una idea ambigua visto desde una perspectiva funcional, pero como se señaló anteriormente, estudiar este fenómeno desde una perspectiva metafórica le da sentido a los diferentes sucesos que acontecen en la organización y además ayuda a visualizar las características organizacionales.

Figura 11. Producción de software mental 


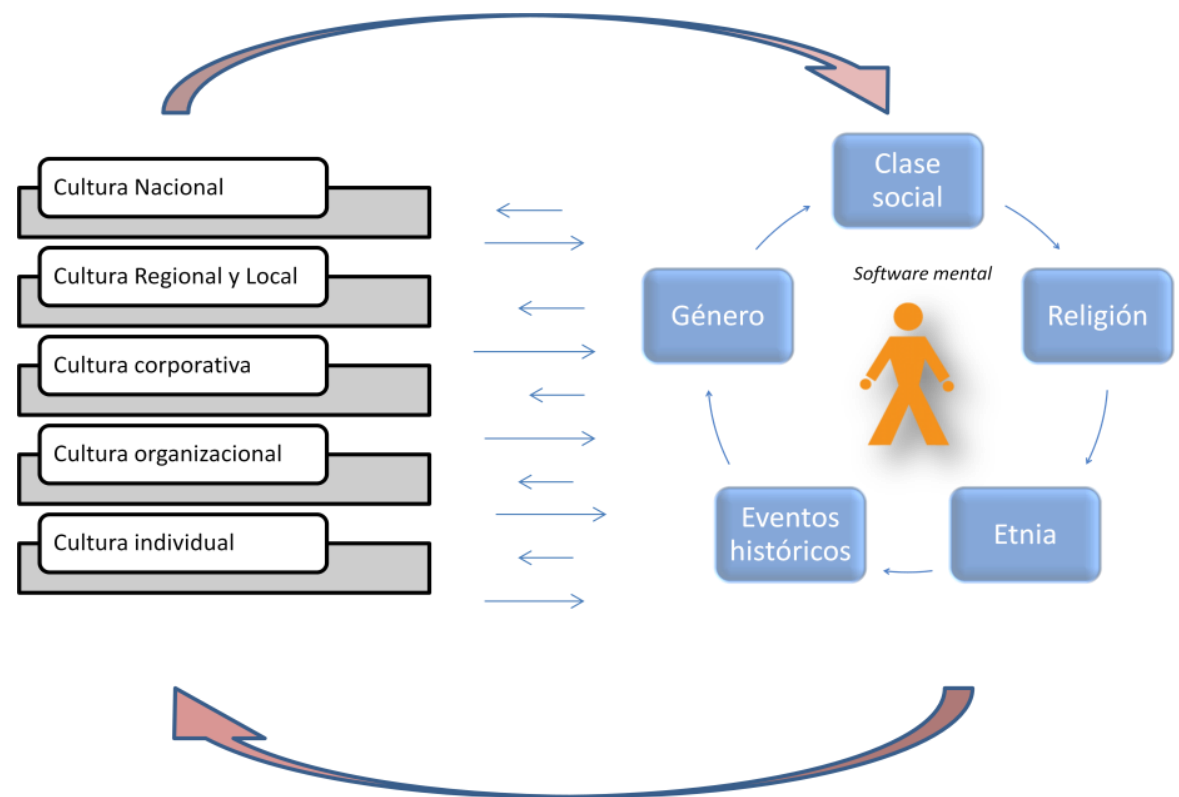

Fuente: Elaboración propia, con base en Hofstede, (1980), Alvesson (1992)

\subsection{4 ¿Cuál es el sentido de la cultura en la organización?}

Hasta ahora se han presentado las características que conforman a la cultura en la organización, así como la visión que cada autor propone. Sin embargo, puede surgir la duda, de cuál es el papel que tiene la cultura y cuál es su lugar como fragmento del rompecabezas que conforma a la organización (tomando en consideración la variable de cambio, estructura, tecnología, el ambiente, entre otras variables tangibles y no tangibles de la organización). Así que, para despejar esta duda, se encuentra la propuesta de Allaire y Firsirotu (1992).

Los autores hacen un análisis, en el cual indican que la organización tiene tres componentes estrechamente ligados: el sistema socioestructural que se refiere principalmente a las relaciones entre las estructuras, las estrategias, las políticas y otros procesos gerenciales. El sistema cultural se refiere a los aspectos expresivos y afectivos de la organización en un sistema colectivo de símbolos 
significativos. Finalmente, los empleados como individuos, los cuales, a través de su talento, de sus experiencias, de su personalidad, forman una realidad organizacional.

Descriptivamente como se ve en la figura 12, los autores proponen vínculos entre los tres componentes señalados, con la finalidad de entender porque las organizaciones pueden tener culturas diferentes a las de la sociedad de la cual forman parte. Los autores, lo hacen notar en su propuesta representativa, al momento de presentar la historia, la sociedad y las contingencias, porque dan a lugar al origen y pasado de la organización, de los modos de adaptación tecnológica, y el ambiente sociocultural en el cual se han desarrollado.

El sistema socioestructural y sociocultural de la organización tienen una relación estrecha, porque son productos de un medio social, político y cultural específico. Por lo tanto, están expuestos a perturbaciones cuando se generan cambios en el ambiente, lo que da lugar a nuevas gestaciones culturales que pueden o no ser percibidas por los individuos de la organización, pero que sí dan lugar a nuevos significados que el empleado utiliza y transforma para dar lugar a acontecimientos organizacionales. Aunque, no es forzoso que una organización presente todos los elementos que conforman a los tres principales sistemas que proponen Alleire y Firsirotu, siempre se conocerá su origen cultural.

Particularmente, este modelo será de utilidad más adelante para explicar cómo funciona la cultura organizacional de la organización del estudio de caso, por eso es que en la figura se ven iluminados tres aspectos en específico (contingencias, 
sistema socioestructural y el sistema cultural), ya que estos tres elementos son los más representativos de la cultura organizacional de la organización de estudio.

Figura 12. Modelo factorial para el estudio de las organizaciones

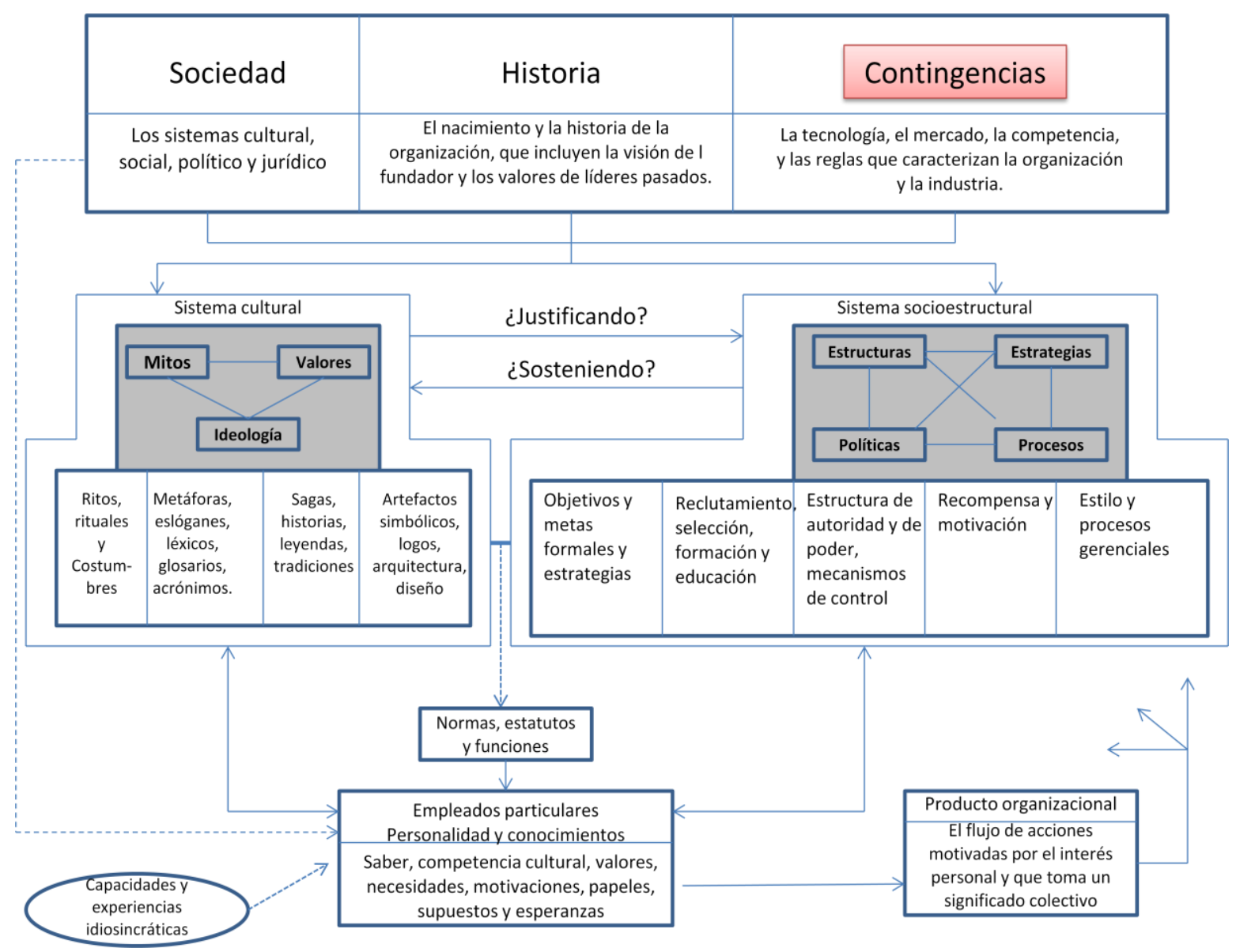

Fuente: Alleire y Firsirotu (1992: 93)

Este modelo permite distinguir los tres factores de los cuales se ha hablado hasta

el momento: cambio, estructura y cultura, y de acuerdo a la propuesta de Alleir y Firsirotu, estos factores tienen relación entre sí. En el aspecto de las contingencias se sumará el factor tecnológico (en este caso serán las tecnologías de información y comunicaciones) a esta tesis con el objeto de conocer cuál es el papel de cada 
uno de estos factores en la organización, así como su correlación si es que la hay. En este sentido, el elemento que falta por conocer es el de la tecnología, por lo que el siguiente apartado será destinado al tema en cuestión. 


\subsection{Tecnologías de la Información y Comunicaciones: Un agente de cambio para la organización}

\subsubsection{Contexto general de las TIC's}

Si bien, hasta ahora se mencionado de manera abstracta la palabra tecnología a lo largo de este escrito, se pretende en este apartado recuperar a una tecnología en particular: las tecnologías de la información y comunicaciones (TIC's). Esto es con la intención de presentar algunos aspectos que permitan entender por qué genera debate hoy en día y cuál es el papel que juegan en las organizaciones. Sin lugar a dudas, actualmente, la tecnología contribuye a mejorar la calidad de vida y ayuda a ampliar el espacio temporal, ya que el solo hecho de vencer barreras de la comunicación ha propiciado abrir enormes posibilidades a la ayuda humanitaria en caso de enfermedades, catástrofes o accidentes.

Para Burbules (2001), las nuevas tecnologías no sólo constituyen un conjunto de herramientas, sino un entorno-un espacio, un ciberespacio- en el cual se producen las interacciones humanas. Por eso es que la Internet se ha convertido en un contexto en el cual se dan interacciones que combinan y entrecruzan las actividades de indagación, comunicación, construcción y expresión. Otro ejemplo de ello, es la telefonía móvil que facilita que el grado de comunicación llegue a ser personal, de forma que cualquier problema o preocupación de cualquier ser humano pueda convertirse en algo de inmediata solución. 
Es sabido, que las naciones del mundo están envueltas en la revolución tecnológica, que está provocando cambios en la manera en que se vive y trabaja, -incluso en la manera de pensar-. Tres amplias tendencias de los campos económico, tecnológico y político proveen las fuerzas motrices principales de esta revolución de alta tecnología (Forester: 1992). Con estas herramientas no sólo ayudan a alcanzar ciertos objetivos existentes: también pueden crear propósitos nuevos, nuevas metas, que jamás habían sido considerados (Burbules: 2001:21:22).

En este sentido, Castells (1999:31) hace una reflexión muy importante al afirmar que la tecnología no determina a la sociedad, tampoco la sociedad dicta el curso del cambio tecnológico, ya que muchos factores, incluidos la invención y las iniciativas personales, intervienen en el proceso del descubrimiento científico, la innovación tecnológica y los procesos sociales, de modo que el resultado final depende de un complejo modelo de interacción.

Aunque, como lo muestra Burbules (2001) las herramientas (TIC's) modifican al usuario; a veces muy concretamente (sobre la cultura y los valores). Esto sugiere que nunca se usan sin que ellas, a la vez, "usen a las personas"; nunca se aplican las tecnologías para cambiar el medio sin ser cambiados. La relación de las personas con la tecnología no es instrumental y unilateral, sino bilateral, por eso se llama "relacional"

\footnotetext{
${ }^{17}$ Esta relación de la que habla Burbules será presentada en el estudio de caso de esta tesis.
} 
Esta revolución tecnológica de la información, que, al igual que en el caso de las anteriores revoluciones tecnologías, se caracteriza por su capacidad de penetrar en todos los ámbitos de la actividad humana, por ejemplo en la comunicación, en el quehacer de la vida cotidiana y también en las organizaciones. Las tecnologías de la información y comunicación (TIC's) están presentes en todos los niveles de nuestra sociedad actual, desde las más grandes corporaciones multinacionales a las pymes, gobiernos, administraciones, universidades, centros educativos, organizaciones socioeconómicas y asociaciones profesionales y particulares.

La aplicación de las TIC's a todos los sectores de la sociedad y de la economía mundial han generado una serie de términos nuevos como, por ejemplo, e business y e-commerce, e-government, e-health, e-learning, e-inclusión, e-skills, e-work, e-mail, banda ancha, domótica, etc. Quizá es común escuchar y hablar sobre estos términos, pero puede que ni siquiera se conozca el significado o su función principal. Cuando estas tecnologías se introducen en la organización, puede surgir dudas como: ¿Quién se encarga de manejarlas? ¿La organización tiene que modificar su estructura? ¿Cómo se deben adoptar?, etc.

En ese sentido, son relevantes estas tecnologías porque están transformando la manera de funcionar de las organizaciones, la forma de trabajar, y también a la esencia de la organización, porque se afecta el proceso mediante el cual una organización crea productos, el modo de realizar cada una de las actividades individuales, también, por la forma de establecer los flujos de información y de 
comunicación, las TIC's incrementan la capacidad para explotar los enlaces entre actividades dentro y fuera de la empresa.

Manejar grandes cantidades de información en una organización puede ser un problema cuando no se tienen los medios suficientes para procesarla, por lo que las TIC's pueden ser un medio infalible para su recopilación, procesamiento y almacenamiento. Clarke y Clegg (1998) plantean el concepto de "sociedad de información" al hacer referencia al fenómeno de que la sociedad actual crea y maneja grandes cantidades de datos a través de distancias geográficas que desaparecen y las tecnologías de la información permiten que el conocimiento existente pueda ser reducido, almacenado y transmitido de manera rápida y poco costosa, en donde las computadoras y las telecomunicaciones han transformado profundamente las relaciones que antes existían en las organizaciones, incluso teniendo efecto sobre su estructura, creando nuevas actividades y reestructurando a las organizaciones.

\subsubsection{Evolución de las tecnologías de la información}

La historia de las TIC's es breve pero penetrante en cuanto a otras revoluciones tecnológicas se refiere, y es que el progreso que tienen estas tecnologías desde su aparición hasta la fecha ha sido continuo, por lo que es importante reflexionar que su desarrollo seguirá existiendo hasta que surja una nueva tecnología capaz de modificar la actividad humana. Los estudiosos de estas tecnologías hacen sus 
propias conjeturas en cuanto a cronología del progreso de las TIC's, sin embargo no hay que perder de vista los tres principales corrientes que definen el desarrollo de estas tecnologías: la microelectrónica, los ordenadores y las telecomunicaciones (Castells: 2001).

La historia de las TIC's como se muestra en la línea cronológica representada por la figura 4.1 tiene sus comienzos en el siglo XIX con la invención del teléfono por Bell en 1876, la radio por Marconi en 1898 y el tubo de vacío por De Forest en 1906. Pero, fue durante la segunda guerra mundial y el periodo subsiguiente cuando tuvieron lugar los principales avances tecnológicos en la electrónica como el primer ordenador programable y el transistor. En la década de los setenta fue que se aceleró su desarrollo sinergético dando como resultado un paradigma tecnológico.

El transistor inventado en 1947 hizo posible procesar los impulsos eléctricos a un modo binario de interrupción y paso, lo que facilitó la codificación de la lógica y la comunicación con máquinas y entre ellas (esto es lo que se conoce como chips).

De esta manera, los circuitos integrados cobraron gran relevancia al desarrollar el microprocesador y reducir así el tamaño y alcance de las computadoras. Pasaron muchos modelos y desarrollos entre la primera computadora UNIVAC y las computadoras personales, pues las características y configuraciones son muy diferentes. 
En 1976 Steve Jobs y Steve Wozniak fundaron Apple y pudieron comercializar el ordenador Apple I y Apple II. Aunque, para el año de 1981 IBM presentó el miniordenador: la computadora personal (PC). Tanto el Apple de Macintosh, como la PC de IBM en 1984 fueron el primer paso hacia una informática más fácil para el usuario personal, junto con la introducción de programas diseñados para diversos tipos de usuarios. El software para la PC también se desarrolló a partir de la aparición de la PC y el diseño de programas de aplicación, con la creación de Microsoft. A mediados de la década de 1980 los ordenadores no podían concebirse en aislamiento, actuaban en redes mediante ordenadores portátiles.

Los importantes avances de la optoelectrónica (fibras ópticas y transmisión por láser) y en la tecnología de la transmisión de paquetes digitales ampliaron de forma inigualable la capacidad de las líneas de transmisión. Las Redes Digitales de Servicios Integrados de Banda Ancha (RDSI-BA) imaginadas en la década de 1990 podían sobrepasar con creces las revolucionarias propuestas de los años setenta de una Red Digital de Servicios Integrados (RDSI).

Finalmente, las diferentes formas de utilización del espectro de la radio (transmisión tradicional, transmisión directa por satélite, microondas, telefonía digital celular), así como el cable coaxial y la fibra óptica, ofrecen una diversidad y versatilidad de tecnologías de transmisión que se están adaptando a una gama de empleos y posibilitando una comunicación ubicua entre usuarios móviles, 
como el caso de la aparición del teléfono celular en 1984, la creación de la world wide web para navegar en internet y actualmente de los teléfonos inteligentes, así como de las tabletas electrónicas. 
Figura 13. Evolución de las tecnologías de la información

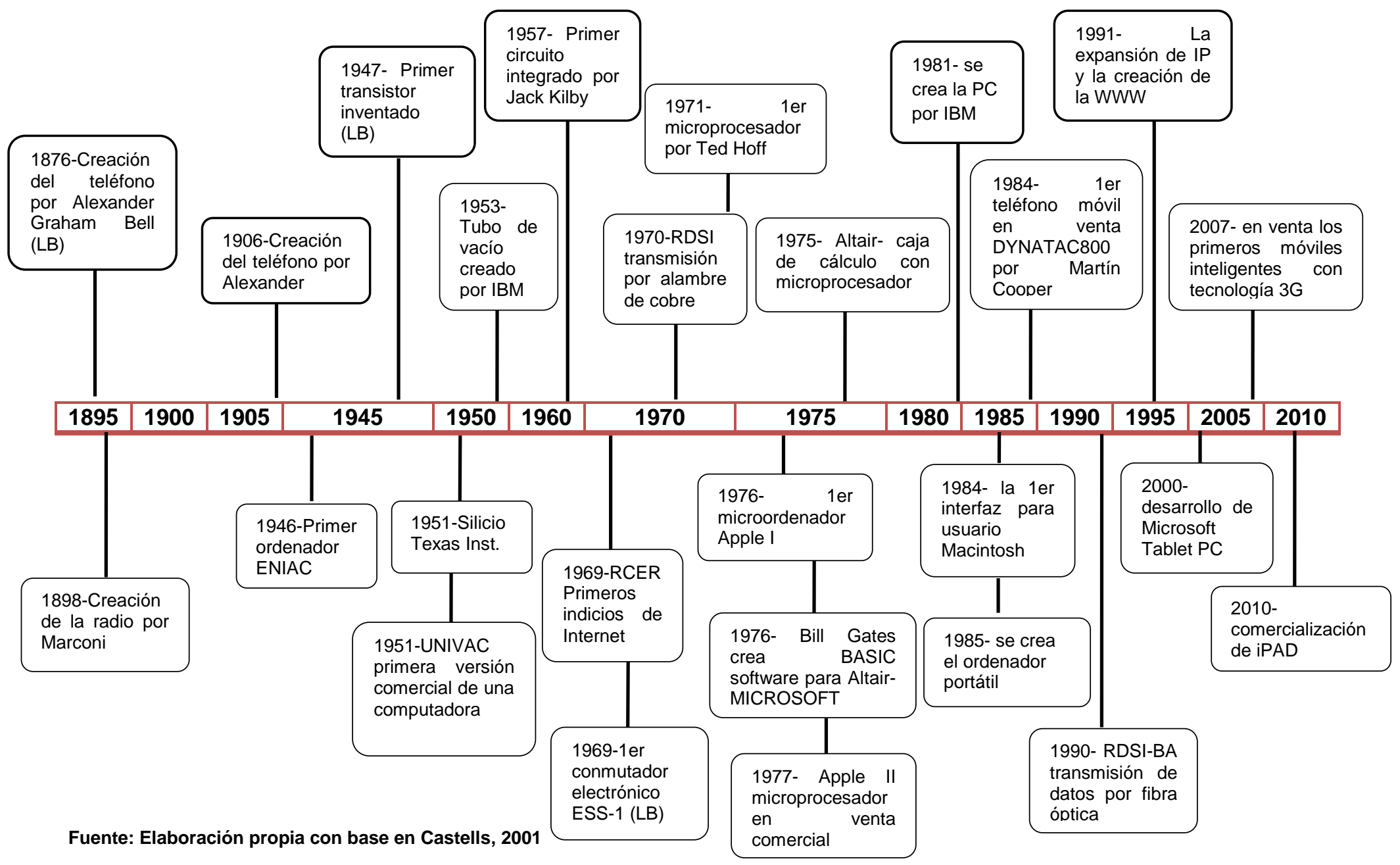




\subsubsection{Definición y características de las TIC's}

Para saber cómo es que funcionan las TIC's, se necesita entender qué son y cuál es du definición. Herdin (2007) retoma dos características muy importantes cuando se refiere a que las TIC's tienen acceso a la información y al conocimiento que se generan en una sociedad especifica. Pero, ¿qué son estas tecnologías específicamente? ¿Cuáles son sus componentes? ¿En dónde se pueden encontrar? En primer lugar, es necesario mencionar qué es tecnología, tecnologías de la información y sistemas de información, para no confundir la terminología.

Ante la proliferación de descubrimientos y avances tecnológicos que vienen acumulándose desde el siglo XIX, Castells (2001:56) ayuda a entender qué es la tecnología cuando indica que es "el uso del conocimiento científico para especificar modos de hacer cosas de una manera reproducible". Y entre las tecnologías de la información incluye el conjunto convergente de tecnologías de la microelectrónica, la informática (máquinas y software), y las telecomunicaciones (televisión, radio y optoelectrónica).

De la misma manera, Suárez (2007) y de Pablos (2004) coinciden en que el concepto de tecnología se define como la ciencia que estudia las técnicas y procesos empleados en las distintas ramas de la industria y los negocios, al ser un conjunto sistematizado de conocimientos aplicados a las diferentes áreas del ser humano, unidos por la consecución de un fin, que es la creación o invención de 
algo, que puede ser desde la fabricación o mejora de un producto hasta la simplificación o el cambio de un determinado proceso. Es un término general, que puede crear confusión porque no se refiere a ninguna tecnología específica.

Sin embargo, como señala Lorette (1990) existe un descuido de la terminología para las TIC's, ya que la tendencia a utilizar palabras con definiciones ampliamente aceptadas entre la sociedad, induce a encasillar a las TIC's de manera limitada. Los profesionales en sistemas de información aceptan diferentes palabras 0 frases cortas que significan la misma cosa, por ejemplo telecomunicaciones, teleprocesamiento, comunicaciones de datos, sistemas de información, etc.

Autores como Lechuga (2007), De Pablos (2004) y Suárez (2007) coinciden con Castells en que las nuevas tecnologías de la información y la comunicación definen como "una tríada que integra la revolución informática, la revolución electrónica y nuevos materiales. Y que son un conjunto de dispositivos, soluciones y elementos, hardware y software de comunicaciones aplicados al tratamiento automático de la información y de la difusión de la misma para satisfacer necesidades de información".

Según la propuesta de los autores, existe una convergencia entre los tres elementos que conforman las TIC's como se muestra en la figura 14, esta tendencia muestra que estas tecnologías, no funcionan en lo abstracto por sí 
mismas, sino que al menos deben concordar con algún otro elemento para que pueda tener sentido su función. Aunque, como ya se ha mencionado, también requieren de los seres humanos para poder operar, y así formar un complejo modo de interacción entre las TIC's y los seres humanos.

Figura 14. Elementos de las TIC's.

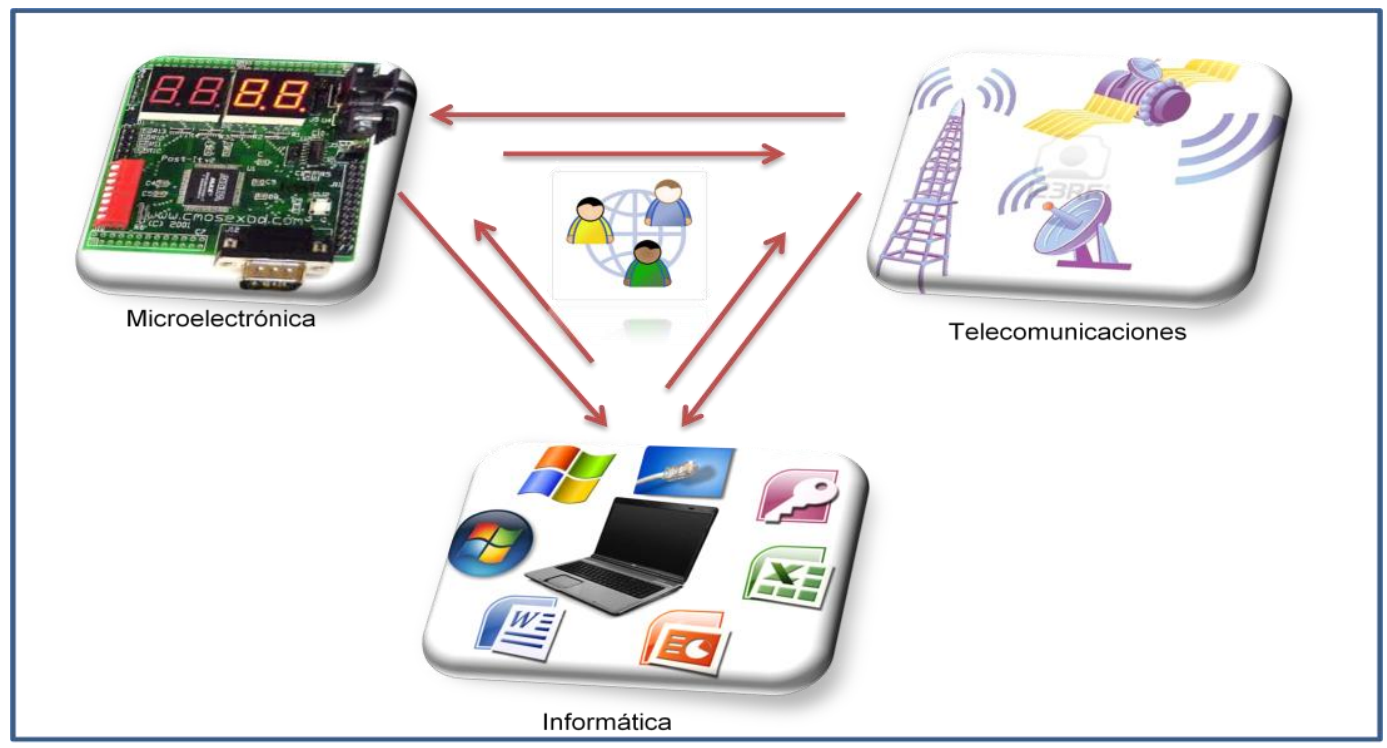

Fuente: Elaboración propia con base en Castells (2001)

En la década de los 80's las computadoras se hicieron presentes en mayor medida, por lo que desde entonces han sido protagonistas de lo que hoy son las tecnologías de la información, lo que ha modificado la vida de los seres humanos en diferente medida, y pueden convertirse en un arma de doble filo sino se les da un uso adecuado. Con la invención de la PC, se ha logrado constituir diferentes programas que sirven a cada disciplina como a las ciencias exactas o a las ciencias sociales, en ese sentido, el término de sistema de información también ha tomado fuerza. 
Según Castells (2005) y Semenov (2005), proponen una definición de acuerdo a la combinación de elementos que ya se han mencionado anteriormente, y señalan que son el conjunto de tecnologías desarrolladas para administrar información y enviarla de un lugar a otro, ya que los sistemas de información (SI) abarcan un abanico de soluciones muy amplio, éstas incluyen las tecnologías para almacenar información (computadoras, internet) y recuperarla después, así, como enviar y recibir información de un sitio a otro, o procesar información para poder calcular resultados, etc.

Para Daft (2009) en la actualidad los sistemas de información cumplen tres objetivos básicos dentro de las organizaciones:

- Automatizar los procesos operativos: se da a través del uso de programas como hoja de cálculo, procesamiento de texto, herramientas para hacer presentaciones, bases de datos y herramientas para el manejo de imágenes.

- Proporcionar información que sirve de apoyo en el proceso de la toma de decisiones: tener acceso a la información de manera rápida y concisa en el menor tiempo posible.

- Lograr ventajas competitivas a través de su implantación y uso: implementar sistemas de información para ahorrar costos en el proceso operativo de la organización

Una vez más, es notorio el hecho de que las tecnologías de la información no son por sí solas redes de computadora, internet de banda ancha, teléfonos inteligentes, tabletas gráficas, etc., sino todo el conjunto que permite realizar las 
actividades mencionadas. Es muy importante no dejar de lado, que algunos autores ${ }^{18}$ definen a las TIC's en forma pragmática, en otras palabras, en función del beneficio económico que pudiera traer a la organización, por ejemplo, comercio electrónico, comunicación interna (entre las áreas funcionales), orientación al cliente, comunicación con proveedores, innovación, mejora de procesos, calidad, entre otros.

\section{Componentes de las Tecnologías de la Información y Comunicaciones}

De acuerdo a lo dicho anteriormente, el concepto de tecnologías de la información hace referencia a todas aquellas tecnologías que permiten y dan soporte a la construcción y operación de los sistemas de información, y son tecnologías de hardware, software, de almacenamiento y comunicaciones. Estas tecnologías forman la infraestructura tecnológica de la organización, que provee una plataforma en la cual la compañía construye y opera los sistemas de información (Cohen: 2009:8). En seguida se presentan en la tabla 5, algunos de los componentes, que generalmente son parte de estas tecnologías.

\section{Tabla 5. Ejemplos de TIC's}

\begin{tabular}{|l|l|}
\hline \multicolumn{1}{|c|}{ Tecnología } & \multicolumn{1}{|c|}{ Definición } \\
\hline Redes de datos & $\begin{array}{l}\text { La infraestructura que permite la transmisión de la } \\
\text { información a través del intercambio de datos. }\end{array}$ \\
\hline Redes de voz & $\begin{array}{l}\text { Grupo de recursos que permiten que la voz viaje a través de } \\
\text { una señal de internet }\end{array}$ \\
\hline Redes inalámbricas & $\begin{array}{l}\text { Conexión de nodos sin necesidad de cables para transmitir } \\
\text { una señal de internet. }\end{array}$ \\
\hline Ruteadores (routers) & $\begin{array}{l}\text { Dispositivo que proporciona conectividad a nivel de red o nivel } \\
\text { tres en el modelo OSI }\end{array}$ \\
\hline Protocolos de comunicación & $\begin{array}{l}\text { Conjunto de reglas usadas por computadoras para } \\
\text { comunicarse unas con otras a través de una red por medio de }\end{array}$ \\
\hline
\end{tabular}

${ }^{18}$ Malone y Rockart (1991), Collinson (2000), y Cohen (1996) 


\begin{tabular}{|l|l|}
\hline Hardware & intercambio de mensajes. \\
\hline Software & $\begin{array}{l}\text { Está formado por el equipo computacional, es decir, por las } \\
\text { partes físicas de la computadora. Por ejemplo, la Unidad } \\
\text { Central de Procesamiento (CPU), la memoria central, y los } \\
\text { dispositivos periféricos (mouse, teclado, bocinas, etc.) }\end{array}$ \\
\hline Internet & $\begin{array}{l}\text { Conjunto de programas que ejecuta una computadora. Estos } \\
\text { programas tienen instrucciones u órdenes, que se encuentran } \\
\text { codificados en un lenguaje que puede comprender la } \\
\text { computadora. }\end{array}$ \\
\hline Base de datos & $\begin{array}{l}\text { Es una red informática descentralizada, que para permitir la } \\
\text { conexión entre computadoras opera a través de un protocolo } \\
\text { de comunicaciones }\end{array}$ \\
\hline Telecomunicaciones & $\begin{array}{l}\text { Colección integrada de registros y archivos. Serie de datos } \\
\text { organizados y relacionados entre sí sobre un contenido en } \\
\text { particular. }\end{array}$ \\
\hline $\begin{array}{l}\text { Elemento de hardware que hace que ocurra la transmisión } \\
\text { electrónica de señales para generar comunicación entre } \\
\text { dispositivos de la misma categoría. }\end{array}$ \\
\hline
\end{tabular}

Elaborado con base en: Cohen (2009) y Lorette (1990)

De acuerdo con la tabla 5, se muestran algunos elementos que se han presentado en la línea del tiempo de las TIC's, así como la definición de dichos elementos para que pueda tomar sentido la triada que se menciona en la figura 15. Esto, para resaltar que los elementos de la tabla 5 no trabajan por sí mismos para el cumplimiento de la comunicación, sino que entre ellos existe una relación que ayuda al cumplimiento de sus funciones.

\subsubsection{Cambio tecnológico y su influencia en la organización}

Sin duda alguna, en tiempos actuales se vive con la aceptación de que las tecnologías de información ya son parte fundamental para el desarrollo de las comunicaciones, y para el emprendimiento de nuevas formas de socializar. Estas tecnologías se han infiltrado desde los hogares de las personas hasta las distintas organizaciones. Esto genera preguntas acerca de cómo es que la sociedad las ha aceptado, o cómo es que las organizaciones las están incluyendo como parte 
fundamental de su estructura. La respuesta es el asentimiento de un cambio tecnológico.

Herdin (2007) señala que existen dos posiciones que permiten visualizar el cambio que se ha producido en la tecnología, el primero es el determinismo tecnológico y el segundo el constructivismo social. El determinismo sociológico se refiere a la influencia de la tecnología en una cultura. Esto quiere decir, que la tecnología se desarrollará por si sola empujando la vida social de un lugar, lo que puede ser positivo o negativo para la sociedad. Sin embargo, los fundamentalistas sostienen que el desarrollo tecnológico es el responsable de que la sociedad pierda los valores que son importantes. El constructivismo social mantiene que la tecnología es construida deliberadamente para ser parte de una sociedad. Aunque, algunos grupos dominantes aprovechan para plasmar sus intereses en el desarrollo de la tecnología.

Por su cuenta, Castells (2001:87:90) sugiere que hay rasgos específicos que dan cuenta a este paradigma tecnológico. Estos cinco puntos son sustanciales de mencionar para que posteriormente se tenga una concepción de porque las TIC's pueden combinarse con otros elementos dentro de la organización.

1. Son tecnologías para actuar sobre la información, no solo información para actuar sobre la tecnología.

2. Los procesos de la existencia individual y colectiva están moldeados por el nuevo medio tecnológico.

3. La configuración topológica, la red, se materializa en todo tipo de procesos y organizaciones mediante tecnologías de la información de reciente disposición. 
4. El paradigma de la Tecnología de la Información se basa en la flexibilidad, ya que pueden alterarse mediante la reordenación de sus componentes.

5. No existen trayectorias separadas entre los componentes de las TIC's, ahora convergen de manera que se vuelven prácticamente indistinguibles.

Como se muestra en los puntos anteriores, los enfoques dominantes sobre la convergencia digital básicamente se refieren a la confluencia entre sectores de telecomunicaciones, medios de comunicación y tecnologías de la información, y también, a la convergencia económico-productiva. Esta reconversión, no es solo tecnológica, es también productiva, social, y cultural.

Es inevitable no aludir a que la reestructuración de las economías nacionales, en la actualidad son ampliamente impulsadas por los adelantos en la tecnología de la información. El capital y la tecnología de la era de la información se han enfocado en la productividad de los trabajadores del conocimiento y de servicios. La tecnología de la información es vista como la herramienta principal para obtener ganancias sustanciales y progresivas de la productividad que modelarán los líderes (individuos, compañías, instituciones y países) del siglo XXI (Tapsscott: 1995). Por lo tanto, para los estudiosos de las organizaciones es una vertiente el conocer cómo han impactado estas tecnologías en la organización.

\section{Influencia de las TIC's en las organizaciones}

Este punto es muy interesante, porque distintos autores concurren en el enfoque económico y le dan un sentido funcionalista, donde la teoría administrativa deja 
caer su peso. Lo anterior, es una ventaja para este tema en el campo de los estudios organizacionales, porque a pesar de que las TIC's ya tienen más de dos décadas de existencia, aun son pocos los estudios que se han hecho desde esta perspectiva en comparación con la Administración y otras disciplinas.

La tecnología no es neutral. Responde siempre a los intereses de quienes la poseen y aplican. Eso explica por qué las TIC's en el mundo, a pesar de su enorme potencial de beneficio, paradójicamente han contribuido a acentuar la disparidad socioeconómica e informativa entre países desarrollados y subdesarrollados, y entre ricos y pobres al interior de éstos. Las TIC son una vía más para alcanzar el desarrollo. Sobre ese presupuesto, no puede eliminarse la brecha digital si primero no se elimina la brecha económica, cultural y social (Lechuga: 2007:167).

Daft (2009), opina que los sistemas de TIC's en las organizaciones en un principio se usaron en las operaciones. Estas primeras aplicaciones estaban basadas en la noción de la eficiencia de las máquinas, es decir, la posibilidad de que las negociaciones existentes se desarrollaran de una manera más eficiente con el uso de la tecnología computacional. La meta era reducir los costos de la mano de obra por medio de las computadoras que se encargaban de algunas tareas, así como para reducir el control administrativo al crear rutinas formales.

Después se utilizaron para que las actividades fueran más eficientes a través de la racionalización de procedimientos, posteriormente con base en estas tecnologías, 
las organizaciones pudieron replantear y agilizar sus procesos de negocios para mejorar la velocidad, el servicio y la calidad. Y finalmente los nuevos SI pueden inclusive transformar la manera en que las organizaciones llevan a cabo sus actividades modificando la naturaleza de las mismas.

No se puede negar el avance que las TIC's han tenido sobre todas las organizaciones de todas las industrias. Algunas implicaciones específicas de estos avances para el diseño organizacional son las empresas más pequeñas, las estructuras descentralizadas, coordinación interna y externa mejorada y las nuevas estructuras organizacionales en redes. En la tabla 6 se detalla:

Tabla 6. Implicaciones de las TIC's sobre las organizaciones

\begin{tabular}{|c|l|}
\hline $\begin{array}{c}\text { Implicaciones de las TIC's en las } \\
\text { organizaciones }\end{array}$ & \multicolumn{1}{|c|}{ Características } \\
\hline Organizaciones más pequeñas & $\begin{array}{l}\text { Realizar más trabajo con menos gente } \\
\text { Reducir el espacio físico así como el equipo de } \\
\text { trabajo }\end{array}$ \\
\hline Estructuras organizacionales descentralizadas & $\begin{array}{l}\text { Reducir los niveles administrativos y } \\
\text { descentralizar la toma de decisiones } \\
\text { Desarrollo de labores en ubicación remota }\end{array}$ \\
\hline Coordinación horizontal mejorada & $\begin{array}{l}\text { Mayor coordinación y comunicación dentro de } \\
\text { la organización }\end{array}$ \\
\hline Relaciones interorganizacionales mejoradas & $\begin{array}{l}\text { Mejorar la coordinación horizontal y la } \\
\text { colaboración con partes externas como } \\
\text { proveedores, clientes y socios. }\end{array}$ \\
\hline Estructuras en red mejoradas & $\begin{array}{l}\text { Mantener bajos costos para expandir las } \\
\text { actividades o presencia en el mercado }\end{array}$ \\
\hline
\end{tabular}

Elaborado con base en Daft (2009) 
Otro tema recurrente en las organizaciones y las TIC's es la oficina automatizada, de acuerdo con Forester (1992:232:233) los trabajadores de cuello blanco son los que se encuentran en la oficina, por lo que el advenimiento de estas tecnologías ha propiciado el cambio del papeleo tradicional a la oficina electrónica, y con ello el aumento de la productividad. Para Castells (2001) la automatización de la oficina acarrea la división de labores, la interconexión entre áreas y los cambios en la toma de decisiones que han propiciado la flexibilización del trabajo.

Lorette (1990) ofrece algunas características de la oficina automatizada: cuentan con correo electrónico, correo de voz, fax y sistemas de teleconferencia. Sistemas de gestión de documentos: almacenamiento de documentos, la reproducción y recuperación a través de la gestión de expedientes, micrografía (en microfilm), y reprografía (copiar y duplicar). Los sistemas de oficina de apoyo: calendario electrónico, archivo ticket, la programación y los sistemas de gestión de tareas. Sistemas de computación personal: cómputo interactivo, gráficos, recuperación de información y modelado en estaciones de trabajo inteligentes en oficinas $u$ otros sitios (telecommunicating). En la figura 15 se representan algunas de las características de la oficina automatizada:

Figura 15. Oficina Automatizada 


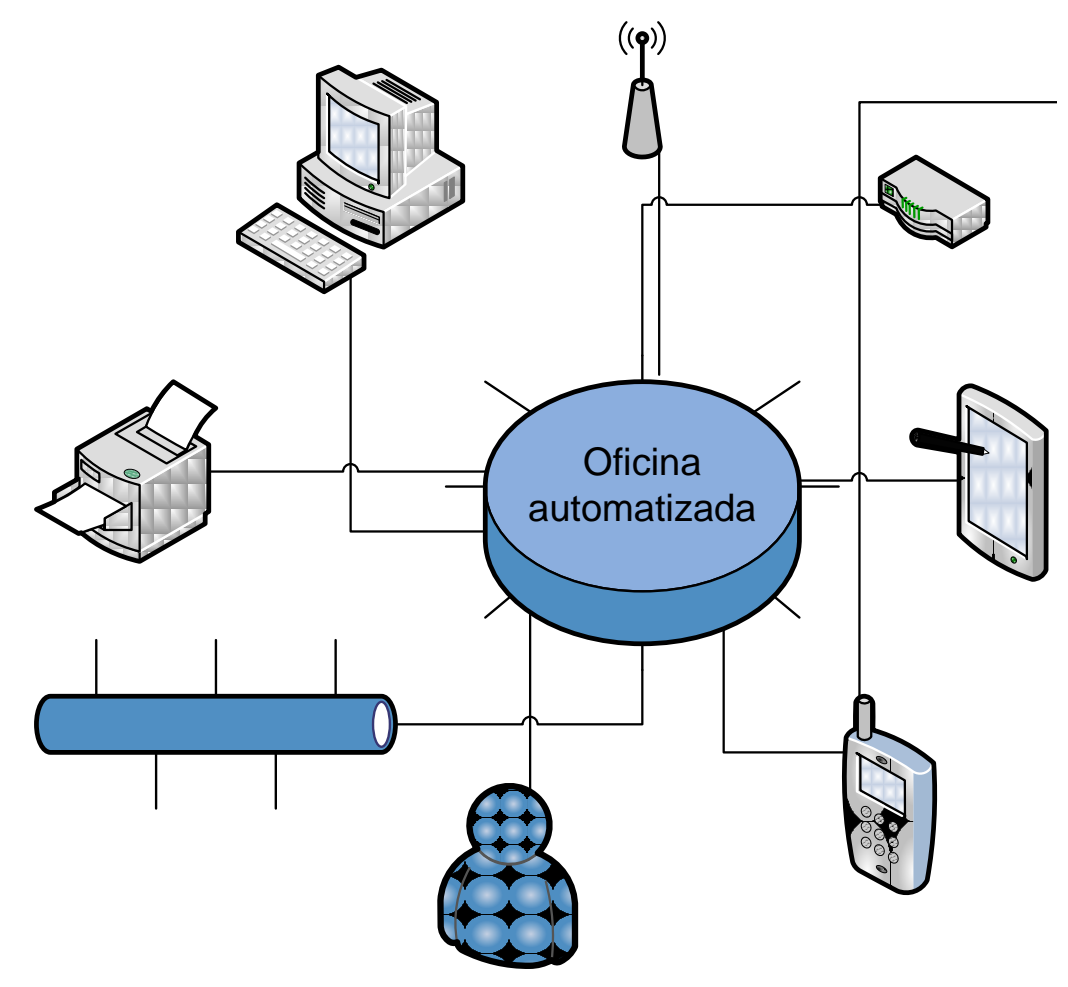

Elaboración propia con base en Daft (2007) y Lorette (1990)

Como se puede ver en la figura 15 , las telecomunicaciones abarcan todas las técnicas, normas y procesos relativos a la comunicación a distancia, desde la transmisión de voz por teléfono, voz y música por radio, imágenes y voz por televisión (además de la transmisión del teletexto y de datos en televisión digital), todo tipo de datos por las redes celulares, de satélite, redes de cable o redes inalámbricas, que intervienen en el proceso administrativo y operativo de una organización.

Otra cuestión que le ocupa a la organización, es la aparición de nuevas profesiones. Suárez (2007) atañe que con la aparición de las TIC, surgieron nuevas técnicas, como la de consultor TIC, ingeniero de software, analista, 
diseñador multimedia, diseñador 3D, ingeniero de red, técnico de redes, técnico comercial Tic, operador de consola, instalador de telecomunicaciones, profesor de informática, técnico de mantenimiento informático, reparador de móviles, etc. Asimismo, resalta el uso de la computadora personal en el trabajo y presenta dos consideraciones:

- De la computación personal al trabajo de computación en red. La computadora personal ha penetrado en la organización para afectar casi todos los oficios, sin embargo, su impacto rara vez puede describirse como un hecho estratégico, pero ha cobrado importancia el trabajo de computación en red, ya que suministra herramientas personales y da trabajo de grupo, información y capacidades para apoyar directamente todas las categorías de las personas en el sector de la información e la economía. Los sistemas de trabajo en grupo hacen posible que los usuarios reorganicen un proceso de trabajo y cambien la naturaleza de las tareas en una unidad de negocio.

- De la computación interna a la computación interempresarial. La nueva tecnología de alcance extendido hace posible el replanteamiento de relaciones con organizaciones externas. Los sistemas empresariales de computación comienzan a dialogar entre sí. (Tapscott 1995)

Para Barrios (2007), los efectos de las nuevas tecnologías pueden clasificarse en cinco aspectos: 1) la transformación de las actividades productivas mediante la automatización de los procesos, 2) la integración de las actividades es crucial, ya que el diseño se convierte en la actividad fundamental en la transformación de 
productos y procesos, 3) un incremento de la capacidad humana para generar valor y riqueza mediante consecuencias cuantitativas y cualitativas, 4) la formación de redes de unidades productivas, co- integrado a los proveedores y usuarios con el objeto de generar "economías de abastecimiento", 5) una cadena de actividades productivas con base en bases de datos y medios crecientemente avanzados en procesamiento de información.

Finalmente, otro punto de vista que presenta Daft (2009) es cuando señala los avances tecnológicos, la desaparición de fronteras entre los mercados nacionales y las expectativas cambiantes de los clientes son la pauta para determinar que es necesario realizar un cambio en la forma de trabajar. Las empresas de hoy deben organizar el trabajo con base en procesos y no en actividades. En la mayoría de las empresas toda la gente participa en procesos, pero no existe alguien que esté a cargo de ellos.

Es necesario un cambio, algo completamente diferente en la forma de realizar el trabajo. La reingeniería con la ayuda de las TIC's busca crear mejoras en costo, calidad, servicio y tiempo. Algunos de los cambios que sufren las organizaciones con la reingeniería apoyada en las TIC's son: la unidad de trabajo cambia; en lugar de tener un departamento para cada función, ahora existen equipos de personas responsables de los procesos. La estructura de la organización deja de ser jerárquica para convertirse en plana. Los puestos de trabajo se convierten en multidimensionales. 
Estas tecnologías pueden favorecer a la organización haciéndolas más flexibles, modificando su estructura, reducir la burocracia, hacer maleable la comunicación, y permitir la racionalización tecnológica, por el contrario, también puede generar problemas en el comportamiento de los individuos, en la cultura organizacional, en la estructura de la organización, qué en realidad estos problemas no son generados meramente por la tecnología en sí, sino por la manera en qué estas tecnologías se usan. Por lo tanto, es relevante conocer algunas características, para posteriormente entender cómo es que están en las organizaciones.

Finalmente, el interés de presentar este apartado es principalmente para conocer qué son estas tecnologías de la información y cómo es que desde la sociedad se han transportado hasta las organizaciones cambiando de manera radical la forma de trabajo y de la estructura organizacional. Este último aspecto es el de utilidad para la construcción de esta tesis, porque es una exposición que se realiza a través de la perspectiva de los estudios organizacionales.

Para entender cómo se han dado estos fenómenos era necesario revisar qué elementos de la cultura organizacional permiten comprender esta introducción de las TIC's a la organización. Por su parte el cambio da las herramientas para conocer de fondo la transformación por la que algunas organizaciones han atravesado al adaptar estas tecnologías, y como se ha mencionado, el resultado de este cambio puede verse de manera directa en la estructura organizacional. 
Por lo tanto, en el estudio de caso se pretende mostrar cómo ha sido este proceso para una organización. Para ello es necesario revisar la metodología de investigación porque es necesario comprender como se hace la construcción del estudio de caso de la organización en particular, ya que haciendo evocación, todas las organizaciones presentan diferentes características que dan lugar a estudios desde diferente perspectiva. 


\section{Capítulo II. METODOLOGÍA DE INVESTIGACIÓN}

En los apartados anteriores se han presentado las características organizacionales que se pretenden estudiar en la propuesta metodológica que se despliega en el siguiente capítulo. Para ello, es necesario crear una ruta de investigación que permita cumplir los objetivos de esta tesis. Así, en primer lugar es necesario hacer un breve recorrido por los tipos de investigación que existen tanto en las ciencias sociales y exactas con la finalidad de encontrar el método que más se acerque al descubrimiento de la realidad organizacional que se pretende en este trabajo.

Es importante enfatizar, que existe un interés particular por obtener resultados en el área de los Estudios Organizacionales, esto significa que a través de un estudio cualitativo se obtengan los datos que permitan profundizar en el tema. Ya que de acuerdo con Ibarra (1990), cuando retoma el paradigma de complejidad organizacional de Morin, señala que el fenómeno organizacional, no pude ser considerado como un objeto teórico que se rija por leyes que hagan predecible su comportamiento, sino es inconmensurable, irregularmente aleatorio e irregularmente determinado.

En ese sentido, es que el método cualitativo toma mayor relevancia por su carácter constructivista. Además la finalidad de generar un aporte en las ciencias sociales repercutirá en el área de estudios organizacionales como para el contexto de las diversas organizaciones mexicanas. Por lo tanto, es necesario explicar de 
manera breve las diferencias entre los tipos de metodología que existen, para posteriormente entender la técnica del estudio de caso.

\subsection{Metodología cuantitativa y cualitativa}

De principio, hay que acentuar el debate que existe entre los tipos de investigación, Cortés (2000) menciona que existe la controversia sobre la investigación cualitativa y cuantitativa porque abarcan varios dominios, lo que ocasiona la mezcla de diferentes tipos de discusiones cuyas bases se asientan en los fundamentos filosóficos en que enraízan las teorías (ontología), en las teorías de la relación de conocimiento (epistemología), en el papel de los valores de producción de conocimiento (axiología) y en las disputas de sobre la casualidad frente a la interpretación; y con temas propiamente metodológicos como la objetividad, la generalización o la medición (confiabilidad y validez de la medida), así como con pugnas en que intervienen cuestiones de carácter técnico, como los alcances y limitaciones de los instrumentos de recopilación de información.

Hasta el momento, parece confuso, sí es que de primera instancia se quisiera saber cuál es la metodología adecuada para realizar una investigación social, y en este caso un estudio de organizaciones. Por eso es importante tomar en cuenta cuál es la unidad de estudio y cuál es el objetivo al que se quiere llegar en la investigación. En la tabla 7 se presentan las características de los paradigmas en la investigación social, con la intención de familiarizarse con las características de los objetivos y preguntas de investigación de este escrito.

Tabla 7. Características de los paradigmas en la investigación social 


\begin{tabular}{|c|c|c|}
\hline Supuestos & $\begin{array}{c}\text { Paradigma Positivista/ Post- } \\
\text { positivista } \\
\text { (metodología cuantitativa) }\end{array}$ & $\begin{array}{l}\text { Paradigma Constructivista } \\
\text { (metodología cualitativa) }\end{array}$ \\
\hline $\begin{array}{l}\text { Ontológicos } \\
\text { ¿Cuál es la naturaleza de la } \\
\text { realidad? }\end{array}$ & La realidad es objetiva & $\begin{array}{l}\text { La realidad es subjetiva y } \\
\text { múltiple }\end{array}$ \\
\hline $\begin{array}{l}\text { Epistemológicos } \\
\text { ¿Cuál es la relación entre el } \\
\text { investigador y aquello que } \\
\text { investiga? }\end{array}$ & $\begin{array}{l}\text { Separación entre el investigador } \\
\text { (sujeto) y el objeto de estudio. La } \\
\text { distancia frente a aquello que se } \\
\text { pretende investigar es vista como } \\
\text { condición necesaria para alcanzar } \\
\text { un conocimiento objetivo. }\end{array}$ & $\begin{array}{l}\text { El investigador está inmerso en } \\
\text { el contexto de interacción que } \\
\text { desea investigar. Se asume } \\
\text { que ambos y la mutua } \\
\text { influencia son parte de la } \\
\text { investigación. }\end{array}$ \\
\hline $\begin{array}{l}\text { Axiológicos } \\
\text { ¿Qué papel juegan los valores } \\
\text { en la investigación? }\end{array}$ & $\begin{array}{l}\text { El investigador busca } \\
\text { desprenderse de sus propios } \\
\text { valores, de su orientación político- } \\
\text { ideológica, sus concepciones } \\
\text { acerca del bien y el mal, de lo } \\
\text { justo y lo injusto, de lo que } \\
\text { deseamos para nosotros y los } \\
\text { otros, etc. }\end{array}$ & $\begin{array}{l}\text { El investigador asume que sus } \\
\text { valores forman parte del } \\
\text { proceso de conocimiento y } \\
\text { reflexiona acerca de ello } \\
\text { (reflexividad) }\end{array}$ \\
\hline $\begin{array}{l}\text { Metodológicos } \\
\text { ¿Cuáles son los } \\
\text { procedimientos que se utilizan } \\
\text { para construir la evidencia } \\
\text { empírica, y cómo se relacionan } \\
\text { lógicamente con el resto de las } \\
\text { etapas del diseño? }\end{array}$ & $\begin{array}{l}\text { Utilización de la educación en el } \\
\text { diseño y la inducción en el } \\
\text { análisis. } \\
\text { Operacionalización de conceptos } \\
\text { teóricos en términos de variables, } \\
\text { dimensiones e indicadores y sus } \\
\text { categorías. } \\
\text { Utilización de técnicas } \\
\text { estadísticas. } \\
\text { Confiabilidad en los resultados a } \\
\text { partir de estrategias de validación } \\
\text { internas. }\end{array}$ & $\begin{array}{l}\text { Conceptos y categorías } \\
\text { emergente en forma inductiva } \\
\text { a lo largo de todo el proceso de } \\
\text { investigación. } \\
\text { Múltiples factores se } \\
\text { influencian mutuamente. } \\
\text { Diseño flexible e interactivo. } \\
\text { Se privilegia el análisis en } \\
\text { profundidad y en detalle en } \\
\text { relación al contexto. } \\
\text { Confianza y autenticidad. }\end{array}$ \\
\hline
\end{tabular}

Fuente: Tomado de Sautu: 2010: 34

Como se puede notar en la tabla 7, existe una gran diferencia entre éstas dos corrientes metodológicas, por una parte se tiene que la corriente positivista se basa en hechos que pueden ser explicativos, objetivos, deductivos, orientados a la prueba de hipótesis, y que tienen carácter universal, mientras que, la corriente constructivista se fundamenta en lo relativista, holista, en lo descriptivo o exploratorio, especulativo o ilustrativo, ideográfico, interpretativista, orientado a poner el significado para los actores, etc. (Cortés:2000) 
La anterior reflexión, permite, de acuerdo a las características presentadas, determinar que la metodología que será utilizada es la cualitativa, ya que de ésta manera se puede lograr establecer la relación entre las variables de estudio en la organización y encontrar alguna respuesta a las preguntas de investigación. Sin embargo, para lograr lo anterior, se deben obtener datos por parte de personas que crean su propio contexto y así llegar al objetivo de mostrar el contexto de la organización lo más cercana posible a la realidad, y esto solo puede ser posible a través de un estudio de caso.

En el contexto de los Estudios Organizacionales, es muy importante retomar la investigación a base del constructivismo; sin embargo, esta idea se presta a que la investigación pueda carecer de validez al permitir que sea una interpretación de la realidad y carezca de resultados universales. $Y$ es justo en este debate en el cual los investigadores de las organizaciones deben ser explícitos en cuanto a la forma de realizar la investigación en una organización, ya que difícilmente se puede volver al mismo resultado en la misma unidad de estudio.

También esta misma libertad que otorga el método cualitativo, propicia que se puedan realizar un sinfín de estudios de diversas disciplinas sociales en la misma organización. Lo interesante en este punto es que existe una diversidad de teorías y supuestos que los autores construyen para así corroborar sus hipótesis, como el caso de Woodward (mencionado en un apartado anterior) que buscaba encontrar relaciones de productividad con la tecnología valiéndose de instrumentos cualitativos como el estudio de caso. 


\subsection{El estudio de caso: una herramienta para evidenciar la realidad de la organización}

Actualmente, la existencia de múltiples formas de análisis en los estudios de las organizaciones se ha evidenciado a través del estudio de caso. Para Barba (2009) el estudio de caso es un método articulador del dato y la teoría, ya que se puede crear una serie de hipótesis que en otros contextos concretos deben verificarse, además, un estudio de caso describe en forma exhaustiva una situación social y explica al menos tentativamente sus múltiples factores y componentes, con base en un marco teórico previo que pueda respaldar los supuestos en la construcción del estudio de caso.

Es así que, según las características mencionadas anteriormente de la metodología cualitativa, puede surgir la pregunta de ¿Cómo construir, interpretar, explicar, etc., un hecho en particular de una organización? Pues bien, según Yin (2003) considera al estudio de caso como una estrategia metodológica que busca a partir de un estudio particular la comprensión de algún fenómeno específico (puede ser de carácter cuantitativo como cualitativo) y éste representa el vehículo gracias al cual se puede tener un acercamiento al fenómeno que se quiera estudiar específicamente en una organización y adaptable al contexto en el que se encuentre.

Con respecto a esta metodología, el estudio de caso puede ser visto ciertamente como una ruta comprensiva para el análisis de la realidad, Yin (2003:15) plantea cinco principales tipos de estudio de caso como una estrategia de investigación: 
1. El exploratorio. Es el preámbulo, aproximaciones al objeto de estudio. Un primer acercamiento respecto de la investigación que se quiere llevar a cabo.

2. El explicativo. Es como su nombre lo señala, el estudio de caso que tiene por objeto comprender el fenómeno que está siendo estudiado de manera profunda y explicar las relaciones causales de la vida real.

3. El descriptivo. El intento aquí está en la descripción, en la representación del fenómeno que está siendo estudiado para poder comprenderlo. En pocas palabras, es describir una intervención y el contexto real en el que se produjo.

4. El ilustrativo. Este tipo de estudios de casos pueden ilustrar ciertos temas en una evaluación, de nuevo en modo descriptivo.

5. La metaevaluación. Es el estudio de caso de un estudio de evaluación.

Como bien se ha señalado en el inicio de este trabajo, se pretende realizar una investigación que permita encontrar la relación entre las TIC's y el cambio organizacional, por lo que en esa búsqueda se presume también hallar la reciprocidad que exista con la estructura y la cultura organizacional. Así que para ello, se eligió una organización que presumiera de todos los elementos que se han descrito. Infotec es un centro público CONACYT que se dedica a la investigación, desarrollo y a la docencia en temas de TIC's.

En el contexto de los estudios organizacionales, es de un alto valor contar una investigación que se asemeje a la realidad de la organización, por lo que la 
investigación explicativa provee las herramientas metodológicas para cumplir con este propósito. Por lo que se eligió enfocarse en la unidad de estudio (Infotec) para crear puentes que permitan facilitar los objetivos planteados. De esta manera, se tomó en cuenta el factor tiempo y la facilidad para recabar información documental y a través de algunos miembros de la organización.

En este sentido, y de acuerdo a la descripción de los estudios de caso propuestos por Yin (2003), se ha elegido realizar la propuesta del estudio de caso explicativo. Las principales razones por las cuáles es viable retomar esta estrategia son las siguientes: en primer lugar, la pregunta de investigación para el desarrollo de esta tesis dice ¿Cómo se presenta el cambio en la Organización con la introducción de las TIC's en el Infotec? El uso de la preposición cómo, permite desarrollar ampliamente una explicación para dar respuesta a la pregunta.

En segunda, porque se procura dar respuesta a las preguntas de investigación, de modo que se tiene libertad para acotar los datos recabados de manera que su uso sea con fines explicativos, por lo que si se encuentran hallazgos diferentes a los esperados, entonces crear puentes entre los datos y la teoría que expliquen el porqué de esos hallazgos. O porqué se generan relaciones entre las variables de estudio en la organización.

Finalmente, Yin (2003:22) señala que es importante tener en cuenta que la estrategia de estudio de caso es más viable para responder a preguntas de investigación de "cómo" y "por qué", por lo que la primera tarea es aclarar con 
precisión la naturaleza de las preguntas de estudio en este sentido. Lo anterior tiene el objetivo de desarrollar la investigación con la pertinencia necesaria para lograr la obtención de las respuestas a la pregunta o preguntas centrales de este trabajo.

Lo mencionado anteriormente funciona como un primer plano, dónde ya se sabe, que para explicar un hecho social y en este caso organizacional, la mejor manera es a través de la metodología cualitativa, y para acercarse más al hecho, hay que hacer la construcción de la evidencia empírica (Sautu, 2010), pero para ello antes deben existir tres elementos que se articulan entre sí: marco teórico, objetivos y metodología, ya que son la guía inicial para comprender el estudio de caso.

Por su parte, el marco teórico se constituye por los conceptos, supuestos y teorías sobre el tema que se pretende analizar. Los objetivos son una construcción del investigador para abordar un tema o problema de la realidad a partir del marco teórico seleccionado (lo que se busca presentar en el estudio de caso). Por último, la metodología está conformada por procedimientos o métodos para la construcción de la evidencia empírica (la forma en que se realiza el estudio de caso).

\subsection{Herramientas metodológicas para el estudio de caso}

cuando se han creado las preguntas de investigación y el marco teórico, en segundo plano, el investigador tiene que buscar la manera de obtener la información requerida para ir construyendo las repuestas a las preguntas qué se 
hace sobre el fenómeno en particular y sobre todo para formular el estudio de caso; así que para hacer la construcción de los datos empíricos y mediante el uso de un estudio cualitativo, se pueden utilizar las siguientes herramientas metodológicas, analizadas desde la propuesta de Vela (2004), que facilitaran la recolección de las referencias y testimonios.

La observación. La observación es una de las herramientas metodológicas más utilizadas en el ámbito de la investigación que involucra la interacción entre el observador y aquello que se esté investigando. Por lo general se reconocen dos tipos de observación: participante y no participante. En el estudio de caso, la observación fue el primer acercamiento para el contacto entre la organización y el investigador, ya que al realizar visitas al Infotec se tenía la oportunidad de ver el rol y comportamiento de algunos de los empleados.

Análisis textual. Es el análisis de los diferentes medios escritos del cual el investigador se vale para conocer el fenómeno que está siendo estudiado. Los textos pueden ser: revistas, libros, cartas, folletos, manuscritos, documentos oficiales o públicos entre muchos otros. Para el estudio de caso de Infotec, se tuvo acceso a los anuarios que se publican de todos los centros públicos de investigación en la página web de CONACYT, buscando en particular los datos de dicha organización, así como la información que se pudo rescatar de la página web de Infotec y en otros portales de organismos que permitieran complementar la información. 
El fin principal era conocer más de la historia de la Infotec y conocer los principales eventos que permitieran explicar su relación con las preguntas de investigación. La investigación documental, fue un eje muy importante para el desarrollo del estudio de caso, ya que principalmente es la referencia donde se constatan los eventos ocurridos y sirvió principalmente para explicar cómo se generó el cambio en la organización.

La entrevista: Las entrevistas pueden ser de dos tipos. Estructuradas y no estructuradas, las primeras son típicamente vistas de una forma estandarizada en las que el investigador pregunta y el sujeto de la investigación posee las respuestas, se intenta en este sentido la comparación de las respuestas para una muestra de personas que por lo general representa un grupo extenso de individuos. La entrevista no estructurada representa "reiterados encuentros cara a cara entre el investigador y los informantes, encuentros dirigidos hacia la comprensión de las perspectivas que tienen los informantes respecto de sus vidas, experiencias o situaciones, tal como las expresan con sus propias palabras" (Taylor y Bogdan, 1996:101).

En este sentido, la entrevista semiestructurada jugó un papel interesante al permitir captar la referencia organizacional y tecnológica que tienen algunos empleados de diferentes áreas de la organización de estudio. Este hecho ayudó a reconfirmar la información contenida en los anuarios, pero también, ayudó a que se pudiera construir de forma lo más real posible el estudio de caso. 
Lo que se puede destacar acerca de las entrevistas semiestructuradas que se realizaron, es que, a pesar de que existía un guion con preguntas cuyo fin era conocer sobre temas en específico, el entrevistado tenía la libertad para proporcionar los datos que considerara pertinentes así como ligar otros temas o mostrar su opinión en cuanto a lo que se preguntaba. Lo anterior, ayudó a que las entrevistas tuvieran un acercamiento y percepción de la realidad de la organización de estudio.

Audio y grabaciones de video. En muchas ocasiones, la recolección de datos visual puede enriquecer la información de manera infinita. Es también una forma de conocer el contexto que rodea las acciones de los individuos e incluso las acciones mismas puesto que ellas rescatan de manera más confiable el fenómeno estudiado, aunque con mayor probabilidad la información recabada puede estar distorsionada. En el proceso de las entrevistas, éstas fueron grabadas para tener una fuente que pueda respaldar los datos cualitativos que se presentan en este trabajo, y posteriormente transcritas para una mayor comprensión de los datos.

\subsection{Un estudio de caso explicativo desde el enfoque organizacional}

De forma particular, el estudio de caso que se pretende desarrollar en esta tesis será abordado a través de la metodología del estudio de caso explicativo. Dada la información breve pero concisa sobre la metodología de investigación, y las herramientas, a continuación se explica cómo fue la recolección de los datos para dar paso al siguiente apartado, donde se puede constatar el trabajo teóricoempírico. 
En primer lugar, hay que recordar que esta es una tesis en la cual se busca presentar cómo se relacionan las variables organizacionales (cambio, cultura y estructura) en un Centro Público CONACYT: Infotec, el cual, es una organización que se desenvuelve en un entorno de las tecnologías de la información y comunicación, y que hace uso de estas desde hace 25 años.

De esta manera, comienza un recorrido interesante para la construcción del estudio de caso, que se sustenta por el marco teórico, en el cual, a pesar de que la bibliografía de TIC's en las organizaciones es un tanto escasa, y los estudios realizados llevan una tendencia técnica y funcionalista, pero no como interpretativa de fenómenos organizacionales. Por eso, es que surgieron las preguntas: ¿Cómo impactan las TIC's en la organización? ¿Cuáles tipos de cambios organizacionales se presentan? ¿Cómo es alterada la cultura organizacional? ¿Cómo cambia la estructura organizacional con la introducción de las TIC's?

La forma de contestar estas preguntas en esta investigación es a través de la realización de un estudio de caso en una organización donde las TIC's estuvieran presentes y tuvieran relación con las variables seleccionadas desde la perspectiva de la teoría organizacional. Para ello, en la figura 5.1 se muestra la ruta que se siguió para generar la información necesaria y requerida para la elaboración del estudio de caso.

Figura 16. Ruta de la creación de Estudio de Caso 


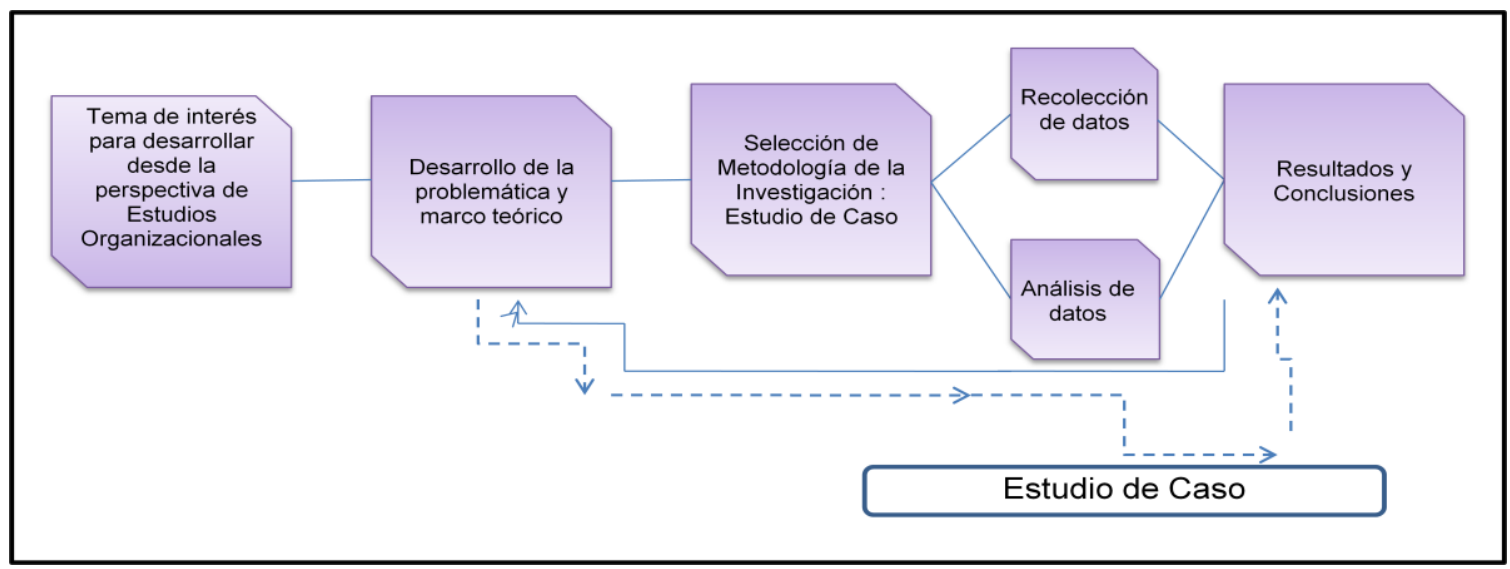

Fuente: Elaboración propia

Para el desarrollo del estudio de caso, como se muestra en la figura 16, la travesía inicia cuando se tiene el interés por investigar acerca de un hecho en particular, en este caso, el interés es acerca del impacto que tienen las TIC's en el cambio, estructura y cultura organizacional. Al tener conciencia del tema a investigar, se procede a realizar una búsqueda teórica que permita sustentar la pregunta 0 preguntas de investigación, además, también respaldará en su momento al análisis de los datos en el estudio de caso.

Posterior a esto, se eligió la metodología a través de la cual se plasman las inquietudes teóricas y empíricas por parte del investigador. La metodología seleccionada es el estudio de caso. Entonces, se puede hacer uso de las herramientas metodológicas por medio de la recolección de datos, para así analizarlos y finalmente obtener resultados y conclusiones. Todo este proceso se lleva a cabo fundamentado en la teoría, así como en la información recolectada para darle sentido al estudio de caso. 


\subsection{La observación no participante y la ruta de estudio en Infotec}

Cuando se acude por primera vez a las instalaciones físicas de la organización de estudio, se tiene la duda de lo que se puede notar a simple vista. La observación no participante jugó un papel muy importante, para no emitir juicios de valor, que pudieran recaer meramente en la subjetividad. Por lo que, en todas las visitas que se realizaron al Infotec, se consideraba tomar nota de los hechos que acontecían en la operación de la organización.

Las visitas a Infotec se iniciaron desde Diciembre de 2012 a Junio de 2013, cabe mencionar que al menos dos veces al mes se asistía a esta organización. Las primeras cuatro visitas fueron para conocer las instalaciones, platicar con el contacto que pertenecía a dicha institución acerca de la historia de Infotec, y sobre el contexto actual. Las visitas restantes fueron para entrevistar a algunos actores que han laborado en la organización por lo menos diez años, entre los cuales están miembros de gerencia en diferentes áreas y de apoyo administrativo.

Para acceder a las instalaciones de Infotec se tenía que realizar el siguiente procedimiento: en la planta baja se encuentra el área de recepción, por lo que se tiene que registrar con la recepcionista y entregar una identificación personal, registrarse en un cuaderno que decía visitantes y escribir el nombre de quién solicita el acceso, de que institución provenía, la hora de llegada, la persona a quién visitaba y firmar, posterior a esto, la recepcionista marcaba el número de extensión para avisar a la persona que se visitaba para que saliera a dar el acceso, mientras, la recepcionista anota los datos en su computadora y da un 
gafete con chip que decía visitante. Al término de la visita se regresa el gafete a la recepcionista, y se anota la hora de salida, para recuperar la identificación.

\section{Ruta para el estudio de caso de Infotec}

En las dos primeras charlas que se tuvo con el contacto de la organización (perteneciente al área de investigación y docencia), la plática sobre la historia de Infotec permitió vislumbrar que dicha organización tenía una historia muy interesante y que a través de la perspectiva de los Estudios Organizacionales se podían hacer números estudios. Sin embargo, como se dijo al principio, revisar la historia de Infotec, se decidió que se había que estudiar las épocas donde los eventos críticos tuvieran mayor acercamiento al estudio, por lo que como ya se señaló en el inicio de este trabajo, los eventos críticos tomarán relevancia en el caso.

\section{Figura 1 Eventos críticos para el Estudio de Infotec}

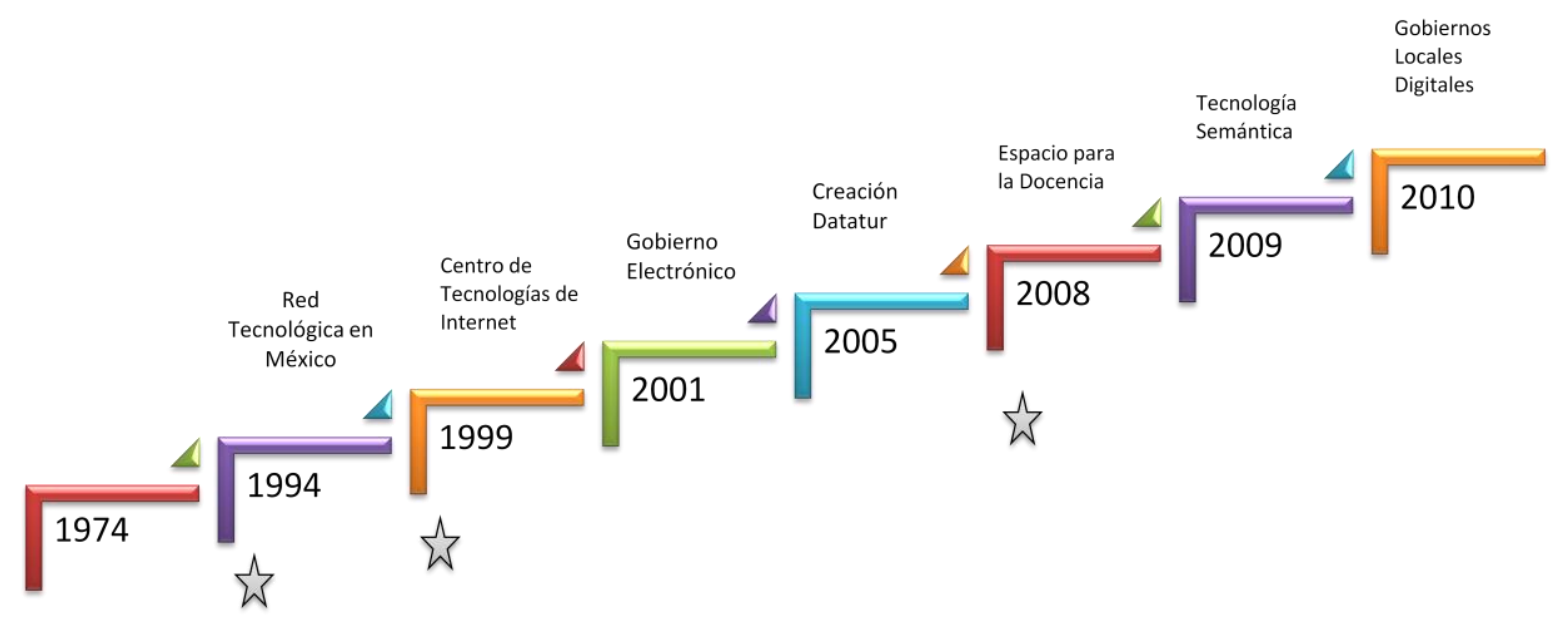

Fuente: Elaboración propia con base en Anuarios CONACYT y página web de INFOTEC 
Como se puede ver en la figura 1, los eventos críticos para el estudio de Infotec son: 1974 porqué en esta fecha se inicia la organización como fideicomiso del Centro Público de Información CONACYT y Nacional Financiera, 1994-1996 porque Infotec tiene que considerar la idea de vender servicios de Tecnologías de Información para seguir subsistiendo como organización, y 2008 en el cuál Infotec tuvo que crear el área de posgrado para impartir maestrías en temas de TIC's. En este sentido, cabe mencionar que los eventos qué están entre períodos serán considerados para justificar a los eventos críticos.

Para realizar el análisis de los datos, se considera agrupar los datos que fueron proporcionados por las personas entrevistadas, así como por el material bibliográfico, y así escoger solamente los que estuvieran en el intervalo de tiempo de las fechas seleccionadas, por lo que el estudio de caso, se realizará en tres etapas de análisis como se presenta en la tabla 8:

Tabla 8. Etapas para el desarrollo de Estudio de Caso de Infotec

\begin{tabular}{|c|l|}
\hline Etapa de análisis & \multicolumn{1}{|c|}{ Objetivo } \\
\hline Etapa 1 & $\begin{array}{l}\text { Explicar cómo ha sido el comportamiento } \\
\text { de las variables de estudio a través de la } \\
\text { historia de Infotec (considerando los } \\
\text { eventos críticos) }\end{array}$ \\
\hline $\begin{array}{c}\text { Análisis del Contexto organizacional de } \\
\text { Infotec en los eventos críticos. }\end{array}$ & $\begin{array}{l}\text { Responder a las preguntas de } \\
\text { investigación vinculando herramientas } \\
\text { metodológicas-teoría de los eventos críticos y su }\end{array}$ \\
\hline relación con las variables de estudio & $\begin{array}{l}\text { Explicar la relación entre cambio- } \\
\text { estructura-cultura en torno a las TIC's, } \\
\text { derivadas del análisis del estudio }\end{array}$ \\
\hline La relación de las variables & \multicolumn{1}{c}{} \\
\hline
\end{tabular}

Fuente: Elaboración Propia 
El objetivo principal de presentar en el cuadro anterior el resumen de lo que será el análisis de los datos para el estudio de caso, es por la inquietud de que el lector no se confunda con los términos utilizados ni con las etapas de estudio que ya se han mostrado. Sin embargo, está breve guía puede agilizar la búsqueda de alguna información en particular que desee revisar el lector. Así, con esta introductoria presentación, se da paso por completo a la realización del estudio de caso en el Infotec y a las reflexiones finales que puedan surgir de la interacción de marco teórico/herramientas metodológicas/análisis. 


\section{Capítulo III. ESTUDIO DE CASO}

En este capítulo se presenta el análisis de los datos obtenidos a través de las herramientas metodológicas señaladas en el capítulo anterior. Con esto, se pretende realizar el estudio de caso de Infotec, para ello, se plantea en primer lugar el contexto de la ciencia y tecnología en México, con el fin de poner sobre aviso que son escasos cuarenta años que las tecnologías y en especial las TIC's tuvieron relevancia en el contenido de políticas públicas en el país.

Además, también se da una pequeña introducción del surgimiento de los centros públicos de investigación, porque esto permite conocer el origen de la organización de estudio y las Instituciones que tuvieron o tienen relación con la organización de estudio, y sobre todo para entender la dinámica de estos centros, para posteriormente comprender el rol organizacional que ha tenido Infotec a través de su historia.

Por último, se presenta el detalle de la comprensión de los datos obtenidos, en el orden mencionado con anterioridad. En el cual se pone mayor énfasis en la comprensión del cambio organizacional para entender su relación con las demás variables de estudio. De esta manera, en la primera fase de estudio se contextualiza a la organización, en la segunda fase se enfatizan el resultado de las preguntas de investigación y en tercera fase se muestran las conclusiones derivadas del estudio de caso. 


\subsection{La Política de Ciencia y Tecnología en México}

Para comenzar, es necesario hablar de lo que antecede a la organización que se ha elegido como estudio de caso: INFOTEC. Ya que al ser un centro público que se dedica especialmente al área de TIC's, pueden surgir preguntas de ¿Cómo? ¿Cuándo? ¿Dónde? Y ¿Por qué se creó? Por lo que es necesario recorrer de manera breve la historia que le precede, esto, con la finalidad de entender algunas cuestiones de porqué INFOTEC ha tenido diferente matices organizacionales a través de su historia.

En este sentido, la aceptación de la ciencia y tecnología en México comienza cuando en el plano Internacional, por la década de los 60's y 70's empieza a crecer la preocupación por parte de organismos internacionales como la Unesco y la OEA para que en América Latina se concibiera a la ciencia y tecnología (CyT) como un instrumento para el progreso (Casas: 1999).

Esto pudo haber sido producto, quizá, según una hipótesis de la autora de este trabajo, una consecuencia del movimiento organizacional conocido como la teoría de la contingencia ${ }^{19}$. Woodward encontró una relación directa entre el avance tecnológico y el cambio en la estructura de la organización. Por lo que, con los cambios que iban sufriendo las organizaciones en aquellas épocas, era necesario adoptar algún o algunos instrumentos que pudieran ayudar a las mismas a permanecer en el ambiente.

\footnotetext{
${ }^{19}$ A través de estudios empíricos Woodward, Pugh, Lawrence y Lorsch, entre otros, con la intención de responder a dos preguntas que caracterizan a esta teoría: qué tipo de variables afectan las características de las organizaciones y hasta qué punto, y cuál es la influencia de esas características en el grado de cumplimiento de las organizaciones (Crozier: 1990).
} 
Por lo tanto, en México, a partir de los sesenta, y con base en Almada y Cruz (1994), algunas bibliotecas universitarias y especializadas y centros de documentación fueron los primeros que utilizaron los desarrollos tecnológicos que iban surgiendo para acelerar el procesamiento, el acceso y la transferencia de la información, con objeto de poner al servicio de los científicos y profesores mexicanos, los avances científicos y tecnológicos que aparecen en diversas publicaciones especializadas. Además se creó un centro de documentación latinoamericano financiado por la SEP y la Unesco.

En el plano internacional, el concepto de políticas de Ciencia y Tecnología (PCyT), surge principalmente como consecuencia de las guerras que se habían suscitado en el mundo. Estas necesidades tecnológicas generadas por la guerra se constituyeron en un factor determinante en la institucionalización de estas políticas y en la creación de organismos y mecanismos dirigidos al desarrollo de la investigación científica y a la aplicación de los resultados derivados de ella. Para los años cincuenta varios países desarrollados habían comenzado el proceso de establecimiento de alianzas (Casas: 199:151)

En México y en otros países en desarrollo, la planeación de CyT es relativamente joven. Antes de 1970, en las esferas gubernamentales no habían considerado la importancia que la CyT tiene para lograr el desarrollo. Por motivos de política económica, se creía más conveniente continuar con la política de sustitución de importaciones que hasta esa fecha estaba vigente, ya que se creía que era mejor importar los conocimientos científicos y técnicos del exterior que generarlos 
internamente. Manteniendo así, un avance mínimo en el sector de tecnologías y en I\&D (Márquez: 1982)

Como respuesta a la presión de la OEA, de la UNESCO y por parte de la comunidad académica, y de las pláticas que tenía el comité ${ }^{20}$ seleccionado para crear un documento formal en el cual estuvieran plasmados los objetivos de la CyT en México, a finales de los años sesenta, el gobierno de la República, en ese entonces presidido por el Presidente Gustavo Díaz Ordaz se preocupó porque la investigación en el país tuviera promoción y estimulación, así como desarrollo y coordinación.

La Declaración Conjunta de los Presidentes de América en Punta del Este, tenía como finalidad la discusión sobre reflexionar acerca de la grave situación de desarrollo científico y tecnológico que, para ese tiempo, mostraba una gran preocupación por la falta de vinculación entre la investigación científica y tecnológica de los flujos económicos de la nación en forma coordinada y sistemática.

Durante los meses de abril a junio de 1969 se realizaron numerosas reuniones por parte del comité, en el cual, el principal objetivo era crear una Política Nacional y Programas de Ciencia y Tecnología que empezara a operar en $1970^{21}$ para formular los programas que coadyuvaran al desarrollo del país. Las principales

\footnotetext{
${ }^{20}$ De acuerdo al documento de РСуТ de 1970, los organismos que se presentaron en la mayoría de las reuniones fueron los siguientes: Instituto Nacional de la Investigación Científica, Secretaria de Educación Pública, Secretaria de Salubridad y Asistencia, Universidad Autónoma de México, Instituto Politécnico Nacional, Instituto Mexicano del Petróleo, Instituto de Investigaciones de la Industria Eléctrica, Comisión Nacional de Energía Nuclear, Instituto de Investigaciones Tecnológicas, Instituto de Seguridad y Servicios Sociales de los Trabajadores del Estado, Centro Nacional de Productividad, y Academia de la Investigación Científica, A.C.

${ }^{21}$ Revisar los lineamientos de la Política Nacional y Programas de Ciencia y Tecnología de 1970
} 
causas que ayudaran a la creación de organismos que se ocuparan del tema son de índole política, social, económica, etc., como se muestra en la tabla 9:

Tabla 9. Causas que favorecieron a la creación de Organismos Públicos de Ciencia y Tecnología en México

\begin{tabular}{|c|l|}
\hline Problema & \multicolumn{1}{|c|}{ Característica } \\
\hline Social & $\begin{array}{l}\text { Se requería atender el fenómeno más } \\
\text { importante de esa época: el gigantesco } \\
\text { desarrollo de la ciencia y su impacto sobre } \\
\text { el progreso de la humanidad }\end{array}$ \\
\hline Científico & $\begin{array}{l}\text { Resalta el desigual movimiento de la } \\
\text { investigación en las diferentes regiones del } \\
\text { mundo, causa principal de que la distancia } \\
\text { separe a los países en vías de desarrollo. }\end{array}$ \\
\hline Político & $\begin{array}{l}\text { La investigación científica no puede } \\
\text { concebirse aislada de la estructura social, } \\
\text { económica, cultural y política de una } \\
\text { nación. }\end{array}$ \\
\hline Investigación & $\begin{array}{l}\text { Debe concebirse la investigación como } \\
\text { fuente generadora de superación, } \\
\text { científica, tecnológica y humanística dentro } \\
\text { del marco político, económico, y social } \\
\text { mexicano que propugna por la superación } \\
\text { individual, la libertad personal y el bienestar } \\
\text { colectivo. }\end{array}$ \\
\hline Económico & $\begin{array}{l}\text { El bajo monto de recursos financieros } \\
\text { destinados a la investigación respecto a lo } \\
\text { que requiere el desenvolvimiento adecuado } \\
\text { del país. }\end{array}$ \\
\hline
\end{tabular}

Fuente: Elaboración propia con base en Programa Nacional de Ciencia y Tecnología de 1970

Es importante señalar, que las políticas de CyT han tenido diferentes matices en su contenido a causa del contexto y de las autoridades del poder ejecutivo en 
diferentes momentos. De acuerdo con Casas (1999), la transición de la PCyT en México ha sido en cinco etapas.

Tabla 10. Etapas de transición de la política de CyT en México

\begin{tabular}{|c|c|}
\hline Etapa & Características \\
\hline \multirow{3}{*}{ 1934-1950 } & $\begin{array}{l}\text { Primeros indicios de preocupación del } \\
\text { gobierno por impulsar asuntos científicos. }\end{array}$ \\
\hline & $\begin{array}{l}\text { La ciencia como solucionadora de } \\
\text { problemas. }\end{array}$ \\
\hline & Formación de la cultura académica. \\
\hline \multirow{3}{*}{$1960-1980$} & \multirow{3}{*}{$\begin{array}{l}\text { Mayor interés del Estado mexicano por } \\
\text { actividades científicas y tecnológicas. } \\
\text { La investigación tuvo un crecimiento } \\
\text { considerable. } \\
\text { Se crearon centros Públicos de } \\
\text { Investigación en CyT. }\end{array}$} \\
\hline & \\
\hline & \\
\hline \multirow[t]{2}{*}{$1980-1990$} & $\begin{array}{l}\text { A consecuencia de las políticas } \\
\text { proteccionistas y de una economía cerrada, } \\
\text { el desarrollo de actividades científicas no } \\
\text { tuvo auge. }\end{array}$ \\
\hline & $\begin{array}{l}\text { CONACYT crea el Sistema Nacional de } \\
\text { Investigadores. }\end{array}$ \\
\hline \multirow{3}{*}{ 1990-1995 } & $\begin{array}{l}\text { Etapa de modernización educativa, } \\
\text { científica y tecnológica. }\end{array}$ \\
\hline & $\begin{array}{l}\text { La iniciativa privada mayor promotor y } \\
\text { financiador de ciencia. }\end{array}$ \\
\hline & $\begin{array}{l}\text { Comercialización de la investigación y la } \\
\text { academia. }\end{array}$ \\
\hline \multirow[t]{2}{*}{ 1996- principios siglo XXI } & 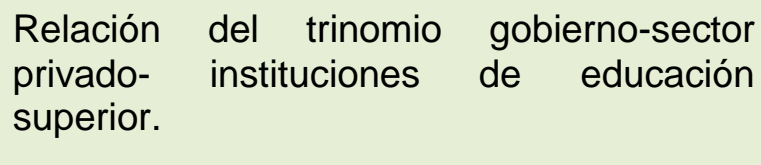 \\
\hline & $\begin{array}{l}\text { La industria privada empieza a jugar un } \\
\text { papel importante en las decisiones de CyT. }\end{array}$ \\
\hline
\end{tabular}

Fuente: Elaboración propia con base en Casas (1999: 154:164) 
Como se puede ver en la tabla 10, la regulación en CyT ha sufrido constantes cambios, sobre todo en el objetivo de su creación. En un principio se creó como un regulador para el crecimiento económico del país, pero, conforme pasaron las décadas y las nuevas gestiones gubernamentales tenían diversos intereses, se fueron incrementando actores que también buscan beneficiarse de la РСyT. Sin embargo, hasta la fecha dicha política no ha perdido la esencia de estimular el desarrollo científico y tecnológico.

\subsection{CONACYT y los Centros Públicos de Investigación}

Después de haber creado la Política en Ciencia y Tecnología en México, se buscó la creación de un organismo que regulara las participaciones de las instituciones que se dedicaban a la ciencia y tecnología, así como proveer de capital humano especializado para la competitividad del mercado de investigación y tecnología. Asimismo, se estaba gestando el auge de las tecnologías que estaban revolucionando la forma de procesar y compartir información de manera diferente a la que los investigadores, empresarios y académicos acostumbraban hacerlo.

De acuerdo con Márquez (1982) CONACYT es uno de los organismos que surgen gracias a la aprobación del Programa Nacional de Ciencia y Tecnología en 1970. Fue concebido en primera instancia como institución tanto de carácter consultivo como de fomento para asesoría del Gobierno en materia de Ciencia y Tecnología. Este organismo público tiene como función principal la investigación y desarrollo 
tecnológico, mejoras a procesos, maquinaria, desarrollo de prototipos y formación de capital humano.

Entre los lineamientos generales de la operación de CONACYT, se establece que debe existir la fijación de un patrón de desarrollo científico y tecnológico propio, para ello debe formar niveles de excelencia científica en las áreas de interés nacional, y libertad de decisión en la búsqueda, selección, negociación, asimilación, adaptación y generación de tecnología. Se señala que para que la СуT participe activamente en el desarrollo del país, la política respectiva perseguirá como objetivo global el desarrollo científico, la autonomía cultural y la autodeterminación tecnológica (Márquez: 1982: 85).

A partir de 1975 se elabora el primer presupuesto nacional de СyT, con el fin de que CONACYT adquiera la capacidad para tomar decisiones independientes y establezca objetivos en dicha materia de desarrollo científico y tecnológico. Para cumplir con esto, se creó un sistema de becas nacionales y también para estudiantes en el extranjero. Así como la inserción de 39 ramas $^{22}$ de la ciencia para la aplicación del desarrollo e investigación en ciencia y tecnología.

Por tanto, se iniciaría una oleada de desarrollo, la cual necesitaba mano de obra calificada, así como centros especializados donde desarrollar y aplicar investigación; por lo que años después fue necesario la creación de nuevos centros públicos de investigación en México, para proporcionar un lugar

\footnotetext{
22 Investigación básica: física, química, matemáticas y biología. Investigación orientada: alimentación, agropecuaria y forestal, salud, ciencias del mar, ecología, ciencias de la Tierra, meteorología, informática, ciencia espacial, y ciencias sociales, entre otros (Márquez:1982: 90)
} 
especializado donde los investigadores aportarán sus conocimientos en el progreso de la ciencia y tecnología.

Los centros públicos de investigación ${ }^{23}$ (CPI) fueron creados en 1992 como resultado de la reformulación de la Ley Orgánica de la Administración Pública Federal que asignó a la Secretaría de Educación Pública (SEP) y al CONACYT al ser responsable del desarrollo científico y tecnológico del país. En 2002, al separarse este Consejo de la SEP, este sistema adquirió la nomenclatura que lleva en la actualidad.

El Sistema CPI Conacyt es uno de los más relevantes actores de la generación de conocimiento en México. Representa una importante opción para la formación de investigadores de alto nivel y tiene una gran incidencia en las estrategias de desarrollo sustentable del país ya que su acción está permanentemente vinculada a las necesidades regionales de la nación. Su principal misión es impulsar el bienestar de la sociedad a través de la generación de conocimiento.

Los objetivos que tienen los CPI unen a las esferas más importantes de la creación de conocimiento en el país, porque tienen un interés en común: el progreso. Por eso es, que académicos, empresarios y políticos, buscan aplicar estos conocimientos en pro de la sociedad. Ese objetivo en común, es lo que ha mantenido en fechas recientes la existencia de estos centros.

Sus funciones operativas son las siguientes ${ }^{24}$ :

\footnotetext{
${ }^{23}$ Datos obtenidos del portal de Centros Públicos de Investigación www.mexicocyt.org.mx ${ }^{24}$ Ibídem
} 
- Investigación científica básica y aplicada, innovación científica y desarrollo tecnológico.

- Producción científica de alto nivel vinculada a las necesidades regionales con especial incidencia en las estrategias de desarrollo sustentable del país.

- Formación de académicos, científicos, tecnólogos y en general profesionales de alto nivel de pre y posgrado.

- Vinculación entre los sectores público y productivo, con particular interés en las pequeñas y medianas empresas.

- Innovación en la generación, desarrollo y aplicación del conocimiento científico, humanístico y tecnológico altamente competitivo en el contexto nacional e internacional.

- Asistencia en innovación y desarrollo tecnológico al sector productivo para potenciar la competitividad de México en el mundo.

- Extensión académica orientada a empresas, gobiernos y organizaciones de la sociedad.

Sin lugar a dudas, la creación de los CPI es una muestra de organizaciones que han sido fruto de la modernización del país en cuestión de desarrollo en ciencia y tecnología. Y, además, la heterogeneidad de las ciencias ha permitido que estos centros puedan especializarse en alguna disciplina en particular. Existen 16 centros, 4 colegios, 4 institutos, 2 fideicomisos y una sociedad anónima. Las instituciones aliadas al Sistema son un colegio y una facultad. A continuación se señalan algunos ${ }^{25}$ de acuerdo al tipo de subsistema al que pertenecen.

\section{Subsistema de Ciencias Sociales y Humanidades}

\section{ब.}

CIDE CIDE. Centro de Investigación y Docencia Económica, A.C.

CIESAS. Centro de Investigaciones y Estudios Superiores de Antropología Social

\section{Subsistema de Ciencias Exactas y Naturales}

${ }^{25}$ Ídem 
CIAD. Centro de Investigación en Alimentación y Desarrollo, A.C.

IPICYT. Instituto Potosino de Investigación Científica.

\section{Subsistema de Desarrollo Tecnológico y de Servicios}

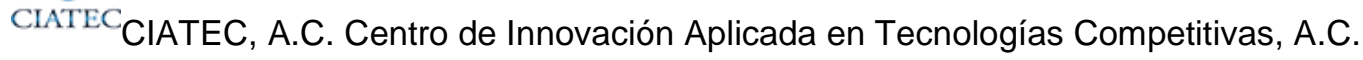

Infợ INFOTEC. Fondo de Información y Documentación para la Industria.

Al presentar los principales CPI en el país, es significativo recordar que el estudio de caso se realiza en una organización que pertenece a un CPI, y en lo particular al Subsistema de Desarrollo Tecnológico y de Servicios: INFOTEC. Es un Fondo de Información y Documentación para la Industria; lo que puede sugerir que su objetivo es el procesamiento de datos. Sin embargo, posteriormente se analiza que ha tenido varios cambios en su objetivo desde su origen, sobre todo en la introducción de servicios de información tecnológica.

\subsection{El Infotec y los servicios de información científica y tecnológica}

Hasta el momento solo se ha dicho que Infotec es una organización que se encuentra clasificada en el sector tecnológico, pero, como también ya se ha señalado es hoy en día en un centro de información. Como se presenta en las próximas líneas, se notará que combina la información con las tecnologías, por lo que, su principal área de estudio son las tecnologías de la información. Pero, ¿cuál el origen de los servicios de información científica y tecnológica en México?

La era de las tecnologías de la información y comunicación cobran importancia en la década de los 60's, donde algunas bibliotecas universitarias y especializadas y 
centros de documentación fueron los primeros que utilizaban los desarrollos tecnológicos que iban surgiendo para acelerar el procesamiento, el acceso y la transferencia de la información, con objeto de poner al servicio de los científicos y profesores mexicanos, los avances científicos y tecnológicos que aparecen en diversas publicaciones especializadas. En México, se creó un centro de documentación latinoamericano financiado por la SEP y la UNESCO (Almada: 1994:684).

Uno de los objetivos de los años setenta y la creación de la PCyT, era agilizar la recepción de información proveniente principalmente de bibliotecas de Estados Unidos y de la biblioteca Británica. El propósito era acelerar el desarrollo científico y tecnológico nacional. Para esas fechas ya se hacía uso de las TIC's en el país principalmente las computadoras en la administración pública y en las universidades. Lo anterior propició que se crearan centros de información tanto en el sector privado y público ${ }^{26}$.

Para 1974 CONACYT instaló una computadora con tecnología de red que sirvió de canal de comunicación a múltiples instituciones mexicanas. Con esa infraestructura y la creación de la red TELEPAC (Red Pública de Transmisión de datos) en México, para el año de 1976 la operación formal del CONACYT del servicio denominado servicio de consulta a bancos (SECOBI) ofrecía acceso a bancos de información científicos y tecnológicos con disponibilidad internacional.

\footnotetext{
${ }^{26}$ Organizaciones como el Instituto Mexicano del Petróleo (IMP), el Centro de Información Científica y Humanística $(\mathrm{CICH})$ de la UNAM, el Consejo Nacional de Ciencia y Tecnología (CONACYT) y la Secretaría de Salubridad y Asistencia (SSA) fueron las primeras en comunicarse a servicios incipientes de anfitriones de diversas bases de datos situados en los Estados Unidos (Almada: 1999: 686:687).
} 
De esta forma se ampliaron las posibilidades de acceso a la información científica y tecnológica para usuarios de diversas instituciones. Sin embargo, no bastaría con esa modalidad, sino que la creación de otros centros de información como INFOTEC creado por CONACYT, ofrecerían servicios de información, no solamente a usuarios de sus instituciones sino a terceros, utilizando las tecnologías de información que estaban a su alcance (Almada: 1994:687:688) y que en esas fechas comenzaban a hacer una carrera de automatización. En ese sentido, la organización de estudio toma un papel importante en el desarrollo de las TIC's en México, y sobre todo permite estudiarla a partir los cambios que ha tenido a lo largo de su historia.

Como bien se ha señalado, todos los centros públicos de investigación tienen su propia historia. $Y$ tienen una orientación por el desarrollo y la investigación de manera distinta entre sí aunque pertenezcan al mismo subsistema. Esta situación permite reflejar que al menos, la propuesta de la creación de una política en ciencia y tecnología ha servido para la reproducción de los CPI y su vigencia.

También como ya se ha dicho, el desarrollo de las tecnologías de la información ha sido un fenómeno relativamente nuevo, que al tener contacto con la organización; produce un cambio dentro de ella, ya sea en toda la dimensión organizacional o sólo en una parte de ella. Por eso, es que a pesar de que han pasado más de cuatro décadas desde la aparición de las TIC's en el mundo, y casi tres décadas desde su aplicación en México sigue causando controversia porque 
es una tecnología en constante innovación, lo que por ende genera cambios también en la organización.

Este pequeña controversia, coloca en un papel trascendental a Infotec, ya que ha sido una organización que desde sus inicios ha tenido a las TIC's como protagonista de su crecimiento y desarrollo. $Y$ aunque parezca atrevido decirlo, dicha organización ha cambiado varios de sus elementos organizacionales para conjugar su papel de CPI y de especialista en venta de servicios en tema de tecnologías de información.

Se ha hecho mención en el apartado anterior, que para realizar el estudio de caso y el análisis de los datos, fue necesario presentarse en las instalaciones de Infotec para visitar al contacto de la organización y realizar las entrevistas. Sin embargo, estar físicamente en el lugar, permitió observar y tomar nota de la dinámica que se realiza en la cotidianidad, así como ver elementos de la cultura organizacional. A continuación se hace un breve relato de cómo fue la primera visita a Infotec.

El primer elemento de la cultura organizacional de Infotec que permite entender porque era necesario presentar un gafete y hacer girar un torniquete en la entrada y salida, es el ritual. Para Hofstede los rituales son actividades colectivas, técnicamente superfluas para alcanzar los fines deseados, pero que, dentro de una cultura, son considerados como socialmente esenciales: por lo tanto, se llevan 
a cabo por su propio bien. Las formas de saludo y el pago respecto a los demás, las ceremonias sociales y religiosas son ejemplos de rituales. (Hofstede: 1980:8)

En este caso, el ritual inicia desde el momento en que una persona quiere tener acceso al Infotec: "mientras se esperaba en la recepción de la organización a que llegara el contacto para que diera el acceso al interior de Infotec, se pudo observar como algunas personas que laboran en dicha organización, pasaban por el torniquete de salida, siempre posicionando su gafete en un aparato que estaba pegado en la pared que al leer el chip que contenía el gafete hacía que tronara el torniquete en señal de que ya podía pasar, este mismo procedimiento era para la entrada, así cualquier persona con gafete podía salir y entrar cuantas veces quisiera. Estos gafetes son de color, amarillo, azul, o rosa, porque cada uno indica el piso al que pertenecen, y si es trabajador o visitante la persona que entra o sale.

Otro aspecto cultural, es la presencia de los artefactos, en este caso, son los gafetes de colores, el detector de metal, la revisión de tecnologías ajenas a la organización. Ya que, de acuerdo con Schein, los artefactos culturales son fenómenos observables y productos visibles, como la arquitectura del ambiente físico, lenguaje, tecnología. Incluye también el comportamiento visible del grupo y los procesos organizacionales que los convierten en rutinas (Schein: 1997:17).

Cuando el trabajador o visitante pasa el torniquete de salida, el/la vigilante pasa un detector de metal, y además pregunta si llevas equipo de cómputo como lap top, disco duro, tableta, etc. Sí cualquier persona lleva equipo de cómputo, entonces 
el/la vigilante procede a anotar el número de serie en un cuaderno para que a la salida cuando registren a la persona corroboren que el equipo con el que entró es el mismo con el que va de salida. Este procedimiento es de rutina y no importa que la misma persona entre o salga 20 veces al día, porque esas mismas veces será revisado.

El ambiente físico y la distribución de la arquitectura, como se muestra a continuación en el relato, también son artefactos que inciden en el comportamiento de los empleados de Infotec : algunas personas que salían, atravesaban la puerta principal y se sentaban en las jardineras a platicar con algún otro compañero o a fumar, porque dentro de las instalaciones no está permitido encender cigarros; otros, salían a comprar algo de comida y podían entrar con ella a las instalaciones o bien quedarse en la jardinera a degustarla o hablar por celular al mismo tiempo.

En la planta baja se observa al fondo una cafetería pequeña, de lado derecho el área de posgrados junto con una sala de espera con sillones muy cómodos, y un baño para caballeros. De lado izquierdo una sala grande con muchas computadoras y un baño amplio y muy limpio para damas. Hacia el sótano había dos mesas con sombrilla y asientos de madera, una pequeña jardinera y acceso al estacionamiento.

En el primer piso había muchas oficinas algunas más grandes que otras, con puertas transparentes, el centro de datos al que sólo tienen acceso las personas de $\mathrm{Tl}$, e igual un baño para damas y caballeros. En el segundo piso hay más oficinas, con cubículos pequeños porque son demasiados, todos con puertas de 
cristal, y una sala grande con computadoras qué es donde se encuentran las personas que dan soporte vía teléfono, también un baño para damas y otro para caballeros, a la misma altura que en los demás pisos.

En casi todas las entradas de las oficinas había pequeñas salas con sillones acolchonados que invitaban a esperar sin impacientar. Cuando el contacto de la organización aparece para dar el acceso al investigador, se procede a realizar todo el ritual para ingresar de la forma relatada. $Y$ así comenzar con el descubrimiento de lo que sucede habitualmente en Infotec".

Infotec tiene una manera de presentarse ante la sociedad, como un centro público de investigación que tiene el fin de ser innovador el área de las TIC's., y quizás esta es la razón por la cual presenta desde su recepción elementos como computadoras, aparatos especiales para el ingreso, recepcionistas con equipo de cómputo y conmutadores, y, su propuesta por reconocer todo el trabajo que han logrado a través de su historia.

Aunque pudiera parecer que Infotec ha tenido el reconocimiento desde siempre, no ha sido así. Por eso, el papel a desarrollar en este estudio de caso es presentar el protagonismo que ha tenido el cambio organizacional, así como las relaciones que tiene este con la apropiación de las TIC's y sus modificaciones en los procesos organizacionales. Para continuar, se requiere conocer un poco de la historia para entender el análisis que se realiza. 


\subsection{Origen de Infotec}

En México, la necesidad de establecer unidades o sistemas para recuperar, manipular, entregar y diseminar información científica y tecnológica se originó en el crecimiento exponencial de la información. Desde los primeros años de la década de 1970, se entendió la urgencia de crear un organismo que concentrara y canalizara toda esa información, pues las actividades productivas se hacían cada vez más intensivas en su necesidad de información científica y técnica, y la satisfacción de esta demanda se consideraba de gran importancia en cualquier proceso de industrialización.

Con este fin surgió, en el seno mismo del CONACYT, el Servicio de Información Técnica (SIT), que a su vez se encontraba integrado en el Servicio Nacional de Información y Documentación. Este servicio se componía de los subsistemas de bibliotecas, centros de documentación, archivos y redes sectoriales de información, de las que el SIT era el núcleo, orientándose principalmente a los servicios de información sobre la industria química, la metalúrgica y las alimenticias, brindando a todas las empresas estadísticas económicas y comerciales para la industria un servicio de información técnica en general ${ }^{27}$.

El Fondo de Información y Documentación para la Industria INFOTEC, es un Fideicomiso Público del Gobierno Federal creado mediante contrato celebrado el 30 de diciembre de 1974, por el Consejo Nacional de Ciencia y Tecnología

\footnotetext{
${ }^{27}$ Revisar el documento institucional INFOTEC: Surgimiento, Evolución y Perspectivas actuales, 2009
} 
(CONACYT), como Fideicomitente, en Nacional Financiera, S. A., ahora Sociedad Nacional de Crédito. (NAFIN), como Fiduciaria ${ }^{28}$.

De conformidad con el Acuerdo de Sectorización expedido el 19 de agosto de 1982, publicado en el Diario Oficial de la Federación el 3 de septiembre del mismo año, el Fondo de Información y Documentación para la Industria, identificado como INFOTEC-CONACYT quedó agrupado dentro de las Entidades de la Administración Pública Paraestatal que integraban el sector coordinado por la Secretaría de Programación y Presupuesto.

Sus actividades, ante todo, se centraron en un programa de enlace industrial, un servicio de pregunta-respuesta y la publicación de un boletín mensual de noticias técnicas. El programa de enlace industrial estuvo diseñado para identificar cuáles eran las necesidades de información técnica de las empresas en la industria manufacturera en México, además de buscar detectar problemas específicos en dichas empresas con el fin de demostrar que Infotec podía ayudar a resolverlos.

El Boletín de Noticias Técnicas que el fideicomiso presentaba de manera mensual tenía por objeto informar a las empresas, en distintas ramas de la industria manufacturera, sobre los acontecimientos tecnológicos de interés. El suscriptor marcaba los artículos de su interés para que Infotec remitiera una copia. Además de estos servicios se iniciaron otros, como el de crear un banco de tecnologías susceptibles de ser objeto de contratos de licencia.

\footnotetext{
${ }^{28}$ Datos proporcionados del manual de organización Infotec, 2009
} 
El contrato se trataba de un registro voluntario de tecnologías desarrolladas o adaptadas por empresas mexicanas con el fin de ofrecerlas y promoverlas en países con niveles de desarrollo similares al de México. Otro de los servicios ofrecidos en aquel tiempo consistía en prestar asistencia a una empresa que deseaba fabricar un producto nuevo en México. Esta ayuda se relacionaba con la búsqueda de la tecnología y que fueran aplicables en el país.

El desarrollo de Infotec constituye la historia de un organismo paraestatal que lucha constantemente por su supervivencia, ya que al ser creado como un fideicomiso para apoyar la productividad de las empresas mexicanas mediante el uso de la información tecnológica y de negocios, su labor ha sido ardua en la búsqueda de innovaciones tecnológicas que puedan ayudar a las empresas a crecer.

De acuerdo con el origen y la historia que ha recorrido la organización que se estudia, Almada y Cruz hacen una aseveración que podría describir de manera general a Infotec, ya que rescatan la mayoría de los objetivos que le dan sentido a la organización y su protagonismo por el uso de las TIC's, además que la principal misión de Infotec ha sido crecer en función de la innovación de las tecnologías de información, así como la incorporación del desarrollo e investigación de tecnologías para el bienestar de la sociedad.

"la evolución continua de una infraestructura de información es un elemento clave para el desarrollo basado en el avance del conocimiento y en su rápida aplicación para el bienestar de la sociedad. Los grandes cambios que en esta década norman cómo nos informamos y comunicamos, se ha dado gracias al vertiginoso desarrollo de las telecomunicaciones de alta velocidad, de la computación y la electrónica que son la infraestructura sobre la que 
fluye la información misma, integran el contenido y el conducto del concepto de información/comunicación/información." (Almada y Cruz: 1994: 683)

Respecto a sus instalaciones fisicas, Infotec se encuentra ubicado en: San Fernando No. 37, Colonia Toriello Guerra, Tlalpan, México D.F., y cuenta con una infraestructura física distribuida de la siguiente manera: en una superficie de 3,345 metros cuadrados. La ocupación de espacios físicos del Centro es de 2,260 metros cuadrados. Cuenta con equipo y software con tecnología de punta para:

$\checkmark$ Desarrollo de proyectos informáticos basados en Internet.

$\checkmark$ Administración y operación de AllS.

$\checkmark$ Operación de servicios de la organización y sus áreas.

\section{Fachada del Edificio de Infotec}

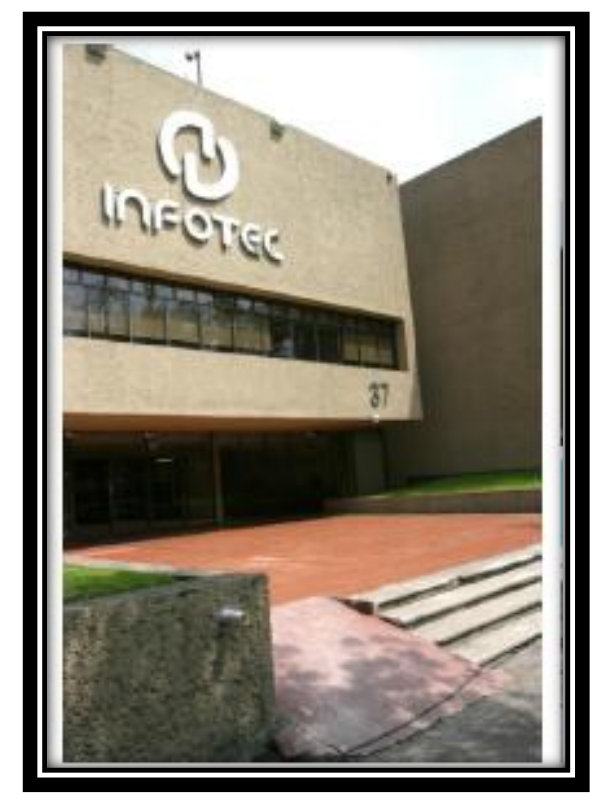

Fuente: Fotografía tomada del Anuario Infotec 2008

Cuenta con una recepción, y áreas de: Administración, Jurídico, Mesa de Servicios, Administración Integral de Infraestructura y Servicios, Oficina de 
Administración de Proyectos, Sistemas de Información Estratégicos, Dirección Ejecutiva, Desarrollo Tecnológico, Innovación, Competitividad, Posgrados, Contraloría Interna, Cinco salas de junta, sala de videoconferencia, dos aulas, aula Magna, aula de colaboración y comedor.

Infraestructura tecnológica de Infotec

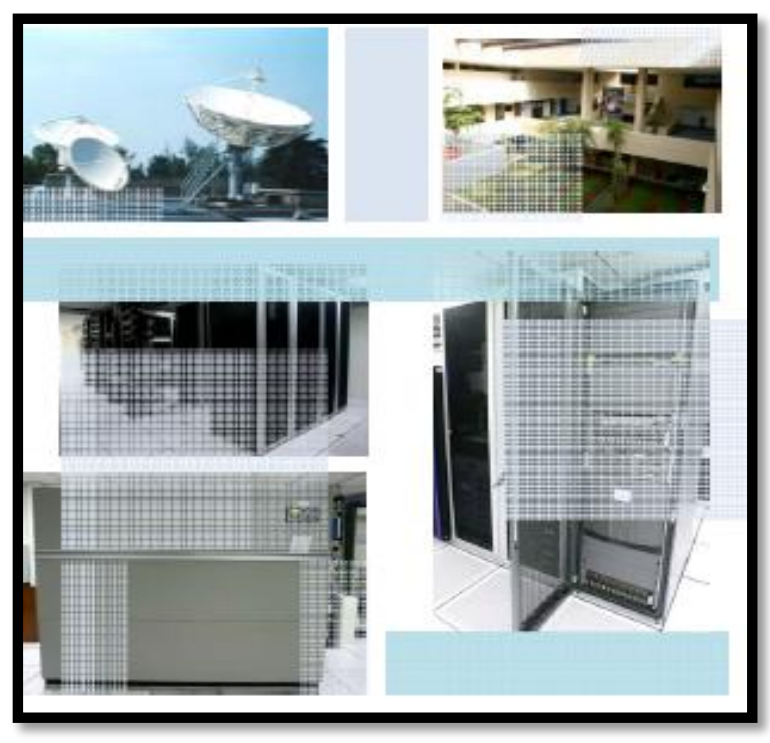

Fuente: Fotografía tomada del Anuario Infotec 2008

Hoy en día es un centro público de investigación, cuyo propósito es realizar tanto investigación aplicada, como innovación y desarrollo en el ámbito de las tecnologías de la información y la comunicación (TIC’s). La principal tarea de INFOTEC es formar recursos humanos especializados, que generen soluciones para mejorar la competitividad de los sectores público, académico, social y privado, por medio de la investigación, innovación y desarrollo tecnológicos, así como modelos y sistemas organizacionales digitales y estratégicos. 
Como institución de gobierno, en Infotec se encuentran comprometidos a ofrecer permanentemente mejores servicios para los ciudadanos. Por lo que apoyan todas aquellas iniciativas encaminadas a mejorar la eficiencia gubernamental de las dependencias públicas y colaborar con otras organizaciones en la adopción de estándares, mejores prácticas y metodologías nacionales e internacionales de reconocida calidad y aplicación exitosa.

Durante los últimos 33 años, el Infotec ha contribuido a través de su experiencia y especialidades en la planeación de sistemas gubernamentales estratégicos, en el desarrollo de la estrategia nacional de e-Gobierno, con diversos portales ciudadanos y en el impulso a la creación de ciudades digitales. Además, en los últimos años ha iniciado la incursión en la Investigación y Docencia, lo cual le ha permitido convertirse en un Centro de Servicios Estratégicos en TIC .Mantiene relación con distintos organismos de gobierno en los ámbitos federal, estatal y municipal, así como con instituciones públicas y privadas y con la sociedad en general.

Los servicios que otorga Infotec a los sectores público y privado están soportados por la siguiente infraestructura tecnológica: redes LAN/WAN e inalámbricas; telefonía y videotelefonía IP; tecnologías para usuarios móviles; infraestructura para esquemas de operación en oficinas virtuales; centro de datos de alta disponibilidad; manejo de plataformas de procesamiento; almacenamiento externo para servidores; administración y control de aplicaciones web y bases de datos 
corporativas, seguridad de la información en redes; planes de recuperación de desastres y continuidad; niveles de servicio con enfoque en el negocio.

En 2013 Infotec finiquitó un avance significativo para su organización, y este fue la creación de Infotec Aguascalientes ${ }^{29}$, el cual, es un espacio de alta disponibilidad diseñado para mantener y operar infraestructura de TIC, para gestionar aplicaciones de misión crítica por medio del almacenamiento, procesamiento y transmisión de datos ejecutados en aplicaciones, contenidos y procesos tecnológicos.

Las principales actividades de $\operatorname{Infotec}^{30}$ se resumen en seis puntos, los cuales abarcan desde la parte operativa, científica y de docencia:

1. Realizar investigación científica e innovación y desarrollo tecnológicos en el campo de las tecnologías de la información y comunicaciones, a fin de contribuir a la apropiación y aprovechamiento estratégico de las tecnologías de la información enfocadas a Internet, así como la formación de recursos humanos de alto nivel, especializados en estos campos del conocimiento, para apoyo de los sectores público, académico, social y privado, y promover la competitividad y el desarrollo tecnológico del país, elevar el nivel de vida de nuestra sociedad y facilitar la transición de México hacia la Sociedad de la Información y el Conocimiento;

\footnotetext{
${ }^{29}$ De acuerdo al portal web de Infotec, uno de los objetivos de la Unidad Aguascalientes es brindar mayor impulso a la investigación que se realiza en Infotec a través de la ampliación de las líneas de investigación, la diversificación de los proyectos, el desarrollo tecnológico y de innovación especializados, la generación y transferencia de conocimiento y la formación de personal especializado en el campo de las Tecnologías de Información (TI)

${ }^{30}$ Según lo presenta el Manual de Organización 2009 de Infotec
} 
2. Generar soluciones a través del uso estratégico de las tecnologías de la información y comunicaciones enfocadas a Internet o a otros medios relacionados con las tecnologías de la información y las telecomunicaciones, con el fin de mejorar la eficiencia, transparencia y competitividad de las empresas y organizaciones de los sectores público, académico, social y privado, a través de actividades de investigación, innovación, desarrollo, consultoría, difusión, formación de recursos humanos y servicios especializados, intercambio y alianzas tecnológicos a nivel nacional e internacional;

3. Ser un Centro Público de Investigación, desarrollo, adopción, comunicación, transferencia y administración de conocimiento de las áreas de las Tecnologías de la Información, con autonomía de decisión técnica, operativa y administrativa, en los términos establecidos en la Ley de Ciencia y Tecnología;

4. Ser un Centro que genere sus propios recursos a través de la aplicación competitiva y uso estratégico de tecnologías de la información y las comunicaciones aprovechando el Internet, mediante un modelo de negocios competitivo que contribuya a su sustento financiero;

5. Planear, organizar y proporcionar soluciones integrales a los proyectos de los usuarios de sus servicios y celebrar contratos, convenios y/o alianzas con instituciones del sector público, académico, social y privado, nacionales y extranjeras, para el desarrollo de proyectos y tecnologías de vanguardia, que conduzcan a la evolución y mejora continua de las organizaciones de esos sectores; y 
6. Llevar a cabo las acciones para el cumplimiento de sus fines, a través de procesos que se encuentren enfocados a la mejora continua, a la satisfacción del cliente, a la capacitación especializada y al beneficio social, así como al uso racional de los recursos.

El cumplimiento de estos fines se realiza a través de la concordancia de sus objetivos, así como de la misión y visión que cambian de acuerdo a la gestión en que se encuentre la organización, pero también dependiendo del cambio organizacional por el que atraviese la institución. Por eso, es que antes de analizar en detalle los datos obtenidos, y de presentar las variables que son relevantes para el estudio de caso, se presenta de manera general, como se encuentra Infotec en la actualidad.

\subsection{Contexto general de INFOTEC}

\section{Cultura Organizacional de Infotec}

Respecto a la cultura organizacional ${ }^{31}$ de Infotec, la ideología en la organización es un vínculo con el empleado que se ha ido forjando a través de los años de vida que tiene la institución. Lo anterior se ve reflejado en la interpretación que le dan al imagotipo, como a los valores institucionales. Siendo, los últimos de carácter de cumplimiento con el trabajo. Lo que puede ser resultado de que por ser un organismo Público descentralizado tiene que brindar beneficios a la sociedad pero también tiene que generar sus propios recursos. Y además, los diversos actores involucrados proporcionan diversas ideologías para el cumplimiento de esos objetivos.

\footnotetext{
${ }^{31}$ Revisar Manual de Operaciones 2009 de INFOTEC
} 
En este sentido, la ideología de Infotec se ha basado en un sistema coherente de creencias, que da explicaciones generales convincentes, a veces míticas de la realidad social; ella justifica el orden social actual o propone metas diferentes, que exhorta a la acción colectiva (Alleire y Firsirotu: 1992: 30). Como se verá en los siguientes elementos de cultura organizacional de la organización, Infotec ha desarrollado elementos que le permiten exteriorizar su ideología, como es el caso del imagotipo.

\section{Imagotipo de Infotec}

En los documentos que se obtuvieron para conocer sobre la historia de Infotec y la información que se ha mostrado hasta el momento, no se encontró una fuente que pudiera esclarecer cuál era el significado de su imagotipo. Aunque a través de una entrevista con un empleado de la organización, pudo conocerse esta información, lo que permitió encontrar que el imagotipo como símbolo es un referente cultural de Infotec.

En este sentido, Alvesson (1992) se refiere al símbolo como una caracterización de cierto tipo de fenómenos organizacionales, como un elemento de función representativa, que siempre representa algo diferente, algo más de lo que es. Es

una herramienta necesaria para combinar experiencias concretas con concepciones abstractas, para crear las bases de manipulación y comunicación. Como se verá, estos elementos los describe la persona entrevistada:

"El imagotipo está conformado por dos elementos simétricos, idénticos que forman visualmente un círculo incompleto. Las formas redondas nos remiten a lo orgánico y resalta el lado humano del Infotec. Las dos formas simétricas están en comunicación, 
están en intercambio tanto interno, como externo. Esto refuerza la idea en abstracto de la organización digital: un círculo humano dinámico en el cual entra y sale conocimiento facilitando la innovación y generación de ideas. Es un símbolo limpio, simple, con un alto grado de impacto visual lo que permite que se grabe en la mente del espectador. Es innovador en cuanto a su tratamiento gráfico, y de nuevo la forma redonda nos da la idea de un todo, de una oferta integral. Es imposible que el espectador capte todos estos conceptos de una manera razonada de primera instancia porque el símbolo es abstracto, pero si tiene la idea de unidad, de cooperación e interrelación, de lo humano y de lo tecnológico. Se eligió el uso de un elemento abstracto porque se concibe a la tecnología como conceptos abstractos que nosotros aterrizamos en elementos que son más figurativos y representativos de ella, como el teléfono celular, computadoras, chips, fibra óptica, pixeles, etc. Sin embargo todos estos elementos cambian constantemente, surgen nuevos elementos conforme avanza la tecnología, por lo que no sería recomendable utilizar alguno, puesto que limitaría la concepción de la Institución o la reduciría a un elemento que no es el más adecuado. Es sencillo y abstracto, lo cual facilita la retención en la mente del consumidor y también pone al espectador a pensar en ella, lo cual no ocurre cuando los elementos de la imagen son obvios y digeridos. La imagen del Infotec es lo que representa a nuestra institución en el exterior, es la primera impresión hacía el público, y como buena marca se debe de posicionar y quedar en la mente del consumidor, con la intención de que la gente recuerde nuestros productos y servicios a raíz de nuestro logotipo".

\section{Imagotipo de Infotec}

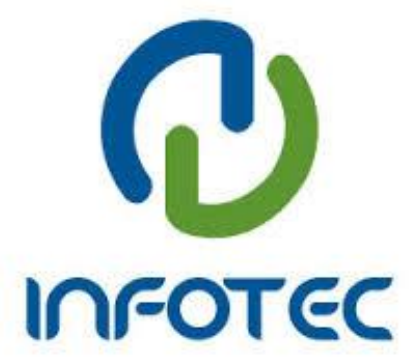

Fondo de Información y Documentación para la Industria INFOTEC

Como se puede notar, el imagotipo de la organización presenta elementos muy notorios que dicen bastante sobre su cultura organizacional, donde se ve 
plasmada su ideología, pero también denota la importancia que le otorga la organización a las TIC's como artefacto cultural que rige a los empleados. EI imagotipo puede considerarse que es concebido como una metáfora, ya que incluye a los individuos que están dentro de la organización como elementos indispensables que contribuyen a darle sentido a los artefactos culturales (TIC's).

Pero también consideran a las personas externas como parte del proceso socioestructural ya que son parte fundamental para la subsistencia de Infotec, por la cuestión de la adquisición de servicios tecnológicos y académicos. Sin embargo, la organización también intenta quedar en la mente del consumidor a través de un software mental, y para lograrlo, ha considerado al imagotipo como parte de ese proceso mental para que los actores relacionados con dicha institución puedan ubicarla por la imagen de los semicírculos abiertos.

Bajo este esquema cultural, la ideología es un elemento representativo de la organización, ya que en una referencia más detallada, Alvesson (1992), señala que es una colección de valores, creencias, descripciones e ideales relacionados y más o menos explícitos. Por lo que, una inferencia de la ideología de Infotec, se propaga mediante los valores que retoman en la misión y visión.

Respecto a la misión y visión, es necesario mencionarlas, ya que como se verá, estas han cambiado sus objetivos a través de los años, en consecuencia de que la ideología ha evolucionado, por lo tanto, tiene que incluir los objetivos necesarios para crear estrategias que les permitan resolver las necesidades tecnológicas que son su principal interés para la organización. 


\section{- Visión 2011-2014}

Infotec es un Centro Público de Investigación, innovación y servicios que hace posible la instrumentación de proyectos clave para acelerar el progreso de México en la Sociedad de la Información y el Conocimiento.

\section{- Misión}

Hacer posible que las organizaciones y las personas se desarrollen mediante el apropiamiento de las TIC.

\section{- Valores}

Los valores institucionales no pueden omitirse, ya que permiten establecer en primera instancia cuál es el papel de la organización en relación al establecimiento y cumplimiento de sus objetivos. Sin embargo, hay que recordar que Schein (1997), señala que los valores compartidos son aquellos que comparten los miembros de un grupo y requieren de validez social. Por lo tanto, de los valores institucionales que se señalan a continuación, como se verá en el análisis de los datos, hay valores que se destacan por ser parte de la ideología de los empleados.

Colaboración: Es la capacidad de sumar nuestro talento dentro y fuera de la organización, y una excelente forma de crear y añadir valor.

\footnotetext{
${ }^{32}$ La misión, visión y valores han sido retomados de la página web de Infotec, lo que permite entender que se han establecido en tiempos actuales.
} 
Confiabilidad: Es la capacidad de cumplir con lo prometido en tiempo y forma, lo cual implica credibilidad, respeto, justicia e igualdad de oportunidades en todos los campos.

Compromiso: Es la capacidad de cumplir con los resultados planteados, tomando en cuenta las condiciones y obligaciones que implican para la institución y las personas. Es una parte integral de la forma en que las personas actúan con convicción en su relación con la Institución.

Transparencia: Cualidad de compartir y revelar con honestidad la información que poseemos mientras caminamos hacia la consecución de los objetivos y respetando las reservas legales

Innovación: Como valor de nuestra organización es la capacidad de idear, diseñar, experimentar y construir nuevas prácticas, procesos, productos y estructuras capaces de crear valor e implantar con éxito soluciones a retos. ${ }^{33}$

De acuerdo a los valores que la organización establece, se puede notar que la construcción de su cultura organizacional se basa tanto en estructuras materiales como en el sistema social, que recae principalmente en los valores y creencias. En este aspecto se visualiza a la innovación como un concepto clave para el cumplimiento de los objetivos a través del compromiso y comportamiento de los empleados. Este suceso será evidenciado en el apartado de análisis.

\section{Estructura organizacional de Infotec}

\footnotetext{
${ }^{33}$ Revisar portal de Infotec www.infotec.com.mx
} 
Como se mencionó al inicio de este apartado Infotec que se creó en los años setenta a partir de CONACYT que es una Institución Pública, cuando fueron evolucionando distintas apreciaciones cada vez más contrastadas, respecto a la burocracia tradicional, se plantea la idea que no es posible establecer una estructura organizativa universalmente eficiente sin tomar en consideración el impacto del entorno y en esencial su potencial incertidumbre. A tal efecto, Infotec comienza de manera categórica a considerar los factores contextuales como elementos críticos en su estructura organizacional.

Esta estructura basada en la teoría contingente, la cual afirma que el diseño de la organización y la maximización de su desempeño vienen dados por el ajuste entre las variables estructurales, actores internos y vinculados al entorno. Dicha teoría toma la visión de que esos factores determinan la naturaleza de los diseños y los procesos organizativos con lo cual busca comprender el funcionamiento de una organización bajo diversas condiciones y desarrollar por consiguiente, los modelos estructurales y de diseño óptimos para cada caso.

Según el Manual de Organización 2009 de INFOTEC, cada área jerárquica tiene su propio objetivo en específico y función, existe una dirección adjunta para cada área, al menos una gerencia, y subgerencia. Su ápice estratégico se conforma por la dirección ejecutiva, la dirección adjunta de administración, la dirección adjunta de desarrollo tecnológico, la dirección adjunta de competitividad, la dirección adjunta de innovación y conocimiento y la dirección adjunta de administración de proyectos.

Figura 17. Organigrama de INFOTEC del período 2009-2011 


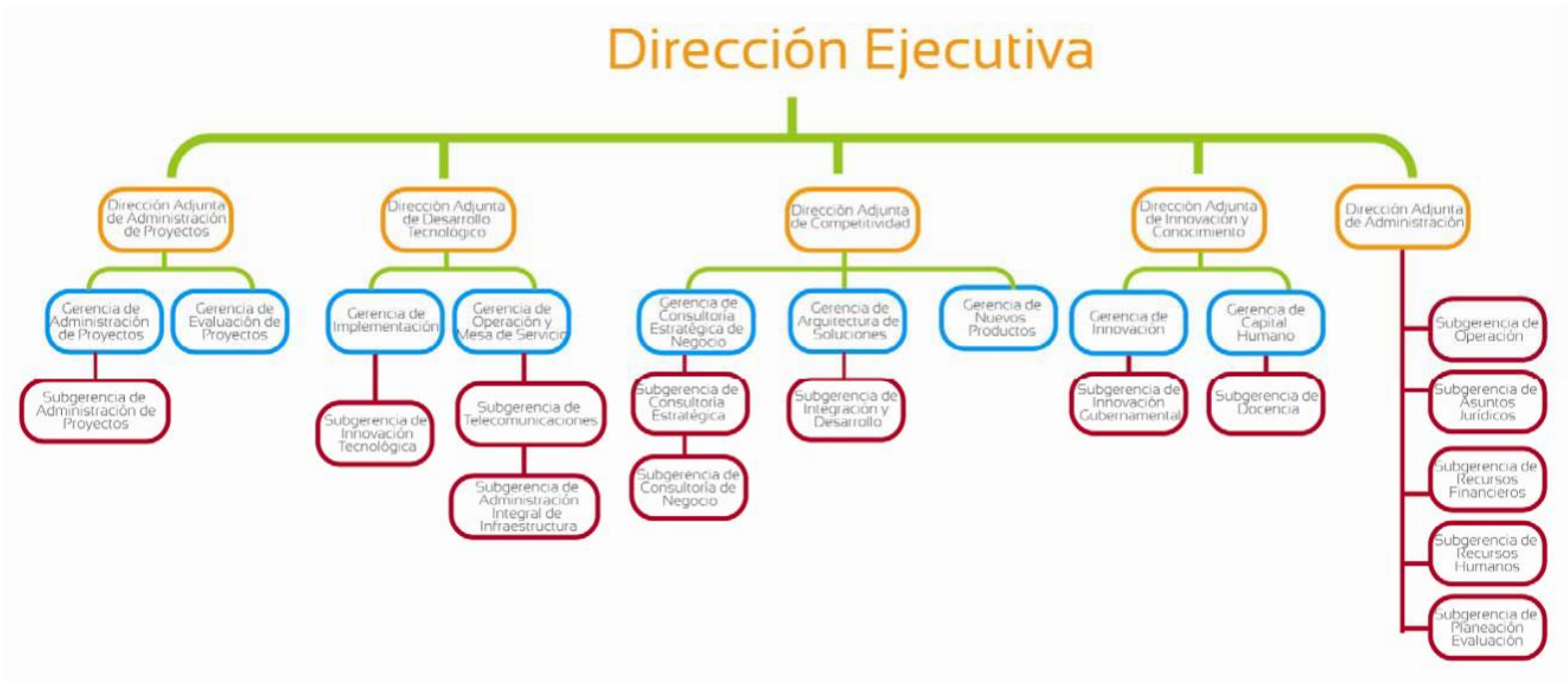

Fuente: Anuario de INFOTEC 2009

Como se muestra en la figura 17 , en general organigrama de Infotec resalta que tiene una estructura orgánica porque no se especializa en una sola tarea, y a pesar de que hay un director ejecutivo, solo representa la autoridad formal para la organización, ya que todas las áreas tienen libertad para la toma de decisiones. Específicamente tiene una estructura divisional por la diversificación de áreas y la descentralización de poder para la toma de decisiones.

Su estructura, en un sentido formal, de primera instancia parece una burocracia profesional, sin embargo, al analizar la forma en que se desenvuelve el Infotec, resalta la mezcla de adhocracia operativa y administrativa, ya que como menciona Mintzberg (1999), la adhocracia operativa busca innovar para proporcionar soluciones originales a sus clientes, lo que requiere de habilidades especializadas y de equipos de expertos.

Por otro lado, la adhocracia administrativa acomete proyectos para servirse a sí misma, para introducir nuevas instalaciones o actividades, por ejemplo en el caso de Infotec, el desarrollo de tecnologías de información, no es exclusivo para la 
venta a los clientes, sino que también se aplica en la misma institución. En ambos tipos de adhocracia, el poder de la toma de decisiones fluye hacia cualquiera que posea conocimientos técnicos requeridos, independientemente de su posición en la organización.

La capacidad que tiene el Infotec para realizar el proceso de innovación organizacional, le ha permitido ser altamente flexible al cambio en sus distintas formas de organización por las que ha pasado a través de su historia. Este hecho se mostrará en el siguiente apartado.

\section{Cambio Organizacional en INFOTEC}

De acuerdo al contexto en el que se vive actualmente, pudiera parecer un tanto obvio que las organizaciones cambian constantemente con la finalidad de permanecer vigentes. Sin embargo, con base en Skip (2001), las organizaciones se han dado a la tarea de responder a las contingencias que surgen en épocas de alta incertidumbre. Ya sea de manera determinista (adaptación al ambiente) o de manera interdependiente (moldear el ambiente), o generando condiciones para tener cambios evolucionarios, basándose en cambios que van desde un pequeño a un alto impacto para la entidad.

Como ya se mencionó anteriormente, Infotec no ha sido una organización que se haya mantenido estática a través de tiempo, no sólo por los cambios estructurales ni culturales a los que ha sido sometido, sino, también por el cambio de tecnología que ha interiorizado, en consecuencia del desarrollo de las TIC's en México. Por eso es que, como se mostró en la figura 1 en la periodicidad de la vida de Infotec se presentan algunos hechos históricos en el ámbito de las TIC's que han sido 
relevantes para justificar el proceso de innovación organizacional al que ha sido sometido.

Las consecuencias de esto, es que han generado diversos cambios en su misión como CPI, por ejemplo, que surjan nuevas áreas jerárquicas y desaparezcan otras, los cambios en la misión y visión de acuerdo al avance de las tecnologías de la informática, luego de la información y finalmente de la comunicación. Lo interesante de estos cambios percibidos de manera general es conocer como han impactado a la organización y como han resultado en eventos críticos que propician la supervivencia de la organización.

Aunque, como se analizará más adelante. Los cambios que se han generado a través de la historia de Infotec tienen diferentes grados de complejidad, además el cambio organización ocurrido manera diferente en su historia, e impactan en otras áreas de la organización. En este sentido, el cambio tiene diversas aristas que dan lugar a la generación de eventos críticos en dicha organización.

\section{Las TIC's en INFOTEC}

En las sociedades actuales, la mayor parte de los empleos ya no están asociados con la industria de productos tangibles, sino con la generación, almacenamiento y procesamiento de todo tipo de información. Para Infotec, las TIC's deben servir para crear ciudadanos informados que puedan hacer uso apropiado y responsable de la información que llegue a sus manos. Asimismo, estas tecnologías brindan habilidades de investigación, organización de datos y reflexión. 
Las principales tecnologías relevantes para la organización que busca expandir el conocimiento mediante el uso de las TIC's, son: Internet, las listas de correo electrónico, los grupos de discusión o salones de conversación (chat rooms), los webblogs o blogs, las presentaciones con diapositivas, el manejo de software, la fotografía digital y los sitios web educativos. En este ámbito Infotec ha sido el pionero en el tema de gobierno electrónico en México, así como en los conceptos de organización digital y sociedad de la información.

De esta manera, han sido presentadas las variables de estudio en Infotec, aunque, aún no es suficiente para entender de qué manera cobran sentido éstas en los Estudios Organizacionales, por ello, es necesario adentrarse hasta el sentir de los trabajadores y contrastarlo con la parte formal (anuarios) y la teoría revisada para deducir y llegar a encontrar respuestas a las preguntas. No todo es el marco histórico de la organización, la conceptualización organizacionalmente ayudará a saber por qué se presentan tales hechos. Por lo tanto, ahora hay que introducirse al análisis de los datos. 


\section{Capítulo IV. ANÁLISIS DE LOS DATOS}

\subsection{Etapa 1 Análisis de los eventos críticos de Infotec: Hacia la construcción de una organización flexible}

En esta primera etapa de análisis, se pretende hacer una revisión de los eventos críticos que se eligieron para hacer la investigación en el Infotec. Así que, es necesario conocer por qué estos eventos son los que han llamado la atención del investigador y no cualquier otro evento de los muchos que ha tenido en su existir la organización. Es pertinente decir que el eje central de este trabajo es conocer como ha sido el cambio organizacional en relación a la aplicación de las TIC's en Infotec, así como el impacto que pudiera tener en la estructura y en la cultura. Por tanto, se analizan los eventos críticos a partir de lo señalado anteriormente.

- Año 1974. INFOTEC: La consecuencia de un cambio revolucionario

En el año que se creó este CPI, como ya se ha mencionado anteriormente, fue principalmente para desarrollar servicios de información y documentación centrados en la tecnología de la producción. Con el fin único de ser un buscador de documentos de investigaciones de Estados Unidos e Inglaterra. Los empleados se especializaron en realizar búsquedas en bases de datos, así como en establecer relaciones con el cliente para entender mejor sus necesidades.

El surgimiento del Infotec es resultado de un cambio revolucionario que tuvo lugar en primera instancia en el Conacyt. De esa situación se deriva que Infotec haya permanecido sus primeros veinte años de existencia en un periodo de equilibrio (Burke: 2011), con objetivos establecidos, pero sin la intención de generar algún 
indicio de evolución. Como bien lo señala un empleado, la organización sólo se ocupaba de la investigación:

"Su fin principal era la investigación, era como una biblioteca, este... venía una compañía y decía "sabes que, yo necesito saber cómo hacer la leche en polvo, dime los mejores métodos". Entonces Infotec se hacía cargo de la investigación y le entregaba un libro blanco con toda la investigación, con las nuevas tecnologías que había en ese momento, lo bueno y lo malo de lo que estabas haciendo." (Entrevistado D)

Sin embargo, en la etapa de su fundación, la organización no considera que la autosuficiencia fuera relevante, sino que al transcurrir una década, los empresarios eran más exigentes en cuanto la información que este CPI les proporcionaba, ya que exigían indicadores de mercado que les pudiera ser útil para sus empresas y además con mayor rapidez.

Así, de esta manera Infotec tenía una estructura profunda (Burke: 2011), la cual se basaba en una estructura básica, cumpliendo con las características de la estructura jerárquica ${ }^{34}$ mecánica, bajo un esquema de centralización para la toma de decisiones, con limitada especialización del trabajo y con la inclusión de escasa tecnología.

Además, dentro de la organización se tenían que realizar prácticas y trámites administrativos que tardaban largos períodos de tiempo en dar respuesta. Esto coincide con la época en que las organizaciones con estructura burocrática tenían mayor vigencia. Aunado a esto, la toma de decisiones era responsabilidad

\footnotetext{
34 En los registros de la organización, no se han encontrado documentos que permitan conocer específicamente la estructura orgánica de Infotec al momento de su fundación. De acuerdo con uno de los entrevistados, señala que una administración que tuvo la organización, ordenó retirar algunos registros que dan veracidad sobre algunos hechos acontecidos en la organización.
} 
compartida con el Conacyt. Estas características tuvieron consecuencias en la demanda de servicios de sus clientes, y por ende en las finanzas del Infotec.

En el aspecto cultural, la organización, se adaptaba al ambiente social y político. El sistema cultural (Alleire y Firsirotu: 1992) solo se basaba en la ideología en que los empleados debían hacer su mayor esfuerzo para contribuir al desarrollo tecnológico y científico del país. Y el sistema socioestructural sólo se conformaba por las políticas impuestas por el Conacyt, y por las normas y objetivos establecidos de manera formal. Sin embargo, este periodo de equilibrio que tuvo el Infotec se vería afectado por contingencias internas y externas.

\section{Año 1994. El origen de una nueva forma de organización en Infotec}

En el periodo de 1990 a 1994, la Institución evoluciona ofreciendo servicios aislados de consultoría, capacitación e información con incorporación marginal de la tecnología de la información en su oferta, esto como consecuencia, de que los niveles de autosuficiencia caen dramáticamente al perderse la competitividad de sus servicios al estar rezagados de las demandas de las organizaciones mexicanas, lo cual ocasiona una situación financiera institucional comprometida al acumularse dos quiebras técnicas y deudas por cerca de $\$ 20$ millones.

Durante 1994, el Infotec enfrentó un entorno económico complejo, derivado de las repercusiones de la baja de los precios del petróleo en las finanzas públicas y su impacto en la economía. Situación a la que se sumó la inestabilidad de los 
mercados financieros y la consecuente deceleración económica ${ }^{35}$.Lo anterior significó el momento del cambio, un cambio que se hizo necesario y urgente conforme fueron pasando los años, ya que, en este periodo, fue evidente la obsolescencia de las antiguas formas de ver y entender la industria y, por tanto, el rumbo un tanto anacrónico que llevaba la institución.

En esta etapa se comienza a gestar una cultura basada en el pensamiento económico y de competitividad en el mercado. La ideología de los empleados tendría que sufrir un cambio de trabajo burocrático, basado en realizar una tarea específica durante veinte años a empleados polivalentes, que tendrían que compartir esfuerzos y labores. Por otra parte, la estructura mecánica también sufriría un cambio en el número de puestos que tenía como $\mathrm{CPI}$, ahora debían crearse nuevas áreas especializadas, porque se iniciaría un proceso que tendría auge dos años después.

El resultado de esta búsqueda de reinvención financiera, presentaba las primeras muestras de una reinvención, propiciada por un cambio externo, aunque para lograrlo el Infotec tendría que pasar por un proceso de innovación organizacional, dicho proceso resultó en la decisión de vender servicios. Pero, el cambio para la organización derivó en un proyecto que hasta la fecha sigue siendo el motivo de que la innovación sea más que un concepto para la organización.

\section{- Año 1996. Las TIC's y el proceso de innovación organizacional en Infotec}

\footnotetext{
35 Para mayor información revisar Anuario de INFOTEC 1999
} 
En este período de tiempo, la misión de Infotec ya había cambiado, ahora su fin principal era promover las actividades que propiciaran la comunicación y la transferencia de conocimientos científicos y tecnológicos en beneficio de la industria nacional. Por lo que se genera un parte aguas en su historia, ya que el objetivo se basaba en la venta de servicios para obtener los medios económicos para subsistir por sí sola, ya sin el financiamiento de Conacyt.

Por lo tanto, las metas cambiaron, la cultura organizacional se gestó en la apropiación de artefactos culturales que años anteriores no existían, y a su vez, en adoptar nuevos valores que dieran sentido al uso específicamente de las TIC's. Infotec busca trabajar en el desarrollo de sistemas informáticos basados en Internet, administrar y coordinar una red de fibra óptica (RTN) integrada por Instituciones Públicas, Educativas, Privadas y Centros de Investigación.

Se planteó la posibilidad de desarrollar una organización de forma innovadora, única y vanguardista, a través de la incorporación y el aprovechamiento de la Red Tecnológica Nacional (RTN), que en ese momento contaba con una gran infraestructura a escala nacional e internacional. Esta red utilizaba la tecnología de telecomunicación más avanzada de la época y tenía un sistema de información con fuentes y servicios de consulta e intercambio de datos de alto nivel, con más de 15 millones de usuarios en 123 países.

\section{Red Tecnológica Nacional de INFOTEC}




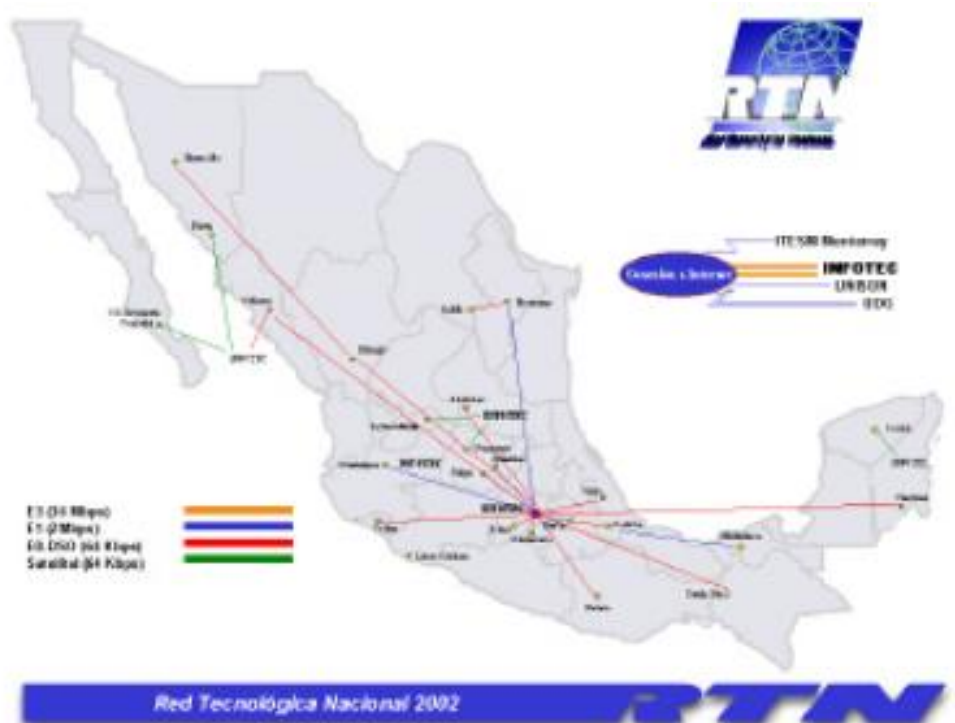

Imagen tomada del Anuario de INFOTEC del 2000

Ahora, el objetivo se concentraba en aprovechar esta nueva herramienta tecnológica para seguir innovando y con ello ser un prestador de servicios en el país. La RTN facilitó grandes cambios en el Infotec, en primera, desde la perspectiva de los objetivos, ahora ya no sólo era un centro público de investigación, sino un prestador de servicios, que además, necesitaba tener retribución económica para su propio sustento.

Así, las tecnologías de Información iban cobrando mayor sentido de apropiación, favoreciendo la innovación tecnológica, de acuerdo al entrevistado: "como te comentaba, cuando empezamos, no había correo electrónico, aquí instalamos lo que es un servidor de correo electrónico, solamente algunas páginas web, algunos sistemas de gestión de tráfico, digo, en realidad fue un crecimiento exponencial en ese momento, ¿Por qué? Porque estábamos hablando de portales web planos y no estáticos, lo más que podías tener era una plantilla de comentarios, de correos, y la verdad es que las TIC's en el Infotec en esa época creció de manera exponencial". (Entrevistado C). El cambio tecnológico al que fue sometido el Infotec, particularmente tuvo un carácter 
reactivo/adaptativo porque buscó responder a los desafíos de permanecer como un CPI, y además de reinventarse por medio del uso de las TIC's.

Para poder lograr este cometido, también había que hacer un cambio en la cultura organizacional, incluyendo nuevos valores que se basaban en la búsqueda de hacer más eficiente las técnicas para generar productos y servicios tecnológicos. Esta situación era nueva para los empleados:

"a nosotros nos dijeron: oigan, tenemos que echarle muchas ganas, tenemos que armar un buen equipo, tenemos que especializarnos, tenemos que ser los mejores, y al final aprender a dar servicios". (Entrevistado $H$ )

Este señalamiento, permite conocer que un sistema colectivo de significados simbólicos (sistema cultural) estaba conjuntándose con los objetivos organizacionales que habían resultado del cambio, y a su vez, se logró modificar la vieja creencia de la estructura mecánica, dando lugar a la estructura flexible. La adaptación a nuevos artefactos que fueron fruto de las contingencias externas que sin lugar a dudas serian parte de la estructura organizacional.

Asimismo, la estructura organizacional no se escapa de este cambio, a consecuencia de la innovación y diversificación que la organización tenía en ese momento, tuvieron que crearse nuevas áreas para poder atender estos servicios, que crecían de manera exponencial de acuerdo a los requerimientos tecnológicos del momento, por lo que el organigrama de la organización después de la aprobación de la RTN se veía así:

Figura 18. Estructura jerárquica de Infotec en 1999 


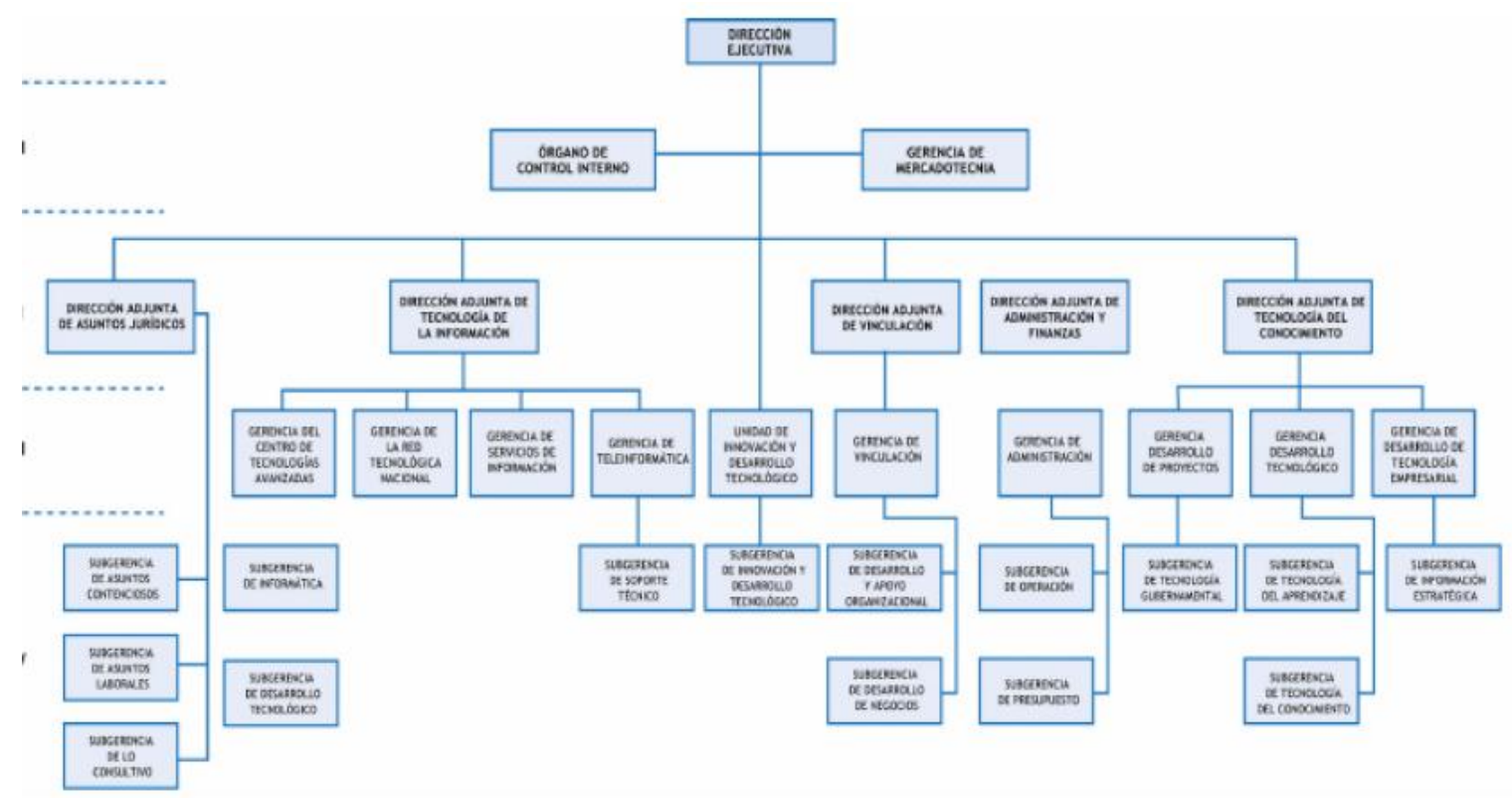

Fuente: Anuario de Infotec año 2000

También, en esta etapa se hace notoria la presencia de la adhocracia administrativa, ya que para el año 2000 La plantilla autorizada del personal de Mandos Medios, Superiores y Homólogos del INFOTEC se integra por 69 plazas de confianza. De estas se encuentran ocupadas 35; las restantes se ocupan de acuerdo a la liquidez que tenga la Institución. La plantilla no básica autorizada de la institución (personal operativo y de apoyo), se encuentra integrada por 103 plazas de confianza, de estas se encontraban ocupadas 41 .

- Año 2008. La innovación en investigación y docencia en Infotec Este periodo también es muy importante para la historia de Infotec, porque una de las características que rigen a la organización innovadora es la tendencia a agrupar a los especialistas en unidades funcionales para los fines de orden interno (Mintzberg: 1999). Sin embargo, se presentaba un cambio más para el Infotec y se trataba de alinear las TIC al fenómeno de la Sociedad del Conocimiento, las 
estrategias, habilidades gerenciales y entendimiento políticas de TIC's, así como aprender de su gestión.

Por lo que el proceso de innovación organizacional, tendría cabida en reinventar las capacitaciones y diplomados que ya se promovían en la organización, pero que no cumplían con el cambio tecnológico y menos con el cambio en la profesionalización del uso de las TIC's. De esta manera, fue necesario generar nuevas plazas de administración de estas nuevas tecnologías, dando como resultado un cambio en el diseño estructural para formar el área de Investigación y Docencia.

\section{MDETIC}

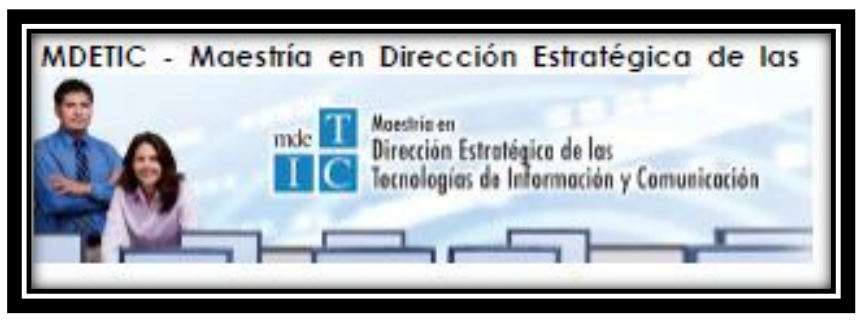

Fuente: tomado del Anuario 2007

Sin embargo, tampoco fue tarea fácil, porque la formalización del área de posgrados fue como consecuencia de un requerimiento del CONACYT, al percatarse de que eran un CPI y no tenían un área de posgrados. Aunque, esto también significó un nuevo cambio para la ideología de la organización, ya que ahora se tenía que pensar en la transmisión del conocimiento también desde la perspectiva académica y de investigación. Estos eventos permitieron que la organización se flexibilizara en cuanto a la gestión de las áreas y las prácticas operativas. 
Al día de hoy, Infotec ya tiene más de 35 años de su aparición, sus proyectos se encuentran más consolidados, las TIC's ya son un reto de innovación y no únicamente de implementación, ha atravesado por varios cambios en las estrategias, en la misión y visión, cambios en la venta de servicios, cambios estructurales como consecuencia de la ampliación de áreas y desaparición o renovación de otras, y además un cambio en la misión al darle espacio a la docencia e investigación. Pero, aún es primordial conocer cómo ha sido este proceso de innovación organizacional en el Infotec.

\subsection{Etapa 2. El comportamiento de las variables organizacionales en la historia de Infotec (período 1974-2008)}

En esta etapa de análisis se busca obtener la mayor interpretación de los datos, haciendo uso principalmente de las herramientas metodológicas descritas en el capítulo anterior, así como su vinculación con el marco teórico que se presenta en la parte inicial de esta tesis. Esta etapa, básicamente se concentra en dar respuesta a las preguntas de investigación y con ello presentar la agrupación de los datos obtenidos por medio de una interpretación de Estudios Organizacionales, de acuerdo como lo indica la tabla 11.

Tabla 11. Eventos críticos para el estudio de INFOTEC y su relación con las variables de estudio

\begin{tabular}{|c|c|}
\hline $\begin{array}{l}1974 \\
\text { Fundación de Infotec }\end{array}$ & $\begin{array}{l}\text { - } \quad \text { Cultura de centro público de información (CPI) } \\
\text { - } \quad \text { Estructura jerárquica mecánica } \\
\text { - } \quad \text { Tecnología informática elemental }\end{array}$ \\
\hline $\begin{array}{c}1994 \\
\text { Autosustentabilidad } \\
\text { financiera de Infotec }\end{array}$ & $\begin{array}{l}\text { - Cambio organizacional de CPI a proveedora de Servicios } \\
\text { de Tecnologías de Información } \\
\text { - Cultura de búsqueda de recursos monetarios a través de la } \\
\text { venta de servicios } \\
\text { - Estructura innovadora-flexible } \\
\text { - Tecnología de Información y comunicación }\end{array}$ \\
\hline 1996 & - Cambio organizacional en la misión, el fin principal era \\
\hline
\end{tabular}




\begin{tabular}{|c|c|c|}
\hline $\begin{array}{c}\text { La RTN: la } \\
\text { formalización de las } \\
\text { TIC's en Infotec }\end{array}$ & $\begin{array}{l}\text { promover la comunicación y la transferencia de } \\
\text { conocimientos científicos y tecnológicos. }\end{array}$ \\
& $\begin{array}{l}\text { - Apropiación de nuevos artefactos culturales } \\
\text { - Diversificación de las áreas funcionales de la organización }\end{array}$ \\
\hline 2008 & - Uso principalmente del internet para la creación de la RTN \\
\hline $\begin{array}{c}\text { La concretización } \\
\text { del área de } \\
\text { posgrados en } \\
\text { Infotec }\end{array}$ & - Cambio organizacional parcial con la creación del área de \\
& - Cultura de docencia e investigación \\
\hline
\end{tabular}

Fuente: Elaboración propia con base en anuarios de Infotec y entrevistas.

Por lo que, según muestra en resumen la tabla 11, los puntos señalados en cada evento crítico son los que tomarán relevancia en este análisis, aunque cada punto señalado tendrá su participación de acuerdo al tema que se quiera abordar. Cabe señalar que el estudio se basa en el cambio organizacional, sin embargo, como también ya se mencionó, se busca explicar cómo se comporta respecto a la introducción de las TIC's en la organización. A continuación, se pretende cumplir con los objetivos señalados en el planteamiento del problema.

\section{A. El cambio organizacional y las TIC's en Infotec}

Como ya se ha explicado anteriormente, la historia de la fundación de Infotec, tiene eventos críticos previos que propiciaron su existencia, el evento más importante es la creación de la política en ciencia y tecnología en México. Esta política trajo como consecuencia una serie de cambios en el pensamiento del desarrollo e investigación que se tenía en el país.

Estos acontecimientos se produjeron principalmente a través de la transferencia de las ideas formalizadas respecto al desarrollo de la ciencia y tecnología que ya se reproducían en otros países. Por lo cual, en el primer acercamiento, la 
conformación de la PCyT se propició a través de un isomorfismo coercitivo, esto a causa de que el gobierno mexicano se siente presionado por organismos externos como la UNESCO para la creación del desarrollo de una nueva política en ciencia y tecnología.

Cuando es formalizada dicha política y se adaptada a las características y necesidades particulares de México; se ve marcada la necesidad de crear un nuevo instituto que se encargue de atender específicamente los asuntos que tienen que ver en la creación del progreso en base a la ciencia y tecnología, por tal motivo surge Conacyt. Esta organización cumple con las características de un isomorfismo mimético, ya que al ser una organización paraestatal copia el Know how y la estructura jerárquica de organizaciones gubernamentales ya existentes. Al darse cuenta de que no era suficiente un solo organismo de este tipo, se crearon otros Centros Públicos de Investigación. Y entonces, en ese período de tiempo es donde el Infotec surge para cumplir la misión que ya se ha señalado.

En este sentido, al revisar la historia de Infotec de manera general, se puede mirar el cambio en la organización desde un enfoque determinista (Skip: 2001), ya que ha resuelto su supervivencia hasta la fecha de hoy, por medio de la solución de los problemas que le ha causado su ambiente exterior, en primera por el caso de la crisis financiera, luego por la apropiación de las TIC's, y posteriormente por la integración del área de posgrados. Todos los anteriores, se han producido por la presión del ambiente exterior. Para el análisis de los tipos de cambio que la autora considera los más relevantes tanto para el área organizacional como de TIC's. 
Se tiene vigente la definición de cambio que ya se ha señalado en el apartado correspondiente: "el cambio organizacional es un fenómeno presente en la organización, que modifica los elementos organizacionales a través del tiempo, $y$, puede ser provocado por el transcurrir cotidiano de la organización como del ambiente, además involucra distintos niveles de participación, lo que genera un nuevo perfil en la organización"

\section{Año 1974. La transición del cambio racional-normativo al cambio regulativo en Infotec}

Todo cambio que se presente en la organización tiene un origen, como ya se ha indicado en un apartado anterior, este origen puede ser interno o externo, además que puede ser producto de presiones de las contingencias, así como de las propias necesidades que requiera la misma organización para su subsistencia, incluso por la inercia de otro tipo de cambio. Sin embargo, el origen de un cambio así como su terminación no tienen un período de tiempo fijo, sino todo está en función de cómo la organización lo apropia.

De acuerdo con la historia, el surgimiento de Infotec fue la respuesta a un cambio revolucionario en materia de ciencia y tecnología que estaba cimentándose a finales de los años sesenta y principios de los setenta. Pero, ¿qué es lo que hace a Infotec en la etapa de su fundación el resultado de un cambio organizacional? Si bien, se toma como referencia que el cambio en Conacyt es prescriptivo porque se pretende hacer una mejora en la organización para su productividad, entonces, 
esta organización ya no podía cumplir con esa función, y al existir un crecimiento exponencial en el desarrollo de la información, se requería un organismo que se dedicara a concentrar toda esa información.

Y así, como una instancia producto de un Fideicomiso entre CONACYT y NAFIN, se funda el Fideicomiso de Información Técnica para la Industria (Infotec). En su etapa inicial, sus actividades, ante todo, se centraron en un programa de enlace industrial, un servicio de pregunta-respuesta y la publicación de un boletín mensual de noticias técnicas.

La principal función que tenía el Infotec en un inicio, se basaba en un proceso racional normativo, basado en un objetivo formal que era actualizar a la industria en investigación. Una de las personas entrevistadas, justo así lo recuerda: "se inició hace ya casi 40 años, e inicialmente era un proveedor de información para la industria, por eso su nombre de fondo de información para la industria, y como en aquella época todavía no había internet, para que la gente pudiera hacer su búsqueda de información referente a cierto tema, se lo encargaban a Infotec, e Infotec era responsable de buscar en muchas fuentes de información, creaban un documento y se lo entregaban a la industria que desarrolló" (entrevistado J)

Bajo el esquema del cambio racional-normativo, permitió que las estrategias no tuvieran mayor cambio, así como la continuidad de una estructura mecánica de Infotec que no sufrió alteraciones. Sin embargo, este proceso de cambio, se estableció durante las primeras dos décadas de la organización, ya que el Fideicomiso cumpliría sus propósitos organizacionales y buscaría su perpetuación 
con base en el cambio tecnológico que se introducía de a poco en las organizaciones públicas desde finales de los años setenta.

Este cambio tecnológico es el que le daba la entrada a las TIC's en Infotec. Ya que el contexto comenzó a cambiar, se establecía un ambiente turbulento y complejo que permitió que el Infotec tuviera que responder de otra manera a las demandas que le hacían sus clientes. Así que para resolver esta contingencia, el proceso de cambio regulativo fue el producto del ingreso de la tecnología:“...yo creo que es el ingreso de la tecnología aquí, si bien aquí antes, en el tiempo que me tocó al principio, la gente cuando iba en búsqueda de información para los proyectos, tenía que salir que buscarla a las bibliotecas ya fuera de la UNAM, o ya fueran de otros organismos que daban información disponible y cuando esto se tuvo aquí en sitio, pues ya minimizó los tiempos. Yo creo que eso fue lo más llamativo" (entrevistado A)

De acuerdo con la cita anterior. El cambio racional-normativo, ya no podía seguir reproduciéndose, porque el ambiente ya no lo permitía. Los procesos lineales y lógicos que estaban lejos de sufrir alteraciones, no podían responder al esquema de introducir una nueva tecnología en el Infotec. Este hecho, favoreció el cambio regulativo, ya que la clave para la organización era el dominio de la técnica de reproducción de la información, para lograr estos fines el organismo debía valerse de mecanismos que pudieran reforzar la autosuficiencia. Por lo que el medio del que se valió el Infotec para lograrlo, fue a través del desarrollo de un área de consultoría y el desarrollo de capacidades en tecnología organizacional, que 
constaba en un principio en mejorar la información que las empresas le solicitaban al Fondo de Información mediante el uso de una computadora.

Otro medio que utilizó la organización fue el Programa de Enlace Industrial, un método rústico pero valido para la época, ya que su principal fin era entender de manera rápida las necesidades de la organización sobre todo en el sector de manufactura, y también otras áreas como la farmacéutica, industria química, administración, etc. Para el cumplimiento de este programa, los medios fueron: visitas personalizadas a las empresas, el servicio de pregunta-respuesta, así como por medio de un Boletín de Noticias Técnicas que el Fideicomiso presentaba mensualmente, actualizando las novedades tecnológicas que pudieran interesarle a los distintos sectores para los que trabajaban.

Al principio parecía que todo marchaba de manera correcta en Infotec bajo el esquema tradicional-racional, y el ocuparse durante dos décadas de cambiar aspectos formales, se olvidó de los aspectos técnicos, y estos últimos ya estaba rebasando en actualización a la organización. Sobre todo, porque para finales de los ochenta, las tecnologías de información ya habían dado un paso más con la creación de la PC y con los primeros intentos de enlaces de Internet. Por lo que, el objetivo de Infotec se cumplía pero no con la eficiencia que le proporcionaban estas nuevas tecnologías, por lo que el cambio regulativo estaba por tener fecha de caducidad.

\section{Año 1994. El fin del proceso regulativo y la crisis de la organización mecánica en Infotec}


En este período el Infotec se ve marcado por tres eventos importantes, que empujaron a un nuevo cambio: la modernización. Dos de estos eventos son de origen externo y uno interno. Los eventos de origen externo, concierne el primero a la situación económica que vivía México, cuestión que no solo afectó a Infotec, sino a numerosas organizaciones del sector público. Por lo que el entorno económico afectaría el modelo organizacional que la institución había reproducido durante veinte años.

Una de las características el cambio regulativo es la respuesta rápida y efectiva a los ambientes turbulentos, llenos de alta incertidumbre. Al respecto de esta situación, el Infotec, no pudo soportar la inestabilidad financiera, como señala el entrevistado: "yo creo que fue en 1994 a raíz de diciembre negro, cuando fue el cambio de poderes, que se vino una situación crítica en lo económico a nivel nacional, muchas empresas desaparecieron, pues Infotec también estuvo en una situación de casi desaparecer, pero, vino un director que sacó adelante la empresa, pero aquí estamos. Esa fue la parte que más me impresionó y me angustió" (entrevistado F)

El segundo evento externo y que hacia conjunción con el primero, se refiere a la modernización que la industria y el gobierno requerían para sobrevivir al entorno económico inestable. En esa época, ya se apostaba por las tecnologías de información como un elemento fundamental para la transformación de la mano de obra. Ya que la intención era disminuir estos costos. Por lo que este cambio tecnológico arrastró a Infotec, porque aún no se modernizaba en el campo de la tecnología, lo que le permitiría hacer la entrega de la información que le solicitaban sus clientes de forma más rápida. 
Y el tercer evento que propicio un cambio regulativo en el Infotec, ocurre al interior de este organismo. El resultado de la auditoría que se realiza a la organización refleja un déficit en sus finanzas, así como una baja operatividad en relación a los objetivos que debía cumplir. Además, la demanda de servicios del sistema de información a este CPI había ido en decremento, por lo que necesitaba modernizarse con el fin de seguir vigente.

La asociación de estos tres eventos dio como resultado la generación de un cambio en el Infotec. Este cambio sería propiciado para dejar atrás el esquema de proceso regulativo, ya que no solo debía adaptarse el ambiente complejo que rodeaba a la organización, sino tendría el reto de aprender a responder de manera positiva a los nuevos eventos que la modernización traía consigo, dejando atrás el modelo tradicional de organismo paraestatal: “...a principios de los 90 había muchas dudas de qué si Infotec, iba o no a lograr esa autosuficiencia y si en verdad los servicios de Internet se iban a vender. Porque lo que más se vendía en Infotec eran estudios con el sistema de información, hay no recuerdo, era el SIE, era el sistema de información que no recuerdo si era Estratégico, que lo que te hacía era estudios en cuanto a "oye, ¿cuántos yogurts hay de este tipo en el mercado?" y te entregaban un estudio en base a ese requerimiento."(Entrevistado $B$ )

La cita anterior, denota que este cambio trascendió, no solo en cuestión de modernización, sino también impactó la visión de los empleados. Traspasó la barrera de resolver los problemas a través de la cadena de medios/fines, para someterse al cambio con la intención de no desaparecer como CPI. Al ser un cambio abrupto trastocó la forma de hacer las actividades de los empleados, al grado de causar duda, en que sí lo nuevo funcionaría. 
Esto nuevo se refería a seguir en pie bajo la modernización a través de la innovación. Para lograrlo, tuvieron que dejar atrás lo tradicional, y someterse a fuertes cambios como por ejemplo, el cambio de director, los cambios en la misión y visión, los cambios estructurales, y sobre todo el aspecto jurídico-administrativo que sería el que le da la independencia económica al Infotec. Además también facilitó la adquisición de nuevas tecnologías de información. Todo este cúmulo de cambios facilitaría un cambio evolucionario que sería el más relevante hasta la fecha en la historia de las tecnologías en Infotec.

\section{Año 1996. El cambio revolucionario y el proceso de adaptación en Infotec: del desorden al orden}

Después de tener un periodo de equilibrio organizacional en Infotec, la ruptura del modelo racional-normativo. Las TIC's se insertaron en la organización provocando un cambio revolucionario, ya que el Infotec no volvería a ser el mismo. Este periodo en definitiva, está marcado por un proceso de adaptación. Los eventos que acontecieron en dos años anteriores a 1996, provocaron que la organización aceptara la modernización y con ello la innovación, siendo como resultado la búsqueda del crecimiento de Infotec. Y así es como las tecnologías de información pasaron de ser una herramienta para cumplir con la búsqueda de información a ser su nueva misión como propulsora para el crecimiento y desarrollo de la organización.

En pocos años, rompieron con el esquema de tecnologías de información al pasar también a tecnologías de información y comunicación. Y esto se ejemplifica en la 
cuestión de que la informática (el uso de PC, programas y desarrollo de sistemas de información básicos que contribuían a la administración en general) ya era algo elemental dentro de la organización. Surgía un cambio en el aspecto tecnológico con la introducción de las telecomunicaciones, donde el internet fue en primera instancia el protagonista de dicho cambio.

Asegurar la sobrevivencia de la organización, compaginó con el cambio como proceso de adaptación que tuvo el Infotec en esta etapa. Las TIC's se ajustaban al requerimiento que tenía el Infotec: “...lo que a mí respecte, que ya me tocó vivirlas (las TIC's), empezaron por 1995 cuando ya nos instalaron nuestras computadoras con internet, bueno, las computadoras ya las teníamos, pero ya con conexión a internet. Allí es donde empezamos a ver cosas nuevas, sistemas nuevos, manejos de información a través de una red, y pues de ahí para acá la tecnología ha estado muy cambiante. Me ha ayudado a encontrar, a hacer una herramienta importante de mi trabajo, pero, también me la ha complicado, porque a medida de que voy resolviendo cosas, también me voy añadiendo más tareas. Pues ahí de una forma, no acabo con mi chamba (entrevistado E)

El cambio como proceso de adaptación que vivía el Infotec hacía referencia a una emergencia tecnológica que se conjuntaba con una necesidad de la organización para equilibrar sus fuerzas internas, con la intención de flexibilizar y ajustar tanto la estructura interna como su forma de trabajar. Se comenzaba a gestar una nueva forma de organización que traería consigo una serie de transformaciones que impactarían al Infotec.

Sin embargo, en esta etapa crítica, los empleados comienzan a vivir los efectos de este cambio revolucionario, ya que la organización ajustó sus requerimientos en el 
aspecto tecnológico, por consiguiente la forma de trabajar, tendría que sufrir los cambios necesarios para flexibilizarse de la manera más rápida posible: "con la introducción de las nuevas tecnologías en al área administrativa, yo veo una cosa, es te acoplas o te acoplas. Porque finalmente, un trámite administrativo tiene que salir, así te pongan de una manera o de otra, incluso si ya vas haciendo un trámite y a la mitad de ese trámite te cambian el curso, o el planteamiento, o el proceso de cómo debe ir, no importa, tu lo tienes que volver a retomar y sacarlo. No hay de otra. Yo no puedo detener, por ejemplo, la contratación de personal porque me cambiaron el formato o porque dicen que era con una $X$ cantidad de tiempo, con $X$ proyecto. Eso no importa. El cambio se hace, $y$ se sigue la línea que se debe seguir. Pero, el impacto, sí en ocasiones ha sido severo, incluso atrasos porque muchas veces no están bien definidos, muchas veces en lugar de acortar las cosas y de hacer los trámites menos burocráticos, la simplificación administrativa, realmente no es tan simplificada. Aún con todo eso y aún con todo y en ocasiones tropiezas al empezar otro nuevo proceso, no importa, el trámite se tiene que continuar y tiene que estar listo". (Entrevistado F)

Como se puede notar, el período de equilibrio que había mantenido la organización al presentarse cambios evolutivos, contribuyó a una diferenciación en el trabajo. Porque ahora, se tenían que preparar especialistas para el manejo de los equipos de telecomunicaciones como routers, antenas, telefonía, sistemas de información, internet. De igual manera se comienza un proceso de automatización del trabajo. Como lo indica un empleado: “... me tocó participar en toda esta revolución de cuando se empezaban a solicitar o a requerir las condiciones de tener presencia de estar en internet, buscar en una página o tener correos electrónicos, bueno, estar comunicados para precisamente poder accesar a los correos electrónicos, te digo en la parte en la que estuve yo involucrado, te puedo decir, sobre su historia. Si bien, 
como todo tiene una curva ascendente, llega a un pasillo o piso y luego cae, pues en efecto hay que buscar otro tipo de negocio, ya no nada más era la de conectividad, sino también ahora ayudarte a soportar esas soluciones con procesos" (entrevistado OG)

Así, con todo este auge de la tecnología que ya había sido acogida por Infotec, se tiene la iniciativa de innovar a la par en que las TIC's cambiaran. Y es que esta red tecnológica utilizaba la tecnología de telecomunicación más avanzada de la época y tenía un sistema de información con fuentes y servicios de consulta e intercambio de datos de alto nivel, con más de 15 millones de usuarios en 123 países. Esto provocó que se desarrollara capital humano especializado, capaz de resolver problemas en el trabajo que fueran más allá de la búsqueda de datos, ahora ese servicio había pasado a segundo plano.

El resultado de la modernización y del cambio jurídico que sufrió la organización, fue para buscar una independencia económica y de no depender en la toma de decisiones de Conacyt, permite establecer que el cambio tecnológico en Infotec es a partir de que opera la RTN, ya que la organización se dedicó a la venta de servicios en tecnologías de información, sobre todo a organizaciones de gobierno y privadas. Sin embargo, esto significaría hacerse responsable de sus finanzas, que en años anteriores habían propiciado el cambio

En la forma tradicional de trabajar, los empleados obtenían su pago puntual según lo estipulado en su contrato. Pero, con la era de la innovación financiera y el cambio estructural, los empleados lo resentirían en los primeros años de este nuevo período, ya que ahora dependían del pago de los servicios de los clientes. 
El área de administración de recursos financieros tenía que aprender a gestionar como una organización que vendía servicios, y no como un CPI.

La nueva forma de organización en la que se estaba convirtiendo el Infotec, consideraba la flexibilización de la forma de trabajo y de los empleados mismos, ya que el cambio demanda el cambio de objetivos, y en esa ocasión el objetivo era satisfacer las demandas tecnológicas de los clientes, pero también la incertidumbre hacia que si este nuevo cambio produciría el impacto positivo esperado. Así, los empleados fueron los primeros en resentirlo: "Yo creo que una de las partes más complicadas es cuando a la gente no se le paga. Y económicamente si hubo quincenas donde literal: se pagaba hasta donde alcanzaba. Ósea, empezábamos por los salarios más bajos hasta donde alcanzara los salarios más altos, y a lo mejor, una semanita después se les pagaba a los demás. Y entonces, te crea cierta incertidumbre porque no sabes si las cosas van bien o mal en la institución" (Entrevistado D)

Sin embargo, gracias a estos nuevos aspectos que vivía la organización, los empleados que en su momento lideraban la nueva forma de trabajar en el Infotec, se percataron de que los cambios en la organización deberían llevar un orden para mejorar la eficiencia y el desempeño. Un entrevistado hace referencia al respecto: “...por ejemplo, anteriormente se hacia un sistema y el sistema se echaba a andar, operaban y lo ponían en marcha. Ahora no, ya se dieron cuenta que finalmente es necesario una planeación, una administración como tal del proyecto, un área de pruebas, un área que complemente ese sistema, a lo mejor requiere de base de datos, o de seguridad, van complementando más los servicios" (entrevistado B) 
De acuerdo con lo anterior, la organización atravesaba por una etapa de cambios, que no se hacían de manera fortuita, sino que hubo un interés por hacerlo de manera planeada, de forma consciente e intencional. Buscando la adaptación de la conjunción de todos los cambios presentes para propiciar la innovación como un instrumento poderoso de la perpetuación de dichos cambios.

Desde la perspectiva de uno de los entrevistados, a partir del 96, la organización entró en una etapa de múltiples cambios, en el cual promovían la planeación de los mismos. Aunque, por ser pioneros en la administración de servicios de TIC's, iniciar el proceso de cambio de su estructura mecánica a una estructura orgánica, el Infotec requería especializarse en los servicios tecnológicos para su uso dentro de la misma organización, como para la venta de los mismos.

Así bajo este nuevo esquema de modernización, por medio del aprovechamiento de las TIC's favoreció el crecimiento y desarrollo de la organización, las secuelas que resultaran de los cambios que se producían en la organización se vería en los siguientes años. Sobre todo porque conforme se diversificaba en servicios la institución, a la par las TIC's seguían en desarrollo, así que seguían acumulándose nuevos requerimientos administrativos para el Infotec. Por lo que uno de ellos fue la creación del área de posgrados.

\section{Año 2007. El cambio como proceso de planeación: hacia la reorganización de Infotec}

El proceso de modernización que emprendió Infotec, no concluyó con la participación de la RTN y la innovación e implementación de las TIC's. Más bien, 
fue el impulso que necesitó la organización para seguir su desarrollo. Por eso, al pasar los años, las TIC's se convirtieron en el artefacto que le proporcionaba sustentabilidad económica al organismo, y esa cuestión debía aprovecharse.

Aunque, en su esfuerzo por convertirse en Centro de Investigación, Infotec ha iniciado trabajos de investigación dentro del campo de las tecnologías de la información y comunicaciones con las siguientes líneas estratégicas: Gobernabilidad, estrategia y políticas,- Brecha Digital y Comunidades Digitales, Innovación y Desarrollo Tecnológico del País, Economía Digital, Desarrollo Social y Participación Ciudadana, e-Gobierno.

Además, también su función es diseñar soluciones y aplicaciones de TIC para la administración pública que le permitan ahorros y sean efectivos para un mejor desempeño. Por lo que sus servicios en e-gobierno cubren las necesidades de TIC's de la administración pública federal, que incluye desde la estrategia hasta la implementación de proyectos de TIC's, por lo que el trabajo se desarrolla conforme las necesidades detectadas.

Cuando la organización cambió de Fondo de Información- Proveedor de servicios en $\mathrm{TI}$ a un Centro Público de Conocimientos, fue necesario renovar y modernizar las capacitaciones y los diplomados que se impartían en Infotec, por un plan de estudios que tuviera un valor agregado para el organismo y la sociedad. Con el principal objetivo de impulsar el crecimiento de la industria nacional de las TIC, y la creación de redes y alianzas estratégicas que contribuyan a la transición de México hacia la Sociedad del Conocimiento. 
Sin embargo, aunque en un principio el cambio en el área de docencia se basó en un proceso de planeación, llegado el momento de formalizar dicha área, el cambio se presentó de forma accidental, con un poco de ambigüedad organizativa. En ese sentido, un entrevistado así lo define: "la parte de los diplomados tiene una historia muy rara porque aquí se dieron cursos de todo, de marketing, cuando Infotec todavía no tenía clara su vocación, te estoy hablando a principios del 2000, había cursos de formación de directores, cuando Infotec todavía no decía mi rollo son las tecnologías de la información y el internet, entonces bueno, porque pasamos la parte de posgrados. Porque como centro público de Conacyt, nuestra vocación era la investigación y la formación de capital humano especializada en TIC's, somos uno de los pocos centros especializados en TIC's, pero para decir que realmente somos un centro público tenemos que hacer investigación "(entrevistado C)

Sin embargo, como lo hace notar el entrevistado, en el área que se dedicaba a impartir cursos en Infotec, no estaban suficientemente coordinados, ni tenían suficiente conocimiento al respecto de formar directores de áreas. Este cambio se estableció en principio como un proceso accidental que tenía una ruta de acción compleja, impulsada por atender un requerimiento administrativo que les solicitaba Conacyt, fue que se tomó la decisión de formalizar el área de posgrados en Infotec para impartir maestrías enfocadas en la gestión de las TIC's.

Para lograrlo, a partir de 2006, la organización trabajaría como un Centro de Desarrollo e Innovación Tecnológica para Pequeñas y Medianas Empresas 
(Pymes) y para el Gobierno mediante el uso estratégico de las TIC. Entonces, fue como aparecieron nuevas líneas institucionales como la investigación, la innovación y la formación de capital humano en el nivel de posgrado; por ello, se dio inicio al plan de estudios de dos maestrías: la de Dirección Estratégica en Tecnologías de la Información y Comunicación (MDETIC) y la de Gestión de Innovación de las Tecnologías de la Información y Comunicación (MGITIC).

A pesar de que sufrió de un proceso de cambio accidental, donde los problemas, las soluciones y los involucrados no encontraban un orden al caos, posteriormente, la organización se renueva formalizando el área de investigación y docencia. De esta forma, el cambio se convierte en un proceso de planeación que se basa en hacer conexión con las TIC's y los valores que se establecían en el Infotec: "a la mitad de la década como en 2007 se crea la dirección de investigación y se reconoce a Infotec como un centro público de información ya propiamente y jurídicamente hablando, esto quiere decir que hace docencia, hace investigación, tiene proyectos de investigación, sobre todo de investigación aplicada, y hasta ahorita sigue con sus principales servicios, que son servicios tecnológicos, pero también ahora con la parte de investigación" (Entrevistado C)

El proceso se realizó de manera secuencial y racional, planeando primero que la integración del área de posgrados e investigación cumpliera con los objetivos y valores que la organización promulgaba respecto a la generación de conocimiento en tecnologías de información. Luego, dando de alta ante la SEP el plan de estudios de la maestría a impartir para que tuviera validez oficial. Por consiguiente, abriendo la convocatoria y difundiendo este nuevo servicio que ofrecía el Infotec. 
Finalmente, se buscó cubrir las plazas de docencia por medio de convenios con Universidades en México y el extranjero, además también se propició el ambiente para contratar investigadores que se dedicaran a la investigación aplicada y en el desarrollo del conocimiento en cuestión de TIC's. Aunado a ello, se creó un espacio físico dentro del Infotec para poder impartir algunas clases y una biblioteca con acervo actualizado. Hasta la fecha, este aspecto sigue en proceso de cambio por medio de la planeación.

\section{B. Nuevas formas de organización y las TIC's en Infotec}

De acuerdo a los supuestos que se hicieron anteriormente, el cambio organizacional que ha sufrido Infotec en sus diversos eventos críticos, ha permeado en la totalidad de la organización en el período de 1994 y 1996, pero también solo ha sido parcial en el año de su fundación y en el 2007. Estos cambios han tenido sus efectos sobre todo en su estructura organizacional.

Como se señaló en el apartado de estructura, esta no se basa únicamente en la estructura jerárquica, sino que también se conforma de otros elementos que permiten hacerla diferente de otras organizaciones. Por ello, es importante decir que en el análisis de los datos se consideran todos los elementos posibles que respecten a los estudios organizacionales, más allá del análisis de su organigrama.

Además, para no perder la conducción con el análisis de cambio, también es importante referir que esta explicación parte de los cambios organizacionales originados por la introducción de las TIC's en el Infotec. Así que para 
contextualizar, se parte de la definición antes señalada de Ranson, Hinings y Greenwood que perciben a la estructura como "un medio complejo de control que se produce y recrea continuamente en la interacción y sin embargo da forma a esa configuración: las estructuras se constituyen y son constituyentes". La anterior definición es pertinente para destacar el concepto de innovación organizacional en el Infotec.

\section{Año 1974. Hacia la construcción de la organización mecánica}

Con base en los antecedentes de la fundación de Infotec, el incremento que tuvo Conacyt en el área de especialidad de tecnologías, propició un cambio en su diversificación de centro público. Por lo que, el Servicio de Información Técnica del Conacyt creció de tal manera y en tan poco tiempo que, hacia 1974, se descentralizó al crearse un fideicomiso auspiciado por NAFIN y el propio Consejo que, en un principio y con un presupuesto bastante limitado, se llamó Fideicomiso de Información Técnica para la Industria (Infotec).

Analizar la estructura de Infotec en sus primeros años de vida, ha sido un poco complicado, ya que la mayoría de los registros que existen de los años en que surgió, se enfocan a resaltar el surgimiento de la PCyT y del Conacyt. Por otro lado, la gente que fue entrevistada, la mayoría hizo su aparición en la década de los noventa y la información que describen los anuarios oficiales detalla brevemente como se estructuró la organización en su fundación.

Sin embargo, el análisis de la estructura en su fundación, se basará en su estructura jerárquica y en los factores contextuales. Sin duda, en el período de 
tiempo en que se establece la Fundación del Infotec, corresponde al modelo de organización mecánica, aunado a ello, era una organización perteneciente al sector público porque es un Fideicomiso de CONACYT. Estas particularidades remiten a que la estructura respondía a una jerarquía de autoridad limitada, una estrecha división de labores, participantes técnicamente competentes.

Infotec, al pertenecer al esquema de CPI, su función era limitada y señalada por Conacyt, ya que no tenía autonomía en la toma de decisiones. El presupuesto financiero era otorgado por la dependencia central, así como los objetivos y la misión. El número de empleados no rebasaba las 100 personas y su trabajo no requería de mayor especialización ya que eran tareas repetitivas (buscar la información para las empresas interesadas, hacer visitas para conocer las necesidades del mercado y hacer la publicación de un boletín con un resumen de las publicaciones).

La estandarización del trabajo se hacía con la ayuda de tecnología, que en ese momento era básica, pero a su vez con técnicas de información relativamente nuevas. Por ejemplo, los trámites a las bibliotecas foráneas se realizaban mediante el correo tradicional, la comunicación con las empresas era de manera presencial, o por medio del teléfono. La transcripción de los artículos la hacía un traductor especializado por medio de una máquina de escribir, o en su caso, si tenía los conocimientos del uso de la computadora, era un plus.

Estos aspectos, aunque de primera vista pueden parecer rústicos, reflejan los cimientos estructurales del Infotec, asimismo, permiten conocer en qué situación se funda la organización y con qué elementos contaba para la realización de su 
función de la búsqueda de información. Finalmente, concuerda con la idea de cambio a causa de que al pasar veinte años su estructura no soportaría la modernización ni la innovación tecnológica.

\section{Año 1994. La expiración de la organización mecánica: el inicio de la organización flexible}

En el período de fundación del Infotec, había un objetivo claro, satisfacer la demanda de servicios de información. La organización no concebía que las

nuevas tecnologías de información empezaran a tomar relevancia en las organizaciones, aunado a ello, que el modelo tradicional de estructura asimismo comenzara a tener variantes que ayudaban a la permanencia o a la desaparición de las mismas. Para el Infotec, todo lo anterior, fue lo que casi hace que desaparezca porque no pudo resistir la crisis financiera del 94.

En esa época dependía financieramente del presupuesto que le otorgaba CONACYT, por lo que el aspecto económico no era de las prioridades de Infotec, y de acuerdo con los datos consultados, la competitividad y la eficiencia no eran metas a conseguir en el corto plazo. Así como tampoco, el tema de modernización. El contexto en el que se desarrollaba el organismo, ya no era el adecuado, así que le trajo consecuencias.

Esta época concuerda con el aumento de la complejidad en las organizaciones, así como con el proceso de cambio regulativo que tendría que adoptar el Infotec para seguir vigente. El contexto organizacional, por el que atravesaba dicha organización era determinante, como bien lo hace notar un entrevistado, era la 
renovación o la desaparición: “¿Qué problema tenia INFOTEC? Bueno, que le dijeron tienes tres años para hacerte autosuficiente, sino te haces autosuficiente, ya no te voy a poder dar más recurso, ya no te voy a poder dar más presupuesto" (entrevistado I)

La secuela, como lo hace notar el entrevistado, era la desaparición del fideicomiso. Sin embargo, ¿Qué significaba esto para el Infotec? De acuerdo con sus estadísticas, el principal problema fue que la obsolescencia de las antiguas formas de ver y entender la industria y, por tanto, el rumbo un tanto anacrónico que llevaba la institución. Se aportaban pocas novedades para las empresas y, por ello, resultó muy poco productiva la oferta de trabajo que brindaba Infotec al mercado de la industria privada y a las instituciones gubernamentales.

El resultado, fue la sugerencia de un cambio por lo menos parcial de la estructura que había conservado Infotec hasta la fecha. Así, que se inició con el cambio de director de la organización, por lo tanto, un cambio en las estrategia, en la misión, y visión. La toma de decisiones ya no estaba centralizada en Conacyt, por lo que Infotec se haría cargo de las medidas que tomaría para su subsistencia, siempre y cuando cumpliría con los objetivos de CPI.

En 1994 la institución evolucionó ofreciendo servicios aislados de consultoría, capacitación e información con incorporación marginal de la Tecnología de la Información en su oferta. El factor de interdependencia hacia Conacyt por medio de la centralización en la toma de decisiones tuvo un cambio, lo que permitió al Infotec empezar a cumplir con uno de los objetivos: "con el proyecto de modernización, pasó esto. Infotec al ser un fidecomiso de Conacyt, en teoría le debería de 
dar dinero, por ejemplo, le da mil pesos al año, de esos mil pesos, úsalos para investigación, para lo que quieras, pero Infotec como vende servicios, la verdad es que no necesita de ese dinero, entonces, sí recibe el dinero pero al final de año se lo devuelve"yo no lo use, yo me valgo por mis propios recursos, todo lo que vendo lo uso para pagarle al personal e invertir en nuevas tecnologías". Entonces, somos una institución autosuficiente" (entrevistado G)

Al adaptarse las tecnologías de Información, la configuración organizacional se hacía más flexible, ya que tenían que adherirse áreas que se encargaran de gestionar todo lo relacionado con las TI. De igual manera, personal capacitado para el uso correcto de las finanzas. Por lo tanto, estos cambios estructurales propiciaron la entrada a un modelo organizacional basado en la diversificación de tareas y en la adaptación del entorno exterior. Donde la estandarización de la organización había quedado atrás y la especialización se hacía más presente porque el proceso de innovación comenzaba a ser parte importante del Infotec.

\section{Año 1996. La consolidación de una nueva forma de organización: la organización innovadora}

El contexto que rodeó a Infotec en los años siguientes al 94 se permeó por la necesidad de obtener recursos propios para su sustentabilidad. Su propósito se lograría con la modernización de la misma organización, por lo que el desarrollo de las TIC's en México, y en especial, la introducción de estas a Infotec, sería una estrategia que le permitiría su desarrollo y permanencia hasta la fecha. No cabe 
duda, que durante este período, se da por terminado un ciclo estructural, para comenzar una etapa de cambio que se tradujo en un beneficio.

La flexibilización que sufrió la estructura de Infotec, como se ya se ha mencionado, tiene como origen el impacto que la innovación financiera, tecnológica y organizacional, sobre la interacción entre los factores contextuales, el ambiente, los individuos y las dimensiones de la estructura misma. Lo anterior, se puede apreciar con la siguiente opinión de un entrevistado: “...Digamos que a partir de ese cambio tan fuerte que hubo, los integrantes de la institución como que estamos mucho más conscientes de que, pues a partir de ese año, la institución ha seguido más o menos con la misma línea, mucha rotación de personal, muchos cambios administrativos, muchos cambios de áreas, de estructuras, reestructuras, de nuevas visiones, ha sido muy, muy dinámico, entonces el personal de alguna manera, pues si nos hemos encontrado más... adaptándonos más a ese ritmo de cambios, que son constantes..." (Entrevistado A)

El entrevistado se refiere al cambio que sufrió la estructura, ya que al tomar como eje a las TIC's, y en especial a internet, hubo la necesidad de adaptar una dimensión estructural renovada mediante la planeación estratégica. De esta forma, la estructura jerárquica no era suficiente para cumplir con los nuevos retos por venir. Así, es como empieza a crecer su estructura jerárquica en forma divisional, incluyendo áreas como: Dirección Adjunta de Tecnologías de la Información, Gerencia de Teleinformática, Dirección Adjunta de Tecnología Organizacional y Unidad de Innovación y Desarrollo Tecnológico. 
Estas áreas surgieron con el cambio de rumbo estratégico que la organización se vio obligada a implantar. Con la aplicación de las TIC's dentro y fuera del Infotec, la alta demanda que se produjo por los servicios en telecomunicaciones, el proceso de innovación organizacional que sufría el Infotec, iba más allá de un cambio estructural, o de la introducción de tecnologías especializadas, la cuestión en ese momento, era lograr aprovechar esa innovación para obtener los recursos financieros suficientes. Según, uno de los entrevistados, señala que esa contingencia favoreció a la organización:

" $Y$ entonces en los tres años subsecuentes Infotec empieza a crecer mucho, con proyectos como la SEIT donde teníamos que atender a mil, a más de mil instituciones, con soporte, con operación, con evangelizar en la parte de capacitación, entonces, Infotec da un gran paso, porque con ese proyecto le permite ser autosuficiente. Y le permite empezar a ver con otras áreas como la de desarrollo la parte de contenidos en Internet" (entrevistado E)

La configuración innovadora comienza a gestarse por el hecho de que, la estructura se hace más flexible para la toma de decisiones en la venta y oferta de servicios. La promoción y oferta de servicios la realizaban bajo condiciones de los áreas que se formaron especialmente en el área de TIC's. El entorno seguía presentando alta complejidad porque el uso de las TIC's no era cuestión de un desarrollo estático, por lo que la innovación tendría que ser constante. Para ello, se valieron de la estrategia de venta en mayor parte al sector gobierno.

La organización innovadora en la que se estaba convirtiendo el Infotec, se caracterizó por su flexibilidad, y sobre todo por la ideología cultural y económica a la que los empleados se adaptaban. Ya que, uno de los aspectos favorecedores, 
era la libertad de introducir nuevas ideas, de renovarse, sin embargo, esto no causó ambigüedad en la estructura organizacional. Al contrario, permitió desarrollar proyectos a gran escala.

Entre estos proyectos, el más relevante es el de e-Gobierno, la creación de un correo electrónico propio de la Institución, así como la creación y asistencia de portales de Internet basado en la innovación tecnológica, según comenta uno de los entrevistados fue lo que permitió tener un crecimiento exponencial tanto para la estructura como para la infraestructura de Infotec:

"cuando empezamos, no había correo electrónico, aquí instalamos lo que es un servidor de correo electrónico, solamente algunas páginas web, algunos sistemas de gestión de tráfico, digo, en realidad fue un crecimiento exponencial en ese momento, ¿Por qué? Porque estábamos hablando de portales web planos y no estáticos, lo más que podías tener era una plantilla de comentarios, de correos, y la verdad es que las TIC's en el Infotec en esa época creció de manera exponencial. Empezaron con páginas, crecieron con sitios de hacer portales y todos los sistemas tenían características de 3.0 totalmente interactivos, vamos, creo que fui parte de los primeros en crear cuentas de correo electrónico en la institución, ya no te digo para clientes, para nosotros..." (Entrevistado $H$ )

Con ello, se consiguió una profesionalización de los procesos más que de una estandarización tanto en la venta de sus servicios por medio de un desarrollo de modelo económico (no tenían hasta el momento). Había poca formalización en cuanto a normas y procedimientos, y la centralización de la toma de decisiones recaía en cada área, dejando las decisiones estratégicas para la dirección ejecutiva, que a su vez tenía que cumplir jurídicamente informando a CONACYT sobre los proyectos que se realizan en el Infotec. 
Otra característica de esta organización innovadora, lo pone de manifiesto una de las personas entrevistadas, y es la característica de que la organización se conforma de gente joven trabajando: "Esta institución durante todos los años que he estado, ha sido en su mayoría, que te diré, un $90 \%$ de gente joven. Siempre ha sido integrada por gente joven, gente muy entusiasta y gente de mucha vanguardia y gente muy abierta." (Entrevistado C)

Esto favorece a la generación de ideas, pero también permite que se moldee su forma de trabajar de acuerdo a la especialización que ocupe a la organización en cierto período de tiempo. Esto beneficia la participación de la adhocracia operativa, porque los proyectos se realizaban con equipos de trabajo, que a menudo sólo eran por contrato, por lo que al finalizar el proyecto algunos empleados eran despedidos.

La configuración de la estructura innovadora, le ha permitido a Infotec aceptar el uso de las TIC's en su propia organización, así como utilizarlas como un medio de subsistencia. Al paso de los años subsiguientes, la especialización de las áreas estructurales le ha permitido desarrollar diferentes proyectos en el área de TIC's, haciéndose cada vez más específicas. Así, con el paso del tiempo estas áreas crecen horizontalmente y permiten el desarrollo de los objetivos establecidos en la planeación estratégica.

El hecho de ser una organización innovadora, donde la adhocracia operativa prevalece para el desarrollo de ideas innovadoras en TIC's, no está deslindada de que haya una burocracia profesional a la par. En este caso, Infotec, depende de algunos recursos que le proporciona el Conacyt para el desarrollo de sus 
proyectos, además, que la forma de organización en la cual opera, no exime a la organización de cumplir con los aspectos administrativos. Por ejemplo, un entrevistado comenta: "Conacyt le dice al Infotec-me gusta tu proyecto, te apoyo, a lo mejor no con el $100 \%$, te doy el $60 \%$ pero tú tienes la obligación de poner el otro $40 \%$ ". Es así como se dan ese tipo de proyectos, cuando ya hay un apoyo, cuando no, pues no hay. O lo hace Infotec con sus recursos y le invierte, o Conacyt apoya con una parte del porcentaje, no hay de otra. (Entrevistado F)

De acuerdo al fragmento de la entrevista presentada, para esta fecha se logra la independencia económica para el sustento del Infotec, por medio de la innovación de proyectos basados en TIC's. Sin embargo, Conacyt sigue cumpliendo con la función de otorgar presupuesto al CPI como parte de sus políticas, aunque la organización no lo requiera al 100\%, tiene que sujetarse a los procedimientos que le corresponden como Centro Público. Lo que permite notar que la burocracia profesional, no desaparece del todo en esta nueva forma de organización, aunque haya reciprocidad entre la capacidad de flexibilización-innovación.

\section{Año 2007. La flexibilización de la organización innovadora}

La estructura que ha conformado Infotec, ha sido impulsada por el contexto que le rodea, así como por el cambio en sus objetivos y principalmente por adoptar a las TIC's como la fuente de innovación y desarrollo de la organización. Una de las funciones de la estructura es adecuar los elementos que intervienen en la organización para el cumplimiento de los objetivos y para desarrollar productos 
organizacionales. Dicho esto, es lo que da lugar a la creación de la Dirección adjunta de docencia e investigación en el 2006.

Ante una nueva evaluación, la organización detectó algunos problemas estructurales, por lo que se aportaron importantes soluciones administrativas y de orientación, pues Infotec había desarrollado su trabajo, hasta el 2005, como un Centro de Servicios Tecnológicos; no obstante, a partir de 2006, trabajaría como un Centro de Desarrollo e Innovación Tecnológica para Pequeñas y Medianas Empresas y para el Gobierno mediante el uso estratégico de las TIC.

En principio, el aspecto de la burocracia profesional, vuelve a tener cabida en este sentido. Porque se tiene que cumplir con los requerimientos administrativos de $\mathrm{CPI}$, pero a su vez, el Infotec tiene que hacerlo de forma innovadora, por lo tanto la flexibilización que ya había alcanzado en la forma de operar, le permitió al Infotec darle un sentido distinto a las TIC's, y esto fue mediante la creación de las Maestrías.

De acuerdo con el entrevistado, la especialización de las TIC's en el ámbito laboral, también favoreció su participación como pionero de formación de capital humano: “...si queremos ser un centro público, tenemos que hacer estudios de posgrado. En planeación estratégica, en conjunto con las Secretarías que eran nuestros clientes nos dimos cuenta que les faltaba la formación de directores en $\mathrm{Tl}$, entonces, por ejemplo, buena parte de la temática en dirección estratégica tiene que ver en buena medida con regulación, con gobierno electrónico, en fin, con aquellos temas de $\mathrm{TI}$ que a los responsables de la organización les hace falta y que acá encontraron una opción, 
entonces, sí surge como parte de la estrategia para volvernos centro público y consolidarnos como tales, pero está basada en identificar necesidades" (entrevistado F)

Por eso, es que al cumplir con un requisito administrativo de Conacyt, una de las personas define que la planeación estratégica volvió a cambiar en 2007 para estructurar el área de posgrados. La creación de esta área hizo más flexible la visión que hasta el momento tenía Infotec. Sin embargo, como lo señalan los entrevistados, al principio, ese cambio de impartir cursos sin validez a hacerlo formalmente no fue tarea fácil: “...Entonces se desarrolló con una asesoría por parte de consultores internacionales la maestría, pero, pues no se tenía ni idea, jamás se había visto el acuerdo 279 de la SEP que rige los estudios profesionales de posgrado, éramos un centro público incipiente, no estábamos registrados como institución educativa, ya habíamos empezado a impartir cuando nos faltaban los cimientos, no había un reglamento de estudios de posgrado, en fin, faltaban muchas cosas..." (Entrevistado B)

El cambio configuracional que sufrió esta área fue tan radical, que causó desajustes en su inicio. La flexibilización trajo consigo que la formalización de los procedimientos pasara a segundo plano en el área de TI. Pero, en este caso se trataba de un área que tenía una función distinta a las demás en Infotec. Sin embargo, como señala el entrevistado, esto pudo encausarse: “...un líder en el área de e-learning, él fue el que retoma toda esta parte y trata de reestructurarlo un poco más, no un poco más. ¡Mucho más! Y de ser más específico, mejor dirigido, mejor alineado con los objetivos institucionales en la planeación y de buscar apoyos, de dirigirlo de la mejor manera posible..." (Entrevistado D) 
Para estructurar esta área, los factores contextuales tomaron relevancia, ya que se buscaba que el posgrado cumpliera con los objetivos institucionales, que a su vez estos estaban basados en las TIC's. Además, la estructuración debía ser diferente a las demás áreas, porque esta nueva área no tenía cimientos en la estandarización de los procesos, ni en su formalización, mucho menos en la especialización para dirigir un sistema educativo. Con el tiempo, se pudo alinear a los objetivos institucionales, situación que le ha permitido al área de Docencia e Investigación tener su permanencia en fechas recientes.

\section{La cultura organizacional como intermediario de la apropiación de las TIC's en Infotec}

Quizás, hasta este punto, parezca que la explicación de cómo ha sido el cambio y la estructura organizacional en Infotec, daría a entender que ha sido trazado de manera que la organización siempre ha sido beneficiada. Pero, justo aquí es donde el análisis de la cultura que ha cimentado Infotec, se introduce en los aspectos que no se pueden explicar tan fácilmente como los puntos anteriores. Respecto al carácter ambiguo de la definición de cultura, en este estudio de caso, solo se prestan atención a los aspectos que ayuden a entender al cambio y a la estructura en relación a las TIC's.

La mayoría de las personas entrevistadas hacían alusión a los valores de la organización, sin embargo, como se expone a continuación, hay más detalles que hacen enriquecer la cultura del Infotec. Aunque, es importante mencionar que en 
los primeros dos periodos de estudio no hay suficientes datos para hacer un escrito en detalle, no obstante, el florecimiento de la cultura en esta organización se ha dado a partir de la mitad de los 90 a la fecha.

Para comprender un poco la dinámica que ha adoptado el Infotec para la formación de su cultura, la definición de Néstor García ayude a su interpretación: “... la producción de fenómenos que contribuyen, mediante la representación o reelaboración simbólica de las estructuras materiales, a comprender, reproducir o transformar el sistema social, es decir, todas las prácticas e instituciones dedicadas a la administración, renovación y reestructuración del sentido". Estos elementos toman sentido de manera diferente en cada uno de los eventos críticos del estudio.

\section{Año 1974. El inicio de un sistema socioestructural en Infotec}

La generación de la cultura organizacional en este primer período, se establece mediante una estructura formal. La cimentación del sistema socioestructural y cultural se crea de manera isomorfa a causa de que Infotec deriva de Conacyt. Ya que forma parte de un aspecto de que la organización debe cubrir para darle sentido a las actividades que en ese entonces se desempeñaban. Anteriormente se ha señalado que la estructura bajo la que se fundó el Infotec fue la mecánica, atendiendo a un plan de fines a medios con el objetivo de cumplir con los requerimientos de un $\mathrm{CPI}$.

Este hecho se facilitó mediante la adopción de los artefactos culturales, de los valores y supuestos básicos (Schein: 1997). En el caso particular de Infotec, en un 
primer momento era dominar la técnica de los servicios de información y documentación centrados en la tecnología de la producción, así como de la incorporación parcial de las tecnologías de información a la organización.

Para este primer periodo, el sistema socioestructural en combinación con las contingencias, y los valores que se establecieron, favorecieron la creación del sistema cultural con el paso de los años. De acuerdo con la información revisada en los anuarios, y como ya se ha referido anteriormente, la organización es un Fideicomiso de dos instituciones paraestatales (Conacyt-NAFIN). Constituyéndose el Fideicomiso de Información Técnica para la Industria, el cual dependía de la autoridad y presupuesto de Conacyt.

Su principal objetivo era identificar las necesidades de la información técnica de las empresas en la industria manufacturera en México, con el fin de demostrar que Infotec ayudaría a resolverlos. El principal vínculo era con el contexto y la organización, basándose en las exigencias del mercado y del contexto político. Los valores, se basaban en la transmisión de la información a las empresas que se lo solicitaban, con base en la tecnología de información que apenas se utilizaba en aquella época.

Sin embargo, a pesar de que la estructura formal facilitaba el desempeño del Infotec como Fideicomiso. En el transcurso de sus primeros veinte años, surgieron algunos problemas entre los que se encontraban el rezago tecnológico de la organización, una autoridad jerárquica que dirigiera las metas y objetivos en función de las contingencias y del medio ambiente, así como el escaso sistema 
cultural, derivó en un problema que podía terminar con el Infotec, ya que como se ha indicado, el sistema cultural y socioestructural en una organización deben justificarse y sostenerse el uno al otro.

\section{Año 1994. La cultura como metáfora para la transición estructural de Infotec}

Para Infotec este período de tiempo, fue sumamente importante, de acuerdo a la información de sus anuarios y también lo reflejaron los entrevistados. Ya que atravesaría por el proceso de interpretar su realidad organizacional. Para ello, tendrían que cimentar las bases para los cambios ideológicos y estructurales que eran necesarios para no desaparecer como organización. Sin embargo, el hecho de que en años anteriores al 94, se condicionara a la cultura como un aspecto formal, posteriormente, se genera una matriz de símbolos y acciones (Varela: 2003) que permiten otorgar nuevos significados a las acciones de los miembros del Infotec.

De acuerdo, al siguiente relato de un entrevistado y de la información obtenida en el documento de la semblanza de Infotec al año 2009, el sistema socioestructural que se había construido durante veinte años había llegado a una etapa que puso en riesgo la permanencia de la organización. La estructura mecánica ya no permitía establecer una forma de ver y entender a la industria que ya no fuera de manera anacrónica: “...Porque ha habido varios parte aguas en Infotec, varios cambios en la mentalidad de Infotec, novedades diferentes de acuerdo a las administraciones que han estado aquí, pero la del 94 era todo, seguir o desaparecer" (entrevistado H) 
Las políticas centradas en asesorías de tipo económico-industrial, se basaban en la en el desarrollo y capacitación de técnicas industriales y en conceptos de calidad, no eran suficientes para proporcionar innovación a las organizaciones privadas y públicas a las que se les vendían los servicios, por lo que el resultado fue un cambio en el estilo de procesos gerenciales.

Con el resultado de la auditoría a la que fue sometida la organización, se solicitó un rumbo en el cambio de las estrategias y de los procesos en específico en el área administrativa y financiera. Sin embargo, estas consideraciones que fueron tomadas en cuenta, propiciaron el cambio del sistema cultural que durante veinte años se había construido. Sobre todo en la parte de la ideología, de los valores.

Por primera vez se introducía el valor del aspecto económico a una entidad que no cumplía anteriormente con ese objetivo. Y se construía un cambio ideológico en la aceptación de las nuevas tecnologías, por ejemplo, el uso de las PC no sólo como una herramienta de trabajo, sino también como un artefacto cultural que lograría el cambio en el sistema cultural en los años siguientes. Esta situación provocaría un cambio en la creación de nuevos materiales simbólicos, en las presuposiciones y en el software mental de los empleados.

La cultura organizacional de Infotec, en esta etapa cobró un sentido diferente, ya que había un énfasis en la mente y pensamiento de los empleados en relación con la forma de la organización y de la forma de operar. Incluso, se vislumbra una evolución en la ideología, con el afán de comprender e interpretar los nuevos 
fenómenos tecnológicos e innovadores a los que tenían que acostumbrarse. Aunque, esta cuestión se haría más notoria en el siguiente evento crítico.

\section{Año 1996. La construcción de un sistema cultural a partir de la introducción de las TIC's en Infotec}

El cambio socioestructural y cultural que el Infotec comenzó a tener a partir del año de 1994 fue trazado por un cambio organizacional que abarcó a todas las áreas de la organización. Hasta este período, la organización ya tenía 25 años vendiendo servicios de Información, había superado varias contingencias como la tecnología, el mercado y la competencia, y tenía la capacidad para responder a los cambios estructurales y tecnológicos por medio de procesos de innovación organizacional. Pero, lo interesante es que también a partir del año que transitó entre 1995 y 1996, el sistema cultural cobró relevancia dentro de la organización.

El ingreso de las TIC's en Infotec, en específico con el desarrollo del proyecto de la RTN, permitió una conjunción entre el sistema cultural y el sistema socioestructural. Y es que se habían presentado varios cambios que iban a la par. El primero de ellos, es que las relaciones que tenían los empleados con la organización se basaban en un esquema burocrático, donde principalmente se dedicaban a resolver problemas, luego cambió a un esquema ideológico de venta de servicios, en el cual el objetivo era vender servicios y resolver problemas del ámbito de las TIC's. 
Por lo tanto, los empleados, debían estar acorde al uso de estas nuevas tecnologías, ya que hasta ese momento solo utilizaban la PC y el internet como tecnología para el desarrollo de su labor, sin embargo, el uso de equipo de telecomunicaciones (telefonía, sites de comunicaciones, monitoreo y administración de la red de enlace con internet, ruteadores, firewalls, entre otros), se introduciría al léxico organizacional, así como a la nueva forma de trabajar y como nuevos artefactos que ya eran parte de la realidad actual del ambiente de trabajo.

En esta etapa, la flexibilización y la innovación también ya habían trastocado a la cultura organizacional del Infotec. Los artefactos culturales se hacían presentes en mayor medida para sostener que la tecnología era un símbolo y una expresión que se convertiría en parte fundamental de la ideología de cada uno de los miembros de la organización. Así lo señala uno de los empleados: “...empezando por la cultura de la gente, de tener un ambiente burocrático a un ambiente de servicios, este... de tener cierta calidad en cuanto a las instalaciones a mejorarlas porque ya éramos imagen hacia otras dependencias, este, pues básicamente en la organización. En la organización en cuanto a la parte cultural, fue un cambio muy drástico, se le invirtió mucho a la gente para que se certificara y certificaran a Infotec, no nada más en la parte de... de tecnología, sino también en la parte de desarrollo, en la parte de los centros de cómputo, y eso al final, nos costaba esfuerzo en contratar gente, en prepararla y en hacer gente de mucha calidad, para que pudieran dar los servicios.” (Entrevistado G)

La nueva ideología, tendría que generalizarse entre todo el personal, para ello, la administración en curso se valió de nuevas estrategias, entre las que se encontraban la nueva contratación de personal en servicio social, que al situarse 
en el inicio de la era del desarrollo de las TIC's, se comprometían con el trabajo y con el desarrollo de la organización, de acuerdo a las experiencias de los empleados, la gente era lo más importante para el Infotec.

Alleire y Firsirotu señalan al respecto que las organizaciones reaccionan a su propia interpretación y a su propia construcción social. Las TIC's no eran simplemente una tecnología como un servicio, sino era un artefacto que distinguía a la organización ante el ambiente exterior. Como se puede ver en el siguiente fragmento de la entrevista: "ahí veías el compromiso que tenía la gente con los servicios, por eso te digo que lo más importante en todo el tiempo que estuve en Infotec era su gente. La calidad de la gente, porque tenía una gente muy, muy buena que sí se iba de Infotec, casi, casi ya tenía chamba segura en algún lado" (entrevistado E).

El proceso de innovación organizacional en la cultura, permitió que los valores institucionales, se convirtieran en valores adoptados en Infotec. Ya no era únicamente que los empleados lo consideraban como una formalidad de la organización, sino el entorno cultural les permitió hacerlos propios, como parte de su estructura mental, como una forma propia de realizarse dentro de la organización. Lo que también puede suponer que la influencia de la cultura organizacional ya ejercía influencia sobre los individuos.

En el sentido de los aspectos expresivos y afectivos de la organización, el aspecto que más lo hace notar, es el tema referente a los valores. El valor de la innovación, es la manifestación cultural que más atribuyen como propio los empleados del Infotec. De ello, se deriva que lo complementen con la calidad, el servicio. Pero tiene sentido, en el aspecto de que fortalecen al sistema 
socioestructural, respecto a los objetivos y estrategias de la organización. Sin embargo, los valores son muy importantes para los empleados, como lo indica un empleado: "Casi siempre, han sido los mismos (valores), innovación, calidad, servicio, honradez, comunicación, respeto, y siempre se han planteado, pero, independiente de eso, a como lo toma la gente y a como lo trabaja realmente, siento que sí en un inicio, aunque no nos lo decían directamente, aunque no lo planteaban en un documento de "ah tienes que ser... trabajar en equipo, tienes que ser honrado, tienes que ser responsable" (entrevistado A)

También, el valor de trabajo en equipo, que años atrás no era parte de los valores, comenzó a estar presente en la vida organizacional, tanto para resolver los proyectos que le competían al Infotec, así como para la vida personal de cada uno de sus empleados. Lo anterior, era una respuesta de la flexibilización y del proceso de innovación organizacional y tecnológica.

Esto, le dio sentido a la estructura que se forma en la cultura, a partir de los tres elementos que señala Schein (1997), en donde los empleados adoptan los valores para aplicarlos dentro y fuera de la organización y construyendo supuestos básicos y sistemas colectivos que se compartían en el Infotec. Los empleados ya habían considerado a las TIC's como un artefacto cultural, los valores de innovación y trabajo en equipo ya estaban programados en su mente, por lo tanto, los requerimientos organizacionales, los cumplirían: "Y hacíamos lo que podíamos, porque tampoco estábamos obligados a lo imposible, entonces decíamos: -oye, si puedo hacerlo, pero en estas condiciones, para lo demás nos toma tiempo y es sobre esto. Ósea si, en ese momento si planeábamos, nada más que los requerimientos nos llegaban de un día para otro, casi era de - si lo quieres es mañana, y llévate ¡todo!, entonces decíamos - 
haber, déjame hacer team back: - jseñores! Está este proyecto, si le entramos, van a ser desveladas, no vamos a dormir, se les va a invitar la cena, la comida y el desayuno, porque aquí vamos a estar 24 hrs. Nada más vamos a ir a nuestras casa a bañarnos y la gente se comprometía. Y veías a gente de 3 días sin dormir" (entrevistado $H$ )

El nacimiento de este sistema cultural, iba a la par con el crecimiento de las TIC's en el Infotec, así como con el cambio del sistema socioestrcutrural, ya que las estrategias, la cultura, las políticas y los procesos se introducían como mecanismos de control a través de la ideología, los valores adoptados, y el artefacto cultural que corresponde a las TIC's, con la finalidad de cumplir con el objetivo principal que era modernizar a la institución con base en estas tecnologías y con ello, la adopción de un nuevo sistema cultural.

Sin embargo, en esta etapa cultural la forma de desarrollar el trabajo bajo el discurso de la innovación, trae como consecuencia un cambio en la forma de entender los artefactos culturales, aunque como todo cambio, o reestructuración, no es percibida de igual manera por todos los empleados. Ya que de principio, la realidad no es percibida de la misma forma, sobre todo si trata de adaptarse a lo nuevo. En el caso de las TIC's, uno de los entrevistados lo describe a continuación: “...tecnológicamente definimos una nueva tecnología para el control de acceso impacta a todos, sea del área tecnológica o no, ¿Por qué? Porque probablemente Ileguemos a que las identificaciones sean un tag, que te ubiquen que estés en tu piso, que no estés cambiando de piso, sobre todo para las visitas, que el acceso se a través de un biométrico o de retina, todas esas mejoras basadas en tecnologías recientes pues sí impactan a todos, los servicios de impresión a los que están acostumbrados a tener una impresora siempre conectada a su equipo, la instalación de la red con el servicio de red 
inalámbrica, de cierta manera generó un cambio en los hábitos del gusto, ya no están en un solo lugar los desktops" (entrevistado G)

Los empleados tienen que aceptar la ideología del uso de la tecnología de información para el desarrollo de su trabajo diario, pero también acostumbrarse a los cambios que pueda sufrir constantemente. Por eso, el valor de la innovación toma un alto sentido, ya que tiene que ser parte del cambio cultural para que permita la aceptación de los artefactos culturales. Y el sistema socioestructural y el cultural, estén en consonancia en el proceso que lleva la flexibilidad y la innovación tecnológica, económica y organizacional.

\section{Año 2007 La divergencia cultural y las TIC's en Infotec}

El camino tecnológico, iniciado por el proyecto de modernización en Infotec, siguió creciendo, y ya hacia el año 2000, la institución se fortaleció y se reestructuró como un Centro Público de Innovación y Desarrollo en Tecnologías de la Información y la Comunicación aplicado a las organizaciones, con un nivel competitivo mundial. En ese año, la generación de recursos propios por la venta de servicios continuó dando los resultados esperados.

Sin embargo, la organización no podía omitir que su fundación se centraba en ser un CPI, por lo que necesitaba reforzar el área de investigación y docencia, que hasta la fecha se presentaba de manera informal en la estructura organizacional. Por ello es que en el 2007 se establece la primera maestría con validez oficial. Uno de los primeros cambios que se presentaron, se tradujo en la modificación del 
sistema socioestructural, que hasta el día de hoy, sigue buscando establecer una relación del sistema cultural del Infotec con el área específica de Investigación y Docencia, ya que existe una divergencia de ideología por parte de los empleados respecto a esta parte de la organización.

Particularmente, en este período se presenta un hecho relevante en el sistema cultural. $Y$ es que los entrevistados coinciden que el área de Investigación y Docencia se creó en el marco de un producto organizacional de Infotec, pero con un sistema socioestructural y cultural diferente al que se tiene en la organización: "entonces digamos que propiamente era una evolución, un crecimiento propiamente del área, cuando entré al área, no había investigadores de planta, solo investigadores externos, por ejemplo de la UAM, con la SEP, pero más bien los cambios fueron, primero, de crecer del área, en la parte de liderazgo, el cambio de liderazgo implicó un poco el cambio de rumbo, pero sobre todo, hacia donde seguir creciendo, luego se trajeron investigadores de planta, ya comenzamos con proyectos de investigación aquí, el área de docencia, sí bien, ya estaba creada, no estaba dentro del programa de la dirección de investigación" (entrevistado l)

En la organización, se tuvieron que realizar los cambios necesarios para justificar la misión y la visión del área, así como los valores que los regirían. Esto, como consecuencia de que la docencia y la investigación, no son un servicio tecnológico propiamente, sino que Infotec, el objetivo de crear el área de docencia fue para cumplir una política establecida dentro de los CPI, por lo que la ideología era diferente a innovar para vender y generar recursos, que hacer investigación que se pueda aplicar en el uso de las TIC's. 
Esa situación, trajo un desajuste para el área de Docencia e Investigación, por el hecho de que la ideología y los valores no eran adoptados de la misma manera, que para el resto de las áreas. Era un fenómeno cultural distinto respecto a la forma de organizarse como en la forma de trabajar. Al ser un área que no vende servicios de $\mathrm{TI}$, le ocasionaría conflictos de acuerdo a los intereses que tienen en común las demás áreas. El entrevistado J lo señala de manera muy clara:

“...Entonces bueno, los criterios de rentabilidad y como se manejan los proyectos no aplican acá, los tiempos son diferentes, entonces bueno, el choque cultural es muy fuerte. Hay muchísima discusión, por ejemplo a mí, me dicen -"haber, tú has gastado tanto, y sólo entró esto de colegiatura", - sí, pero y lo de las becas, - ah no, pero como no cobras, - pues espérate, es como si tu hicieras un descuento del $80 \%$ a tus clientes, sí yo cobrara los 240 mil pesos qué me cuesta el posgrado, no andaría tan mal. Entonces, ese tipo de criterios es lo que ellos están acostumbrados a una administración, no a una institución educativa, entonces sí, ha sido fuerte, tener que apegarte a normas hechas para otra cosa y no para una institución, ha sido difícil" (entrevistado J)

Más que la creación de una nueva cultura, se encontró este aspecto que es interesante, y es que el área de docencia, se encuentra en el proceso hasta la fecha para encontrar su identidad en el Infotec. Esto es como consecuencia del periodo de consolidación de una cultura de venta de servicios de TI, que se gestó desde 1994. Donde los valores como el trabajo en equipo para obtener un resultado de la exigencia de un cliente, no se pueden expresar de la misma manera en la investigación.

El enfoque gerencial, es el que no le permite tener identidad ni estructura propia al área de docencia, como lo sugieren los entrevistados. Las estrategias se basan en 
las ventas del posgrado, lo que causa un sentido extraño entre los empleados, ya que al ser un CPI, no comprenden como la estructura jerárquica se componga por gerentes en un área de docencia que tiene establecido como fin crear capital humano en nivel de posgrado.

"¿Tú has visto un centro público donde haya un gerente? hay gerentes y subgerentes aquí..." (Entrevistado F)

"ha sido todo un proceso, la verdad al principio yo hacía venta, salía a las oficinas públicas a visitar a los directores para promocionarles el posgrado, me encargaba de las pláticas informativas, de la primera parte del proceso de reclutamiento y selección, nosotros mismos vendemos el posgrado, aquí siempre se ha dicho que todos vendemos pero los demás no venden esta parte ni nosotros vendemos servicios de comunicaciones" (entrevistado E)

"La vocación nuestra no es negocio, acá si lo hacemos con el espíritu de formar capital humano, es grato, es grato hacerlo, ver los resultados, ver a la gente y ver que los proyectos que hacen $y$ diseñan aquí tienen un impacto en sus organizaciones" (entrevistado A)

Los fragmentos anteriores, pertenecen a diferentes entrevistados que concuerdan en que no es un servicio de comunicaciones lo que venden en su área. Lo perciben desde otra misión. Esto como consecuencia de las modificaciones en el sistema socioestrctural que rompen el vínculo legitimador del sistema cultural que tiene la organización en conjunto al concentrarse solo en la venta de servicios de TI y a su vez de la estructura orgánica que se ha orientado a la innovación y al desarrollo de TIC's.

Sin embargo, el área de docencia e investigación, se identifica de diferente manera en el apropiamiento de las TIC's, y esto genera confusión. Ya que en la 
misión de Infotec no se hace explicita la palabra "utilidades" en el sentido económico. Razón por la cual, a los empleados del área de formación académica le cuesta comprender la dirección para integrarse al sistema de valores y creencias que los demás empleados de la organización comparten. Aunque, esta situación, no merma la capacidad que tiene propiamente esta área para realizar el proceso de innovación organizacional a través de la docencia e investigación.

No se puede negar que existe un grado diferente de presuposiciones, de expectativas y de perspectivas en cuanto a la interpretación de la cultura organizacional. Solo existe una reproducción parcial del sistema cultural y estructural del Infotec en esta área específica. Lo que ha causado que el software mental de los empleados se encuentre fracturado. Lo que coincide en la siguiente opinión: "yo creo que más bien es que hay 2 Infotecs, uno que se maneja con el criterio empresarial, qué es casi todo el edificio y otro lo qué es un centro de investigación y docencia, y, ha costado mucho trabajo, no sólo a mi sino a los investigadores, en dónde los criterios de administración de una empresa de TI y de servicios de telecomunicaciones y demás a los de una qué es más académico son diferentes, entonces, siempre nos han querido medir por rentabilidad, en fin, si, esto no es negocio...para sobrevivir porque tampoco a la fecha se puede decir que Infotec haya gastado demasiado, siempre hemos recurrido a fondos públicos como son la SE" (entrevistado C)

La creación de los significados colectivos se ha fomentado en el área de docencia, donde los empleados están conscientes de la relación que tienen con la organización y que hasta cierto punto delimita el sistema estructural. Los supuestos básicos fomentan la aceptación del área, entre la parte de Infotec que se dedica únicamente a la innovación y desarrollo de los servicios de TI para su 
venta, como del área de docencia que adapta a las TIC's pero de modo isomorfo en donde el sistema cultural busca encontrar su identidad a la fecha.

Sin embargo, aún falta conocer entre todas etapas, cómo ha sido la relación entre los elementos presentados. Cómo se han comportado entre ellas y sí existe una correlación. Por ello, a continuación se presenta la última etapa del estudio de caso, donde se explica cuál es la relación entre los elementos organizacionales en relación a las TIC's en Infotec.

\subsection{Etapa 3. La relación entre cambio, estructura y cultura organizacional de Infotec en relación a las TIC's}

Esta última etapa de estudio, tiene la finalidad de explicar que las organizaciones se conforman de elementos que ayudan a su creación y a su reproducción, como se ha hecho mención en la introducción de este trabajo. Para ello, se utilizará como base la figura 2 presentada al inicio. $Y$ con base en los eventos críticos que la autora de dicho trabajo ha elegido y que también se han presentado en la figura 1.

La figura base es la que se presenta de lado derecho, la cual pretende mostrar la relación o vínculos entre las variables que conforman a la organización. Aunque, también se aclara, que a partir del análisis efectuado, se ha encontrado que dicha relación no se presenta de manera lineal o estática, sino que para llegar a la producción de cambios, se presentan alteraciones que generan otro proceso al que se le ha denominado innovación organizacional.

Figura 2 La relación de las variables organizacionales en relación a las TIC's 


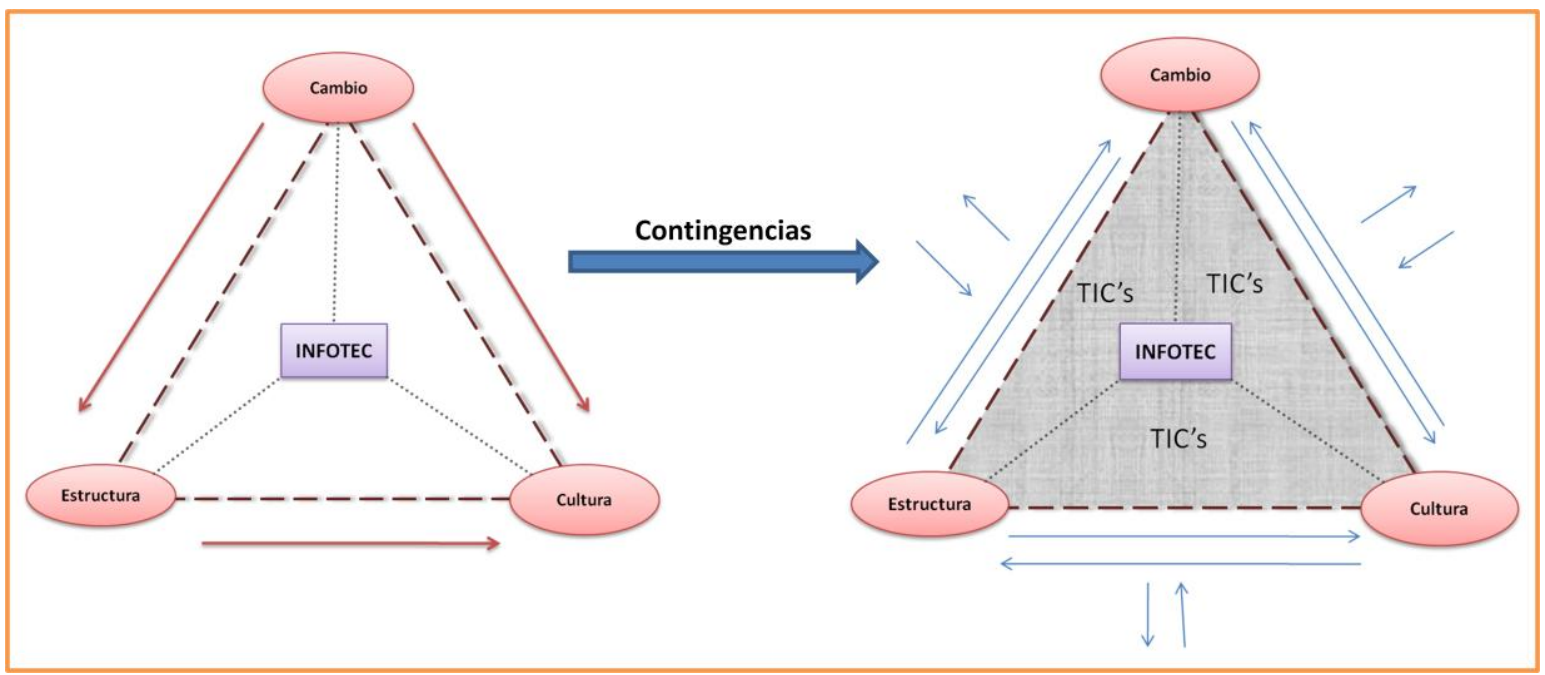

Elaboración propia

Si bien, se ha presentado cuál ha sido la evolución de dichas variables en el apartado anterior, es importante conocer si hay alguna relación entre ellas dependiendo de los eventos críticos que ya se han instaurado, no con la pretensión de generalizar, ya que se ha establecido que todas las organizaciones son entes que se estructuran de diferente manera, así como los individuos que las conforman se comportan de forma heterogénea.

Esta idea o representación es a causa de la revisión de material documentado sobre las TIC's en México, y la necesidad de estudiarlo es porque las TIC's en las organizaciones tienen escasos 25 años, en los que sólo se ha puesto atención en la manera en que incrementa o decremento la productividad de los trabajadores. Sin embargo, al revisar la interactividad que tienen las variables de la organización con las TIC's, se puede ver que impacta en todas ellas, la cuestión aquí es ¿Cómo? ¿Es de manera equilibrada? ¿Cómo es está interacción en el caso concreto de Infotec? 


\section{F Año 1974 El origen de la innovación organizacional de Infotec}

La fundación del Infotec como se ha explicado es consecuencia de una contingencia externa, provocada por el cambio revolucionario en el que se encontraban las organizaciones en temas de tecnología. En ese sentido, Conacyt tiene que crear los distintos $\mathrm{CPI}$. Sin embargo, la incidencia de este cambio, provocaría que el Infotec tuviera una incidencia externa para la formación de su configuración y cultura organizacional, que se iría reforzando durante sus primeros veinte años de vida.

La figura 19 representa las tres variables de análisis que se han estudiado en el Infotec, representadas en cada uno de los ejes del prisma. Y los puntos dispersos se refieren a la introducción de las TIC's en el Infotec. En este caso, la base triangular que semeja a la organización, abarca en mayor medida a las variables

de estructura y cultura. $\mathrm{Y}$ las flechas que aparecen apuntando en dirección al prisma se refieren a la presión que ejerce el ambiente exterior sobre Infotec.

Figura 19. Relación de las variables organizacionales y las TIC's en el evento crítico de 1974 


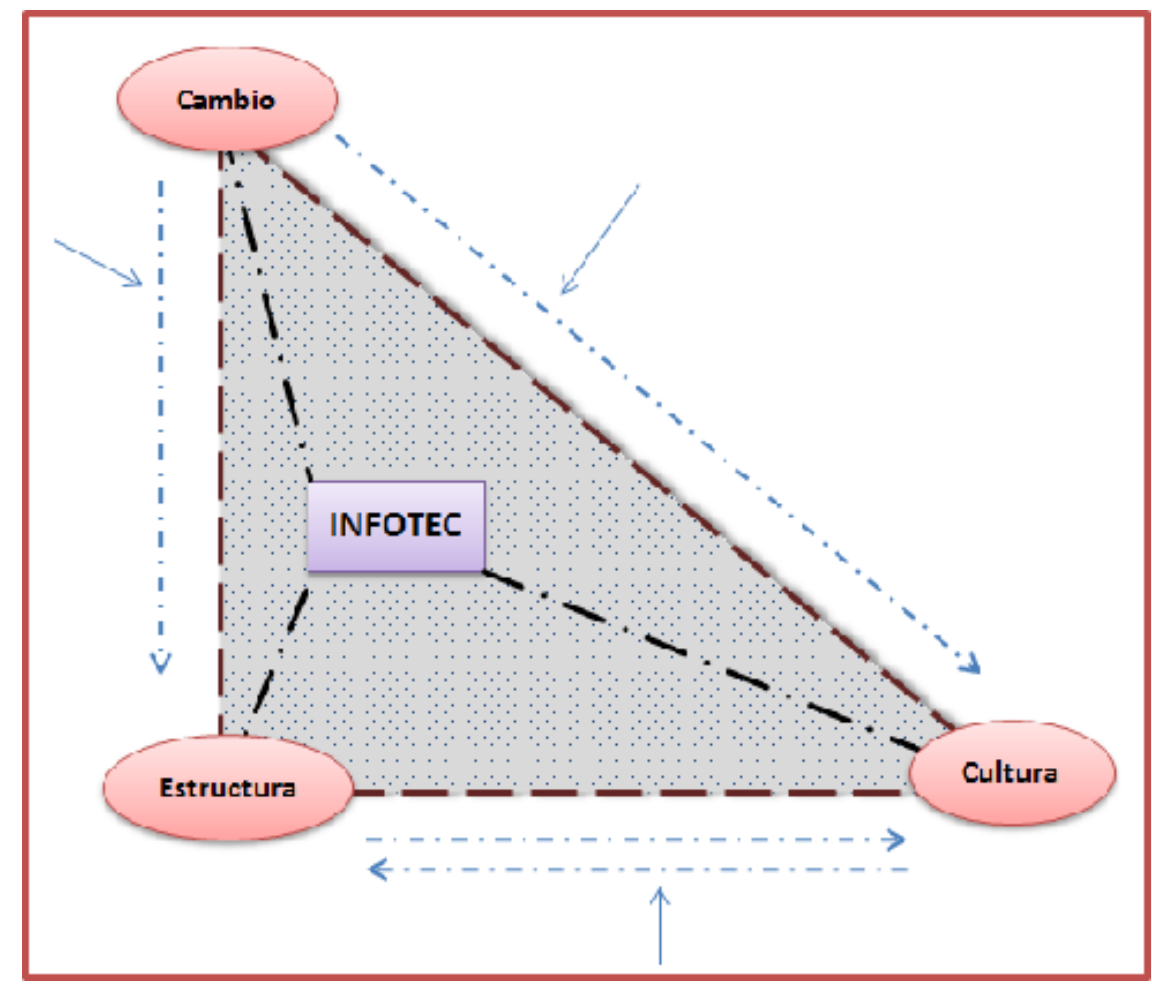

Elaboración propia

De acuerdo a la figura 19 y al análisis presentado en la parte uno y dos de estudio, el ambiente externo es el principal factor para que la fundación de Infotec fuera el resultado de un cambio revolucionario, por causa del contexto político y social que se vivía en la época de los 70's. Este cambio, pudo perpetuarse en el Infotec a través de tomar como base de desarrollo el uso de las tecnologías de la informática que se establecieron con el uso de las primeras computadoras que se utilizaban para el almacenamiento de la información. En el esquema se representa con los puntos dispersos en toda la figura.

La estructura organizacional se relaciona con el cambio porque se valió de la configuración mecánica para dimensionar los procesos formales y las estrategias a seguir para el cumplimiento del objetivo de obtener la información requerida por la industria a partir de vínculos con otros países. Esto requirió de un sistema 
socioestructural que se apoyara de políticas, procesos y estrategias que estaban condicionadas por un organismo externo.

A su vez, este sistema socioestructural sustentaba al sistema cultural que se conformaba hasta entonces de los valores y de la ideología que se reproducía por medio del sistema colectivo de significados que sobre todo se relacionaban por medio de la base estructural. Por ello, es que en esta etapa se ejerce una relación bidireccional en la estructura y en la cultura organizacional de Infotec.

En el caso de los valores se desarrollaban de acuerdo al objetivo organizacional, por otro lado, el tamaño de la organización y la tecnología se estructuraban de acuerdo a los requerimientos de la sociedad y del mercado. En ese sentido, en los primeros veinte años de existencia de Infotec, la relación entre la estructura y cultura se correspondían para conformar los demás aspectos como toma de decisiones, grados de autoridad, el uso de las tecnologías y finalmente generar una cultura de Información que permeaba a toda la organización.

En esta secuencia, el proceso de innovación organizacional que tiene Infotec es muy pobre en cuanto a aportaciones se refiere. Ya que la mayoría de los elementos organizacionales en este evento critico se mantienen estables, sin mayor novedad. Pero, como se verá, el permanecer en esta situación, provoca que haya un impulso de la creatividad organizacional años más adelante.

\section{허 Año 1994 La innovación organizacional financiera de Infotec}

Las contingencias que surgían alrededor del Infotec se fueron sumando durante sus primeros veinte años de existencia. Pero el más grave, que puso en riesgo la 
permanencia de la organización, fue el contexto económico y político porque el que atravesaba el país. Que derivó en la quiebra de numerosas organizaciones paraestatales. Así fue el caso de Infotec, después de recibir los resultados de su auditoria tenía pérdidas financieras por más de 20 millones de pesos. Lo que derivó de la mala eficiencia del uso de los recursos, así como el rezago de innovación y tecnológico que la organización tenía hasta ese momento.

Cuando el Infotec pide la oportunidad de valerse por sus propios recursos, se comienza por un cambio regulativo para controlar el ambiente turbulento y complejo en el que la organización se situaba. Como se indica en la figura 20, en esta etapa el cambio organizacional predominó en el Infotec. Asimismo, las tecnologías de información y comunicaciones se incrementaban con el uso del internet.

La relación directa que presentó el cambio sobre la estructura y a la vez la estructura sobre el cambio fue por cuestiones de dejar de funcionar sólo como un centro público. Lo que a su vez repercutió en el sistema cultural. Ya que el cambio regulativo dejaría atrás el esquema de medios a fines que sustentaba la estructura mecánica, para con ello, iniciar la transición de una estructura orgánica y un nuevo cambio que impactaría los procesos y estrategias del Infotec.

Con la flexibilidad de la estructura sustentada por el cambio, se produjo un nuevo objetivo que se basaba en el retorno de la inversión, en la venta de servicios de tecnologías de la información. Por ello, es que la estructura cambió de acuerdo a las contingencias y exigencias que el exterior sugería. Esto a su vez, impactó a la 
cultura porque los empleados tendrían que cambiar su ideología, así como los valores que practicaban dentro de la organización.

En la figura 20 se mira como la relación entre las variables parte del cambio regulativo en el proceso, aunque esta correspondencia se da también en la estructura porque actúa como un agente de cambio para la cultura. La consecuencia de esto, es que la misión y visión por medio de la nueva estrategia cambia para poder justificar ideológicamente a las TIC's como artefacto cultural.

Aunque, en el trayecto para lograr la consecución de esta nueva estrategia financiera, el Infotec se valió del proceso de innovación organizacional, cuando se percata de que tiene que innovar en una forma de obtener los recursos monetarios para su sobrevivencia, por lo que se vale de ese impulso económico para introducir a las TIC's como un recurso que pudiera ser parte de conseguir el objetivo. A su vez, esto justifica los cambios que se reproducen en la estructura y en la cultura.

Figura 20. Relación de las variables organizacionales y las TIC's en el evento crítico de 1994 


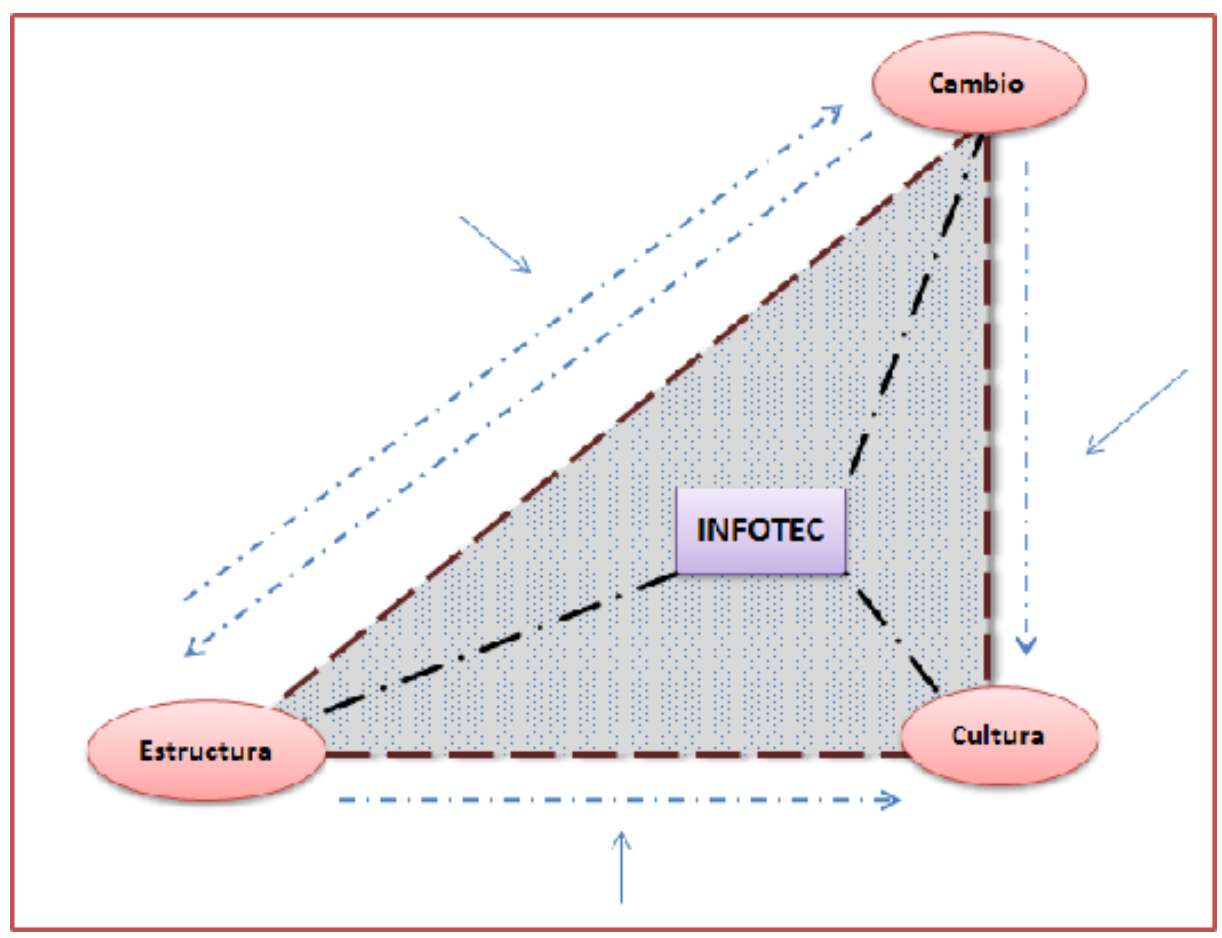

Elaboración propia

Los puntos que se encuentran dentro de la figura representa la forma en que las TIC's se empiezan a expandir. Ya que en este período se empieza a hacer uso del internet, por lo tanto, cambia la estructura porque es necesario crear nuevas áreas específicas que se encarguen de utilizarlo de manera correcta y solucionar los nuevos problemas que de ello se derive. Por otro lado, los empleados tienen que aceptar la ideología a través de la creencia del uso de las TIC's para el desarrollo y modernización del Infotec, en ese sentido, el cambio se asimila de manera que se hace una estrategia para la venta de servicios basados en $\mathrm{TI}$.

\section{후 Año 1996 La innovación organizacional de las TIC's en Infotec}

Este año es, desde el punto de vista de la autora, el año donde convergen las variables de estudio de la organización con la introducción total de las TIC's en Infotec. A partir de los cambios estructurales y culturales que se iniciaron en 1994 
tuvieron como principal objetivo la modernización de la organización con base en la misión de la innovación y desarrollo de las TIC's para su aplicación en la propia organización, como para la venta de servicios a empresas y gobierno.

Así, cuando se presenta la oportunidad de desarrollar el proyecto de la RTN, inicia un cambio que se reproduce en todo el Infotec. Se presenta un vínculo entre el cambio, la estructura y el cambio con base en el uso de las TIC's. En la figura 21 se muestra que las flechas que representan las contingencias del ambiente exterior, lo hacen de igual manera de la organización hacia afuera. La explicación es que la misión de Infotec en este período tiene como principal objetivo hacer uso de las TIC's para que sean de utilidad a las empresas, gobierno y sociedad.

Este cambio revolucionario, tendría el efecto de adaptación de las áreas estructurales, de las formas de trabajo, y de los empleados para aceptar que la tecnología de información y comunicaciones era un artefacto cultural con el que estarían en contacto en la organización. Además el proceso de innovación organizacional, tendría como su principal representante a la innovación de las TIC's, en este aspecto, la organización se reinventa y no sólo cumple con el objetivo de vender servicios de $\mathrm{TI}$, sino también innova con la creación de productos que aplica dentro de la organización para su beneficio, y posteriormente los vende.

La figura 21 indica que los cambios a partir de esta fecha era constantes, la estructura provocaba un cambio que a su vez repercutía en el sistema cultural, y éste se vinculaba con el sistema socioestructural, donde ambos se relacionaban 
para justificar los cambios en la ideología, los valores, los artefactos culturales, las estructuras, las estrategias, las políticas y los procesos que ya se han descrito anteriormente.

Figura 21. Relación de las variables organizacionales y las TIC's en el evento crítico de 1996

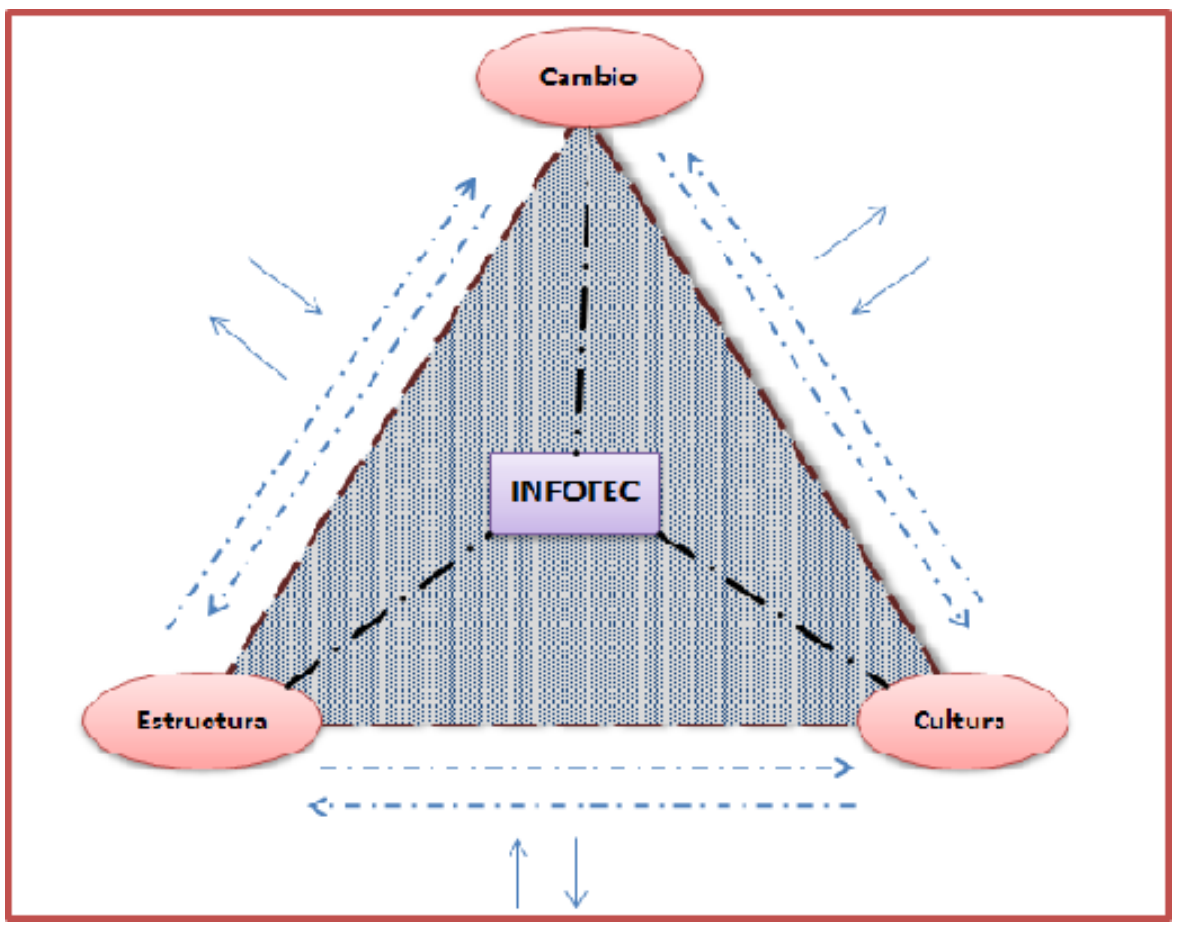

Elaboración propia

La totalidad de las TIC's en el Infotec, sin duda genera cambios, en comparación con los períodos anteriores. La estructura se flexibiliza y se generan nuevas áreas, y esto tiene sentido, ya que las TIC's se han reproducido en las organizaciones que tienen una estructura orgánica, ya que la innovación en la organización, solo decisiones y tecnología muy especializada, además que involucran a los seres humanos para su uso. 
Para que los empleados lo aceptaran, la organización se basa en el sistema cultural, como se muestra en la figura 21, esta relación es fundamental para que pueda coadyuvar al desarrollo de las variables restantes. Por medio de la ideología y de los valores, en el cual, estos últimos son los que toman relevancia para la reproducción del trabajo y de la aplicación de las TIC's. Por lo que, se generan supuestos en la organización que le dan sentido a los cambios que sufre la forma de trabajar y del nuevo lenguaje en telecomunicaciones al que deben acostumbrarse para aceptar los cambios en las áreas y en los procesos de trabajo.

\section{답 Año 2007 La innovación organizacional del área de docencia en Infotec}

Anteriormente se ha hecho mención de que a partir del año de 1996, las TIC's se apropian del Infotec, para su aplicación en la misma organización, como para la venta de servicios. A la vez, se genera una oleada de cambios que propician la estructura y la cultura que actualmente existe en Infotec. Sin embargo, al ser una organización que se dedica a la aplicación e innovación de las TIC's las contingencias y el ambiente turbulento ejercen presión para que la organización se desarrolle conforme avanza el desarrollo de las TIC's, ya que estas tecnologías no tienen un desarrollo estático.

El asunto es que conforme transcurrieron los años, el CPI necesitaba cumplir con uno de los objetivos bajo los que se rigen estos centros, y se trataba de la investigación y docencia. Por lo que CONACYT le solicitó a Infotec que cumpliera con esta política de manera formal. Para lograrlo, la organización debía recurrir a 
un cambio que aunque no afectaba a por completo a la organización, si sería de manera parcial.

En esta etapa, el Infotec requiere de un cambio que ayude a la conformación del área de docencia e investigación. Este cambio evolucionario, se reproduce en solo una parte de la estructura jerárquica, como se muestra en la figura 22 , al generarse una nueva área en la configuración innovadora. El sistema cultural también incide en esta estructura, ya que de acuerdo con los datos presentados, existe un choque cultural entre las áreas restantes, y surge una lucha por la búsqueda de la identidad del área de docencia e investigación.

El proceso de innovación organizacional que se desarrolla en este evento crítico tiene diversas formas de expresión. En primera, el área de docencia se reinventa al formalizar los objetivos de difundir el conocimiento y desarrollar las maestrías a impartir con base en lineamientos administrativos y en respuesta de la apropiación de las TIC's hacia la fuerza de trabajo. En segunda, se flexibiliza para adaptar los valores del área con los valores institucionales. $Y$ finalmente, se renueva para luchar por un reconocimiento de identidad como parte complementaria de la organización.

Por esa razón es que se encuentran en constante vinculación porque para desarrollarse una y otra necesitan contener elementos que las justifiquen. Sobre todo, porque la ideología, los valores, los procesos y políticas, los atribuyen de diferente manera los empleados de las distintas áreas. Como se muestra en la 
figura 22, a pesar de que las TIC's cubren en la totalidad a la organización, existe una tendencia de un cambio que afecta en mayor medida al sistema cultural.

Figura 22. Relación de las variables organizacionales y las TIC's en el evento crítico de 2007

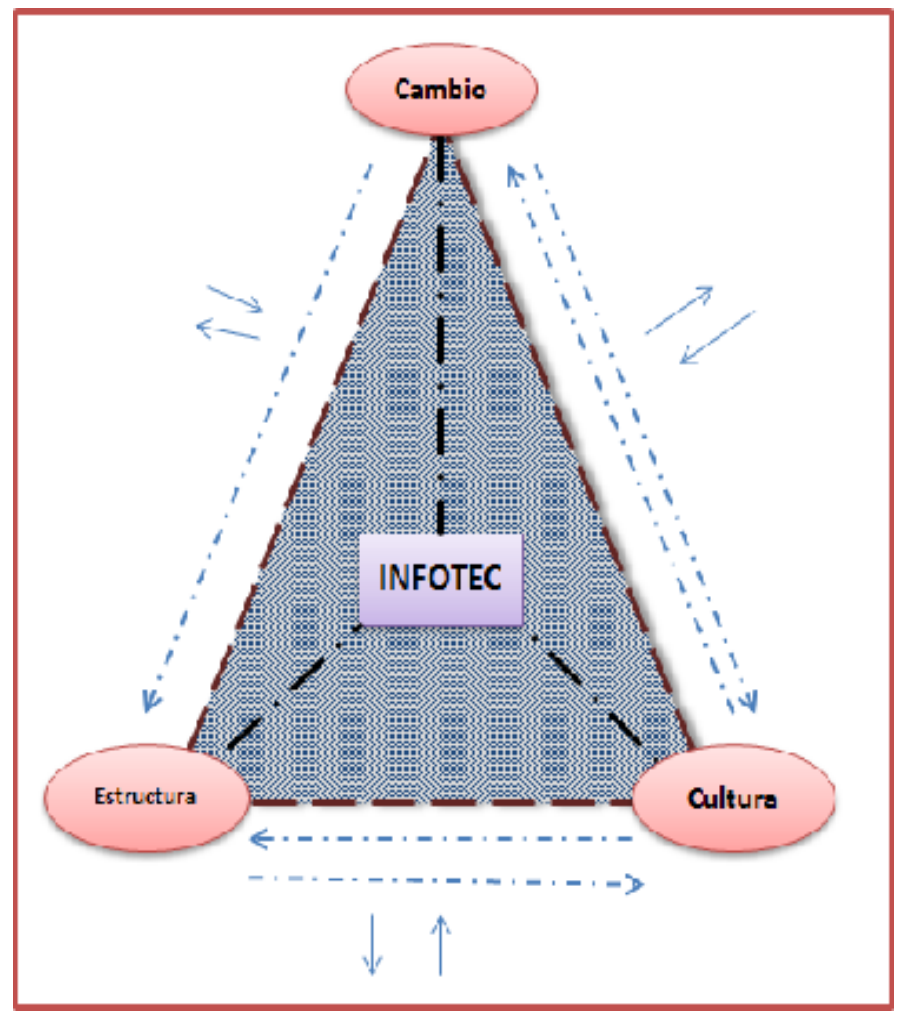

Elaboración propia

Estos vínculos que se muestran en la figura 22, permiten explicar que a pesar de que una contingencia exterior genere cambios en el Infotec, estos cambios impactan de diferente forma a las distintas áreas de la organización. Así como sus vínculos, puede ser recíprocos o no, dependiendo de cómo se presente el cambio, ya sea evolucionario o revolucionario, normativo o regulativo.

Por presión del ambiente exterior, o por el sistema cultura que requiere reforzarse. En el caso de Infotec, se percibe que en ninguno de esos eventos críticos se presentan los cambios de igual forma, sin embargo, sí interfieren en la estructura y 
en la cultura. De igual forma, las TIC's han sido un artefacto cultural protagónico para el desarrollo de estos cambios y para el crecimiento del Infotec. Sin embargo, como también se ha señalado, la intención de utilizar una representación para explicar que los cambios que se tienen lugar en la organización, no se llevan a cabo de manera lineal, sino que se deriva un proceso de innovación organizacional que le da sentido al impacto que tiene el cambio en las áreas de la organización. 


\section{CONCLUSIONES}

El trabajo que se ha realizado en el Infotec ha permitido comprender a las TIC's desde un acercamiento más que pragmático, como un tópico que se ha introducido en diversos campos de las Ciencias. En esta ocasión correspondió analizarlo desde la perspectiva de los Estudios Organizacionales. Realizar una perspectiva de cambio desde esta materia, resulta útil para comprender que la teoría de la contingencia sigue vigente como un eje que permite entender que la tecnología sigue siendo un factor que determina la estructura y a su vez la estructura puede terminar el tipo de tecnología en la organización (entre otros factores, como la cultura, y en este caso, el proceso de innovación organizacional).

Asimismo, tener un acercamiento con una organización que es $100 \%$ mexicana, también permite contextualizar cómo el Infotec se ha reinventado ante los diversos cambios en diferentes eventos críticos, y cómo es que las estructuras y los individuos cambian la forma de trabajo al aceptar el uso de las TIC's para el desarrollo de su trabajo. En ese sentido, mencionar a estas tecnologías como un elemento que cambia a la organización, no sólo se queda en la teoría, sino que el dinamismo de las organizaciones para responder a las contingencias y al desarrollo tecnológico permite corroborar los supuestos teóricos.

Como se pudo mostrar, el sólo hecho de estudiar el comportamiento de las TIC's en la organización permite generar un complejo modelo de interacción con otros elementos organizacionales, en este caso, se pudo relacionar con el cambio, la 
estructura y la cultura. Pero, cabe aclarar que desde la perspectiva de estudios organizacionales puede tomar diferentes puntos de partida, como la toma de decisiones, la estrategia, el poder, el comportamiento de los individuos, la comunicación, y como ha alterado las formas de trabajo, entre otros, que de manera fortuita se encontraron como el proceso de innovación organizacional.

En este caso, la introducción de las TIC's en Infotec, refleja que desde el momento en que se insertan como una nueva tecnología generan un cambio. Este proceso de cambio requiere de tiempo aunque este último sea relativo. Ya que se modifican aspectos de la organización que no son tangibles, sobre todo en la ideología de los empleados, porque ante el evento crítico que se reproduce genera un cambio cultural que debe ser aceptado e interpretado bajo un esquema cultural tripartita que considera a los artefactos culturales (TIC's), los valores y los supuestos adoptados, que permiten darle sentido al cambio en la organización.

El cambio organizacional es un tema que se reproduce de acuerdo a las condiciones en las que el ambiente o la organización se presenten en un determinado momento. Por ello, es que existe una variación en cuanto el tiempo de aceptación y de respuesta. Aunque, en el caso de Infotec los cambios que se han presentado desde su fundación a la fecha han sido favorables para la organización, no significa que el cambio en general siempre obtenga resultados positivos.

En el caso de Infotec, el cambio organizacional, ha tenido diversas variantes, desde que fue producto de un cambio revolucionario a causa del contexto en el 
que se inicia, no solo para el Conacyt, sino para la sociedad misma. Ha presentado también en su historia una tendencia de cambio evolutivo, acompañado de cambios subsecuentes que respaldan esta evolución. Estos cambios han sido impulsados por la inserción de las TIC's, por lo que puede parecer de primera instancia que sólo responde a las contingencias que se presentan como consecuencia de dicha tecnología.

Las TIC's empujan al cambio organizacional como se pudo constatar en el estudio de caso, ya que, no solo tienen el papel de utilizarse como una tecnología para el beneficio de la organización, sino que adquiere un valor cultural, se adapta como un proceso de innovación. Esta situación conlleva a que la organización evolucione y por lo tanto se den los cambios en diversos periodos de tiempo, porque la tecnología no es un elemento estático.

De esta manera, la reproducción de los eventos críticos en Infotec, coincidían con la integración, renovación y adaptación de las TIC's a todas las áreas de la organización. A su vez, trajo como consecuencia que la cultura y la estructura de la organización también sufrieran cambios que han sido de manera paulatina. $\mathrm{Y}$ como se ha señalado, el mecanismo de respuesta ha sido desarrollar el proceso de innovación organizacional.

En este sentido, Infotec ha demostrado que, en todos los procesos de cambio, la capacidad de reinventarse, renovarse, e incluso evolucionar, considerando los recursos propios de la organización, así como la innovación de las TIC's, tanto para vender servicios, como para aplicarlas en la misma institución, y finalmente 
para adaptarlas a un modelo educativo. Han sido respuesta a las diversas contingencias que se han sumado así como a la evolución de las TIC's.

En el caso de la estructura organizacional de Infotec, quizá en algún estudio diferente pudiera retomarse la idea de analizar en qué tipo de configuración se adaptan las características estructurales de esta organización. Ya que, como se permitió analizar en el estudio, pasó de ser en sus primeros veinte años de vida una organización mecánica con una base altamente burocrática, a una organización que se ha flexibilizado, caracterizada por una adhocracia innovadora, pero se cuestiona que sigue teniendo el sustento de una burocracia profesional de la que no se desprende.

Sin embargo, es interesante ver la manera en que todos estos elementos se compaginan para desarrollar los objetivos organizacionales, que si bien, tienen flexibilidad de adaptarse a los cambios y en consecuencia innovar procesos operativos y organizacionales, no se deslinda el Infotec de cumplir con lineamientos estrictamente formales que son característicos de una configuración mecánica que tiende a caer en la estandarización de los procesos, como es el caso del área de investigación y docencia.

En ese sentido, se nota que el sistema cultural juega un papel relevante entre el cambio y las TIC's en el Infotec, ya que los empleados deben adaptarse tanto al cambio en la organización como al cambio tecnológico. $\mathrm{Y}$ es que en la organización se ha generado una cultura de adaptación al cambio, lo que se ha transformado en una ventaja para la supervivencia de la organización. La 
ideología es un elemento clave para la renovación de la cultura organizacional en Infotec en consecuencia del cambio organizacional que se presenta en cada evento crítico.

La ideología en Infotec, es determinante en la construcción de su sistema estructural como en el cultural. Lo anterior, lo respaldan los empleados en las respuestas a las entrevistas. El elemento de TI considerado como un artefacto cultural también cobra importancia relevante, sobre todo cuando en los valores, está en primer lugar la innovación, que se ha traducido como una forma de trabajar en el Infotec, independientemente de que el área no sea específicamente de desarrollo de las TIC's.

Resultó una labor interesante comprender como Infotec ha atravesado por diferentes eventos críticos que han sido el origen de sus diversos procesos de cambio, donde se muestra que puede tener una relación directa con la introducción de las TIC's, así como generar una estructura diferente que es justificada por medio del sistema cultural. Aunque, es necesario mencionar aquí que estos vínculos en su conjunto han ayudado al desarrollo de la organización, sin embargo, muestran como la forma del trabajo y de aceptar ideológicamente un instrumento ha sido perpetuado a través del tiempo y no de manera instantánea.

Aunque, esto no pretende ser una generalización de que siempre sucedan estos vínculos en las organizaciones que adoptan a las TIC's. Quizá, sería de utilidad realizar un estudio comparativo en un $\mathrm{CPI}$ de similares condiciones tecnológicas 
para comprender como el cambio organizacional puede reproducirse en contextos similares y como son sus condiciones de respuesta ante tal contingencia.

Como se ha venido mencionado en algunos momentos del trabajo, el realizar el análisis desde el enfoque de cambio organizacional en Infotec, permitió encontrar que el vínculo que se producía con la estructura y la cultura, no se reproducía de forma lineal, aunque en algunos momentos si podía tener un impacto de manera bidireccional. Asimismo, estos cambios se generaban a consecuencia del ambiente exterior por el uso de las TIC's, pero también se reproducen generados por la misma organización como un proceso de innovación.

Lo anterior, es lo que señalo como proceso de innovación organizacional, un concepto que permite entender que el momento que se produce un cambio, también atraviesa por dicho proceso para generar un impacto en la organización. Esa característica, está permeada por la capacidad de respuesta que ha tenido el Infotec ante los diversos eventos críticos, con el objetivo de reinventarse y de adaptarse, como ya se ha indicado, no sólo han sido en el ámbito tecnológico, sino también en el financiero, en el sistema estructural y cultural. En consonancia con la característica la flexibilización de la organización que en consecuencia permite la innovación.

Finalmente, la relevancia de este trabajo, es explicar la vinculación del enfoque de los Estudios Organizacionales en relación al tema de las TIC's. Los resultados muestran que el Infotec ha tenido que adaptarse a los cambios como un estilo estratégico y cultural, ya que por el lado de la estrategia, se busca optimizar los 
recursos bajo la creación de áreas que permitan sustentar la innovación, y por parte de la cultura, tiene un acercamiento de compañerismo con los empleados para que la ideología pueda ser aceptada, así como los procesos que se generan.

Quizá, sería útil mantener una línea de investigación que permita comprender a fondo la vinculación de estos conceptos, y sobre todo, atrapar elementos que permitan sustentar de manera teórica el proceso de innovación organizacional, ya que considero es un aporte que enriquece al estudio de la complejidad organizacional, y que no sólo se puede reproducir en organizaciones enfocadas al área de $\mathrm{TI}$, sino en organizaciones que tengan la capacidad de reinventarse en consecuencia de un cambio.

Además, revisar un periodo de tiempo más adelantado de la organización, puede servir para conocer cómo es que Infotec ha seguido su proceso de innovación, en qué áreas de la organización, y qué implicaciones han tenido las TIC's, ya sea en generar procesos de innovación progresivos, o de mayor intensidad que generen un nuevo cambio organizacional. 


\section{BIBLIOGRAFÍA}

Abravanel, Allaire, Firsirotu, et al, (1992), Cultura Organizacional: aspectos teóricos, metodológicos y prácticos, Legis, Colombia, pp. 3-34

Almada de Ascencio, Margarita, "La ciencia de la información y la Tecnología en México", en México: ciencia y tecnología en el umbral del siglo XXI. Consejo Nacional de Ciencia y Tecnología, CONACYT y Miguel Ángel Porrúa, México, 1994, pp. 683697

Alvesson, Mats, (1993). Cultural perspectives and organizations. University Press. London, Cambridge

Arellano, David, Enrique Cabrero, (2000), Reformando al gobierno una visión organizacional del cambio gubernamental, Miguel Ángel Porrúa, pp. 78-94

Barba Álvarez, Antonio y Solís Pérez, Pedro, (1997). Cultura en las Organizaciones: Enfoques y Metáforas de los Estudios Organizacionales, México, Vertiente Editorial.

(2001), Calidad y Cambio organizacional: ambigüedad, fragmentación e identidad. El caso del laboratorio de prueba de equipos y materiales, Tesis de Doctorado en Estudios Organizacionales, UAMI

(2009), Reflexiones sobre el estudio de caso en el análisis organizacional, en "Pequeñas organizaciones: complejidad y diversidad organizacional. Estudio de casos de organizaciones mexicanas”. Ayuzabet de la Rosa, et al (Cords.), UAMJuan Pablos Editor, México, pp.13-21

Barrios, Miguel A. (2007), "La actual Revolución Tecnológica en el Ciclo Largo. Reflexiones sobre la base Tecnológica del Quinto Ciclo de Kodratiev", en Tecnologías de la Información y la Nueva Economía, Coord. Jesús Lechuga Montenegro, Universidad Autónoma Metropolitana, Unidad Azcapotzalco, México, pp. 103-123

Burbules, Nicholas (2001), Educación: Riesgos y Promesas de las Nuevas Tecnologías de la Información, Garnica, S.A., España

Casas, Rosalba, "Entre el Sentido Común y la adopción de un paradigma. La definición de la política de ciencia y tecnología en México", en Ciencia y Tecnología e 
Innovación en América Latina, Publicaciones de la Universitat de Barcelona, Barcelona, 2000, pp. 149-173

Castells, Manuel, (2011),"La Era de la Información: Economía, Sociedad y Cultura”, en La sociedad red, Vol. 1, Siglo XXI, España, pp.31-258

(2009), Tecnologías de la información en los negocios, McGraw Hill, México, pp.1-30

Cortés, Fernando, La investigación cualitativa frente a la Cualitativa, El Colegio de México, México, pp. 27-58

Clarke, Thomas y Stewart Clegg, (1998), Changing Paradigms. The Transformation of Management Knowledge for the 21' 1 Century, Harper Collins Business, London, pp. 9-59

Clegg, Stewart (1990), Modern Organizations. Organization studies in the Postmodern world. Sage, London, pp.176-207

Cohen Karen, Daniel (1996). Sistemas de información para la toma de decisiones, Mc Graw Hill interamericana de México S.A. de CV. Pág.234

Cruz Rodríguez, David Salvador (2010), La PC como artefacto cultural y su relación con los valores organizacionales: el caso de la pequeña empresa desarrolladora de software, Tesis de Maestría en Estudios Organizacionales, UAMI

Daft, R. (1998), "Fundamentos de la estructura de la organización”, en Teoría y diseño organizacional, México, Thompson Editores, pp. 200-243

Derray, A. et A. Lausseault (2006), "Typologie des structures“, dans Les structures d'entrepise, Paris, Ellipses, pp. 39-48

Dimaggio, P., Walter Powell, (1983), "The iron cage revisited: Institutional Isomorphism and Collective Rationality in Organizational Fields", American Sociological Review, Vol. 48, pp. 147-160

De Pablos, Carmen, et al, (2004), Informática y Comunicaciones en la empresa, ESIC, Madrid, pp. 30-45

Hall, R. (1996), "La estructura organizacional: sus formas y sus resultados", Organizaciones: estructuras, procesos y resultados, México, Prentice Hall, pp. 5091 
Harigopal, K. (2001), Management of organizational change, leveraging transformation, Response Books, New Delhi

Herdin, Thomas, et al, (2007), "Culture and Technology: a mutual shaping approach", Information Technology: Ethics Cultural Perspectives, Hershey PA, Idea Group Reference, pp. 54-67

Heydebrand, Wolf (1989). New organizational forms, work and occupations, SAGE journals. New York University press Vol. 16, No. 3. USA, pp 323-357

Lawrence, P., and Lorsch, J., (1967), "Differentiation and Integration in Complex Organizations" Administrative Science Quarterly 12, 1-30.

Lechuga, Jesús (2007), "México y Cuba: ¿hacia una sociedad de la información?, en Tecnologías de la Información y la Nueva Economía, Coord. Jesús Lechuga Montenegro, Universidad Autónoma Metropolitana, Unidad Azcapotzalco, México, pp. 125-169

Lorette, Richard (1990), Cases in the management of Information systems and information technology, Homewood, Boston, pp. 97-106, 157-163

Magallón Diez, María Teresa (2004), "La figura del cambio organizacional en la construcción de la teoría de la organización. Evolución y nuevas perspectivas" en Los estudios organizacionales en México. Cambio, poder, conocimiento e identidad, Luis Montaño (Coord. General), UAM-UDO-PORRÚA-CÁMARA DE DIPUTADOS, México, pp. 65-911

Malone, T.W.; Rockart, J.; "Computers, networks and the corporation". CISR Center for Information Systems Research, MIT. Working paper Nro.232.

Márquez, Ma. Teresa (1982). 10 años del Consejo Nacional de Ciencia y Tecnología. Ed. Conacyt, México, 1982

Mintzberg, H. (1989), Mintzberg y la dirección. Madrid. Días de Santos Ediciones, pp. 109354.

Montaño Hirose, Luis (2003), "Modernidad y cultura en los estudios organizacionales. Tres modelos analíticos", en Organización y Cultura. Controversia, complejidad y realidad. Revista Iztapalapa, Núm. 55, Año 24, julio-diciembre, pp. 15-33 
Paterson, Barbara (2007), "We cannot eat data: The need for computer ethics to address the cultural and ecological impacts of computing", Information Technology: Ethics Cultural Perspectives, Hershey PA, Idea Group Reference, pp. 153-168

Pugh, D., et al, (1968), "Dimensions of organization structure", Administrative Science Quarterly, Vol. 13, No. 2, pp. 65-114

Sautu, Ruth, (2010), Manual de Metodología: construcción del marco teórico, Prometo Libros, Buenos Aíres.

Schein, Edgar, (1997) "Culture: The Missing Concept in Organization Studies" en Administration Science Quarterly, 41. pp. 229-240

Semenov, Alexey, Fernanda Trías (traductor), (2005), Las tecnologías de la información y la comunicación en la enseñanza: Manual para docentes, UNESCO, Francia, pp. 15-36

Skip, J., Albert Delerer, (2001), "How organizations handle rapid IT change: Five Coping Mechanisms", Information Technology and Management, Vol. 2, pp. 95-112

Smircich, Linda (1983), "Concepts of culture and organizational analysis", en Administrative Science Quarterly, Num. 28, pp. 339-358

Suárez, Ramón (2007), Tecnologías de la información y comunicación: Introducción a los sistemas de Información y Telecomunicaciones, Ideas Propias, pp.2-45

Tapscott, Don (1995), Cambio de paradigmas empresariales, McGraw Hill Interamericana SA, Colombia, pp. 1-30

Varela, Roberto, 1997. Cultura y comportamiento, en revista Alteridades 1997, 7(3) pp. 47-52

Wallace, W.L., (1963) “The Winchester-Western Division Concept of Product Planning. Olin Mathieson Chemical Corporation, Nueva Haven, Enero, pp. 2-3

Woolgar, Steve, 1996 Technologies as Cultural Artefacts. En Dutton, William, (comp.) Information and communication technologies. New York, Oxford University Press

Yin, Robert K. (2003), "Case study research: design and methods", Sage Publishing, Thousand Oaks, CA.

\section{Páginas web}


Anuarios INFOTEC, 1998-2008, CONACYT

CONACYT http://www.conacyt.gob.mx

INFOTEC http://www.Infotec.com.mx

Manual de Operaciones de INFOTEC, 2009 en Portal de Obligaciones de Transparencia http://portaltransparencia.gob.mx

Política Nacional y Programas de Ciencia y Tecnología en 1970, en Sistema Integrado de Información sobre Información Científica, Desarrollo Tecnológico e Innovación http://www.siicyt.gob.mx/siicyt/ 


\section{ANEXOS}

\section{Guía de preguntas para entrevista semidirigida a actores de Infotec}

Los datos aquí proporcionados, serán utilizados de manera confidencial y anónima por el entrevistador.

1. ¿Puede relatar la historia de Infotec? En este marco histórico, desde su punto de vista, ¿Cuál es la historia de las TIC's en Infotec?

2. ¿Qué cambios se han presentado a través de la historia de Infotec? ¿Cuáles fueron planeados?

3. ¿Conoce si la misión y visión de Infotec ha sufrido alguna modificación?

4. ¿Considera que los valores organizacionales han sufrido alteraciones? De acuerdo a su percepción, ¿existe una relación entre los valores y los cambios?

5. ¿Puede mencionar algún comentario que crea importante?

¡Le agradezco su atención! 
Tabla de acrónimos

\begin{tabular}{|c|l|}
\hline Acrónimo & \multicolumn{1}{c|}{ Significado } \\
\hline CONACYT & Consejo Nacional en Ciencia y Tecnología \\
\hline CyT & Ciencia y Tecnología \\
\hline INFOTEC & Fondo de Información y Documentación para la Industria \\
\hline NAFIN & Nacional Financiera \\
\hline PCyT & Política en Ciencia y Tecnología \\
\hline SEP & Secretaria de Educación Publica \\
\hline TI & Tecnología de Información \\
\hline TIC's & Tecnologías de Información y Comunicaciones \\
\hline UNESCO & $\begin{array}{l}\text { Organización de las Naciones Unidas para la Educación, la } \\
\text { Ciencia y la Cultura }\end{array}$ \\
\hline CPI & Centro Público de Investigación \\
\hline RTN & Red Tecnológica Nacional \\
\hline & \\
\hline & \\
\hline & \\
\hline
\end{tabular}




\section{Material fotográfico}
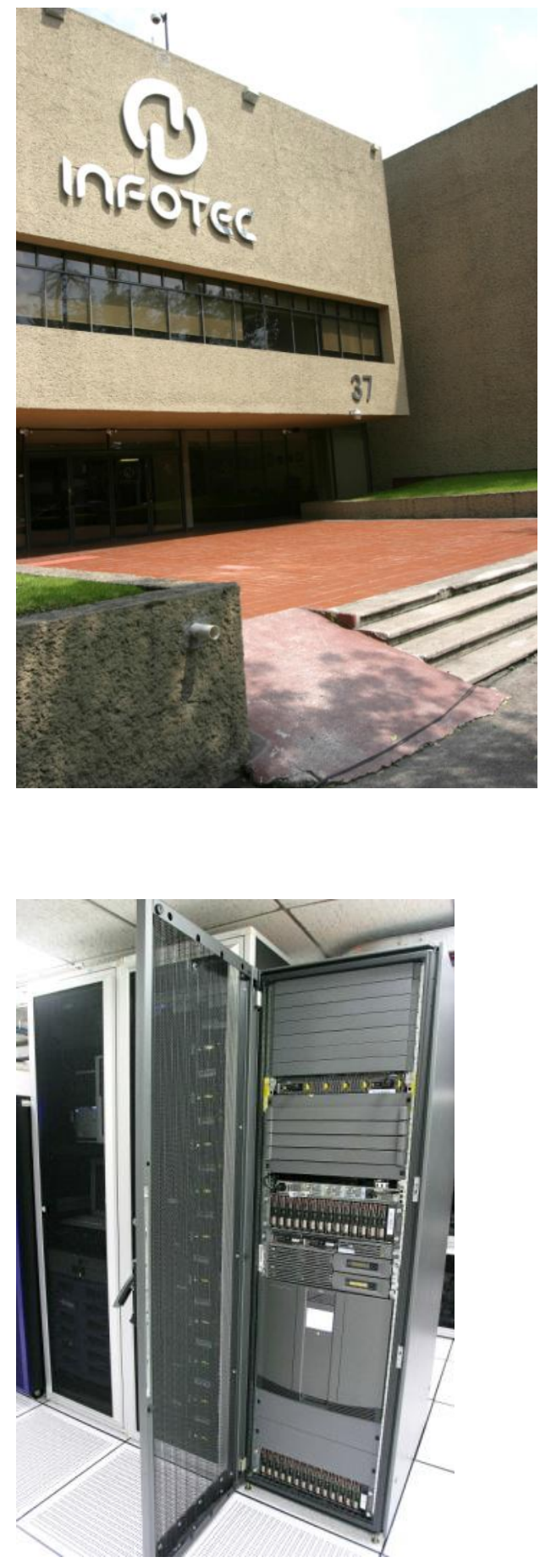

Fachada de la entrada a Infotec. El imagotipo al frente para cumplir con uno de los objetivos. "Quedarse en la mente del cliente"
Equipo de Telecomunicaciones especializado que forma parte del artefacto cultural de Infotec. 

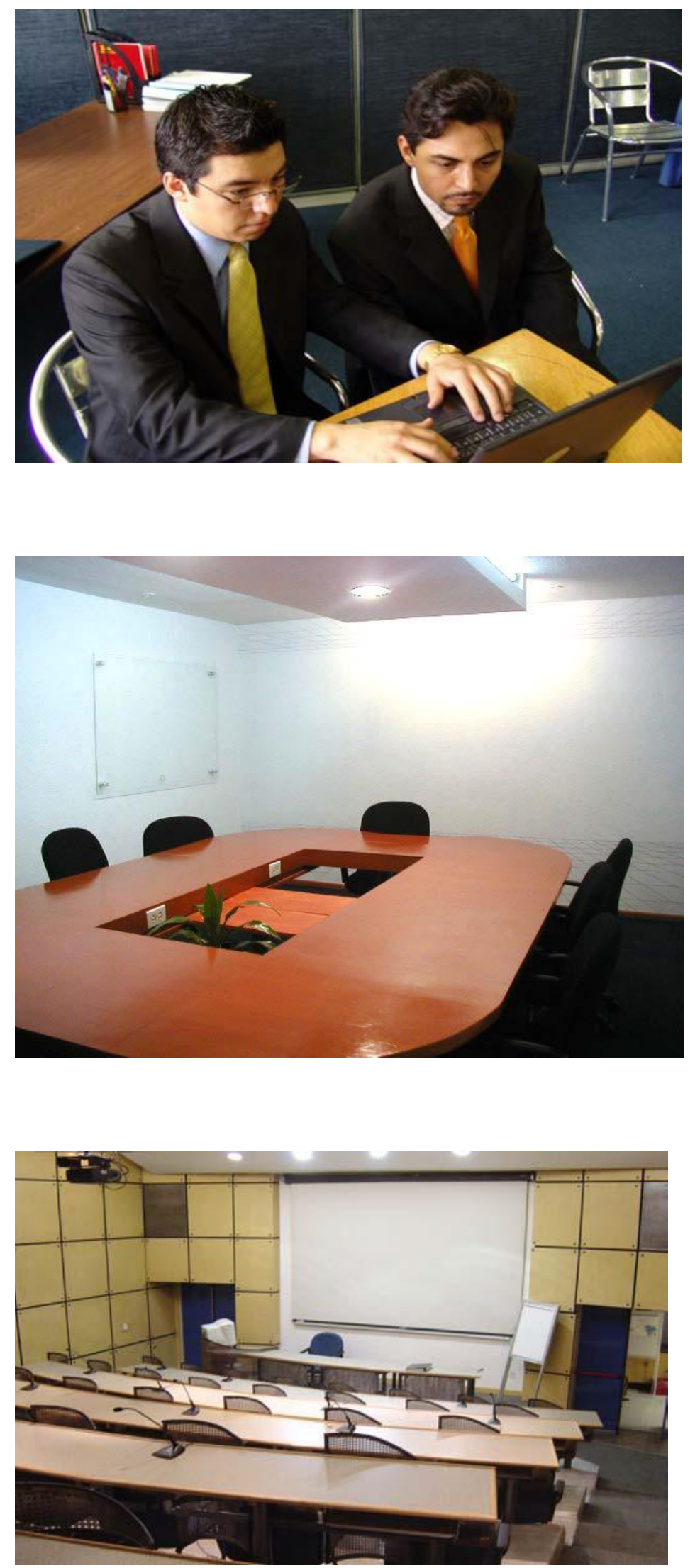

Capital humano de
Infotec, resolviendo
problemas del cliente,
con la ideología del
valor de "trabajo en
equipo"

Aula de colaboración. Se utiliza para atender asuntos relacionados a la venta de servicios. Así como para la innovación y desarrollo.
Aula magna. Representa la parte del área de Docencia e Investigación. Se ocupa para dar seminarios, así como para clases del posgrado. 
PROCESO DE INNOVACION

ORGANIZACIONAL. EL CASO DE INFOTEC
En México, D.F., se presentaron a las 10:00 horas del día 21 del mes de julio del año 2014 en la Unidad Iztapalapa de la Universidad Autónoma Metropolitana, los suscritos miembros del jurado:

DR. ANTONIO BARBA ALVAREZ

DR. VALENTINO MORALES LOPEZ

DRA. MARIA TERESA DEL SOCORRO MONTOYA FLORES

Bajo la Presidencia del primero y con carácter de Secretaria la última, se reunieron para proceder al Examen de Grado cuya denominación aparece al margen, para la obtención del grado de:

MAESTRA EN ESTUDIOS ORGANIZACIONALES

DE: MARIA DEL ROSARIO MONROY SANTANA

y de acuerdo con el artículo 78 fracción III del Reglamento de Estudios Superiores de la Universidad Autónoma Metropolitana, los miembros del jurado resolvieron:

$$
\text { Halarar }
$$

Acto continuo, el presidente del jurado comunicó a la interesada el resultado de la evaluación $y$, en caso aprobatorio, le fue tomada la protesta.

LIC. JULIO CESXR DE LARA ISASSI DIRECTOR DE SIS NEMAS ESCOLARES

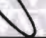

DIRECTORA DE LA DIVISIÓN DE CSH

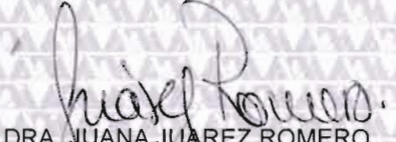

DRA. UUANA JUAREZ ROMERO

()

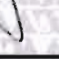

DR. VALENTINO MORALES LOPEZ
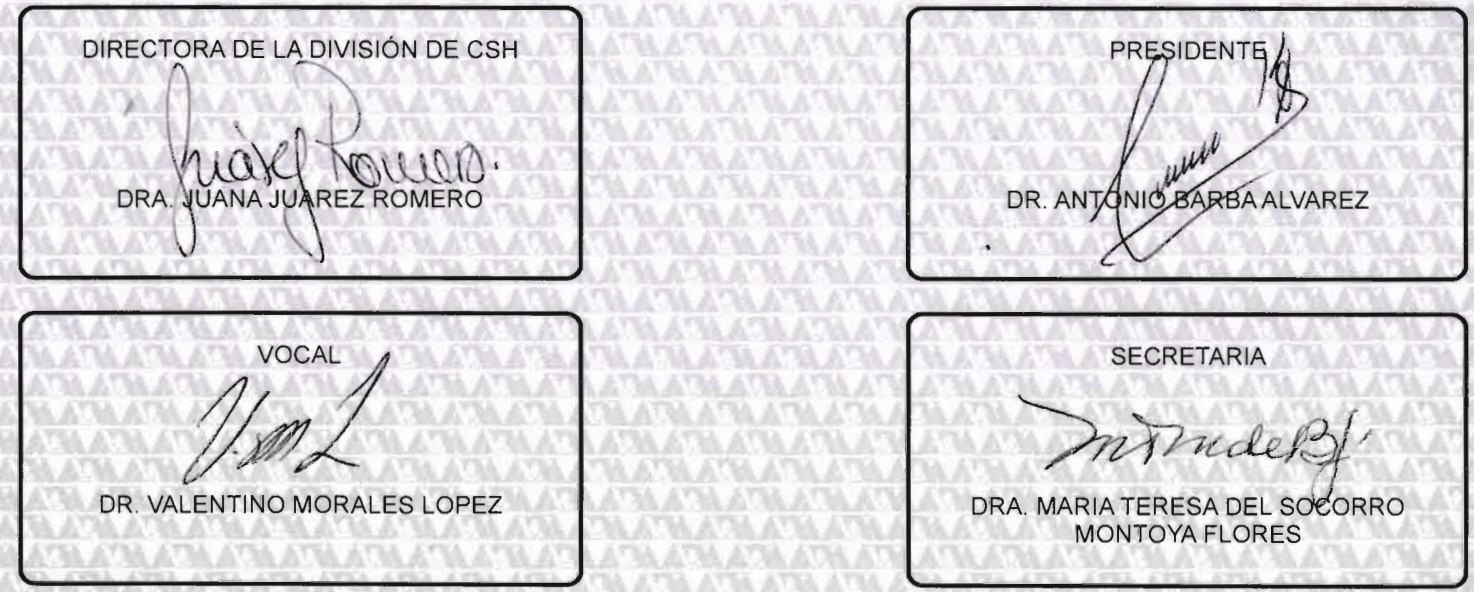